From Harmful to Useful Algae

Harry Blaas 


\section{Thesis committee}

\section{Promotor}

Prof. Dr Carolien Kroeze

Professor of Water Systems and Global Change

Wageningen University \& Research

\section{Other members}

Prof. Dr Wolf M. Mooij, NIOO/ Wageningen University \& Research

Prof. Dr Cees J.N. Buisman, Wageningen University \& Research

Prof. Dr Paquita Perez, Open Universiteit, Heerlen, The Netherlands

Dr Wilfried P.M.F. Ivens, Open Universiteit, Heerlen, The Netherlands

This research was conducted under the auspices of the Graduate School for SocioEconomic and Natural Sciences of the Environment (SENSE) 


\title{
From Harmful to Useful Algae
}

\author{
Harry Blaas
}

Thesis

submitted in fulfilment of the requirements for the degree of doctor at Wageningen University

by the authority of the Rector Magnificus

Prof. Dr A.P.J. Mol,

in the presence of the

Thesis Committee appointed by the Academic Board

to be defended in public

on Wednesday 25 January 2017

at 1.30 p.m. in the Aula 
H.H.T.J. Blaas

From Harmful to Useful Algae

124 pages.

PhD thesis, Wageningen University \& Research, Wageningen, NL (2017)

With references, with summary in English

ISBN: 978-94-6343-035-7

DOI: $10.18174 / 400012$ 


\section{Table of content}

$\begin{array}{ll}\text { 1. Introduction } & 1\end{array}$

2. Excessive Nitrogen and Phosphorus in European Rivers: 2000- 9 2050

3. Possible future effects of large-scale algae cultivation for biofuels on coastal eutrophication in Europe

4. Conceptual Factory Design for Micro-Algae Cultivation and 55 Processing

5. Eutrophication Control in European Seas: The Role of Nutrient Man73 agement, Waste Water Treatment and Seaweed Production

6. General discussion

References

Summary

Acknowledgements

About the author 

Chapter 1 Introduction 


\subsection{Background}

Eutrophication of coastal waters is a worldwide phenomenon (Diaz and Rosenberg, 2008; Scheffer, 2010; Seitzinger et al., 2010). This study focuses on eutrophication in the coastal waters of Europe. Eutrophication is mainly a result of the increased transport of nutrients from watersheds by rivers to the coastal waters. Nutrient losses from watersheds are generally from agriculture, sewage, atmospheric deposition and from natural sources (Seitzinger et al., 2005). In case of an overload of nutrients in the coastal waters, algal blooms may develop which increase the risk of hypoxia, fish mortality, and loss of biodiversity. This can have consequences for fisheries and tourism (EEA, 2001). Algal blooms consist of green or other micro-algae, which are single-cell plants (Gould, 1997). Algal blooms can be observed by satellites (Sutton et al., 2011). The main nutrients that stimulate the growth of algae in the coastal waters are nitrogen $(\mathrm{N})$ and phosphorus $(\mathrm{P})$.

Harmful algal blooms develop in particular when the $\mathrm{N}$ and $\mathrm{P}$ concentrations in coastal systems are high compared to the concentrations of dissolved silica (Si). An indicator for the appearance of algal blooms is the ratio of $\mathrm{N}$ and $\mathrm{P}$ to $\mathrm{Si}$ in the water. If there is sufficient $\mathrm{Si}$ available, algae species tend to form siliceous skeletons and may sink to the bottom of the waters when they die. Without sufficient $\mathrm{Si}$ available, potentially harmful algae may grow. The critical nutrient : Si ratio can be calculated from the Redfield ratio that reflects the biochemical composition of algae with siliceous skeletons. According to this ratio, $\mathrm{N}, \mathrm{P}$ and $\mathrm{Si}$ have a fixed ratio. If the ratio is out of balance by an overload of $\mathrm{N}$ or P harmful algae blooms may appear (Billen and Garnier, 2007; Garnier et al., 2010).

River export of nutrients has been increasing in many world regions as a result of human activities on the land, such as food production. Densely populated regions need increasing amounts of food, not only because of a growing population, but also because of changing diets. Meat consumption has been increasing in many world countries. As a result, both crop and animal production has been increasing worldwide. Not all world regions are self-sufficient, and import food. In Europe, many agricultural regions export food. There are, for instance, regions with a high livestock density, much more than needed for 
the local population. In agriculture manure and synthetic fertilizers are used to grow crops. Depending on the intensity of the agriculture and fertility of the soil more or less fertilization is needed. The nutrients in the fertilizers that are used in arable land are only partly taken up by the crops. The remainder is lost to the environment: to the air or it may leach to soil and groundwater and, after a delay, transported by rivers to coastal waters (Fresco, 2013; Lægreid et al., 1999). Also in Europe there are agricultural areas with a high livestock density producing large amounts of manure that cannot be fully recycled and disappear into soil and groundwater with severe consequences for rivers and coastal waters.

Sewage systems are another reason of increased nutrient loads in rivers. Most countries have a sewerage system. Sewers transport waste water from households and industries to rivers or to waste water treatment plants. These treatment plants purify waste water. The effluent is mostly transported to rivers and finally to the coastal waters of the region. The rate of nutrient removal in waste water treatment is important for the quality of the effluent. Scenario analyses indicate that by the year 2050 90\% of the population of Europe will be connected to waste water treatment systems with an increasing nutrient removal rate (Van Drecht et al., 2009).

So far, I discussed algae only as part of a potential environmental problem. However, algae are not only harmful. They are increasingly considered an interesting product. For instance, micro-algae can be grown on land to produce proteins, lipids and fatty acids. Some studies indicate that micro-algae can be an important feedstock in the future for, for instance, the production of biodiesel (Wijffels and Bardosa, 2010). However, cultivation of micro-algae requires inputs of water, energy and fertilizers. When fertilizers are ending up in waste streams, they can become a source of water pollution. Life cycle assessments of algae cultivation are described in literature (Brentner et al., 2011; Clarens et al., 2010; Lardon et al., 2009; Liu and Ma, 2009; Yang et al., 2011). These studies focus to a large extent on the use of energy and water. Losses of nutrients to the environment, however, are not well studied.

There are different ways to reduce nutrient loadings of coastal seas. For instance, by reducing nutrient inputs to rivers. Nutrients inputs to waters can 
be reduced by, for instance, reduced nutrient losses from food production, and by improved waste water treatment. An important source of nutrients in rivers is livestock, which produces manure. Obviously less livestock would be an effective solution but it is unlikely that people will eat less meat in the near future. Other possibilities to reduce nutrient losses from agriculture is to use less fertilizers. Technically it is possible to reduce losses by increasing nutrient use efficiencies (Bongiovanni et al., 2004; Hart et al., 2004). With the use of GPS and high-tech machines less water and fertilizers are needed (Baltissen, 2014; Bongiovanni et al., 2004; Chen et al.; Keller et al., 2002). Worldwide experiments illustrate the success of precision agriculture. Improving waste water treatment is another option to reduce nutrient loadings in rivers and coastal waters. Waste water treatment is poor in many world regions, so with current technology it is possible to reduce pollution considerably.

Another way to reduce coastal eutrophication is to remove $\mathrm{N}$ and $\mathrm{P}$ from aquatic systems. Implementing the above mentioned reduction measurements would result in less fertilizer use and improved waste water treatment. Despite these options, it may be difficult to ensure that the coastal waters are free of harmful algae. There may still be excess $\mathrm{N}$ and P over Si. Once in the water, it is not easy to remove the nutrients before they affect the environment. However, it is not impossible.

Nutrients can be removed from eutrophied coastal waters by growing seaweed. Seaweed is a multicellular alga and grows in seawater (Koning et al., 2008). The coastal waters with nutrients supplied by rivers are suitable to grow seaweed. With the harvested crop, nutrients leave the coastal system (Bouwman et al., 2011; Reith et al., 2005). Edible seaweeds can be grown for human consumption or to feed livestock. Seaweed can also be used to produce energy. It is possible to grow seaweed in European seas, but it is not common practice yet. Currently, there is a farm in the North Sea producing seaweed on a limited scale (Reith et al., 2005).

Summarizing, we may distinguish three categories of measures: improved nutrient use efficiency, improved waste water treatment, and growing seaweed. These are all available and technically feasible. In this study I use computer models to investigates the combinations of different measurements 
to mitigate the eutrophication in the coastal waters. I do this with a focus on both harmful algae in coastal seas, and on useful algae that are grown to produce food or fuels.

\subsection{Modelling coastal water pollution}

I use the Global NEWS (Nutrient Export from WaterSheds) model as a basis for my analyses. This model has been developed to estimate future trends in the export of nutrients by rivers to the coastal waters based on the Millennium Ecosystem Assessment (MA) scenarios (Mayorga et al., 2010; Seitzinger et al., 2010; Seitzinger et al., 2005). The most recent version of Global NEWS was released in the year 2010 and has been used to analyse trends in nutrient export by rivers for the years 1970, 2000, 2030 and 2050. In Global NEWS the flows of the $\mathrm{N}$ and $\mathrm{P}$ in the watersheds of more than 6000 rivers worldwide are calculated. The Global NEWS model is a valuable model to estimate the nutrient transport to the coastal waters (Kroeze et al., 2012).

The MA scenarios are developed on initiation in 2000 by the United Nations to analyse the relations between human activities, ecosystems and human well-being (Alcamo and Van Vuuren, 2005; Bennett, 2006). There are four MA scenarios. They differ in their basic assumptions on socio-economic trends (globalization or regionalization), and on the societal approach towards ecosystem management (reactive or proactive). These four scenarios have been implemented in Global NEWS to analyse future trends in coastal eutrophication worldwide. For Europe the scenarios project relatively small changes (mainly decreases) in nutrient export by rivers to coastal waters for the year 2050 (Seitzinger et al., 2010).

Global NEWS uses model inputs provided by the IMAGE (Integrated Model to Assess the Global Environment) model (Bouwman et al., 2006), and the Water Balance Plus (WBMplus) model (Fekete et al., 2010). The main inputs from IMAGE are related to food production and land use, which are diffuse sources of nutrients in rivers. The WBMplus model provided hydrological inputs for over 6000 rivers in Global NEWS. 
Gobal NEWS quantifies $\mathrm{N}$ and $\mathrm{P}$ inputs to rivers from agriculture, sewage and natural sources. It also accounts for the effects of damming and human water consumption. However, it does not consider the production of micro-algae on sea, nor does it model the effects of seafarms on coastal eutrophication.

In this study Global NEWS is modified to estimate the nutrient transports by 48 rivers in 27 European countries to the coastal waters with a focus on harmful and useful algae. The 48 rivers have been chosen based on their nutrient loading: only rivers that export more than $10 \mathrm{Gg} /$ year $\mathrm{N}$ transport at the river mouth are accounted for (see chapter 2 for details). These rivers are rather evenly spread over de European Union as of 2015.

\subsection{Objectives and research questions}

This thesis deals with the sources of eutrophication of the European coastal waters.

The objective of this study is to analyse past and future trends in nutrient export by rivers to European seas with a focus on the role of algae. Three types of algae will be distinguished: (1) harmful algal blooms in coastal seas, (2) cultivation of micro-algae on land for the production of proteins, lipids and fatty acids, and (3) cultivation of multi cellular algae in seaweed farms for human consumption or other products.

To meet the objective the following research questions are addressed:

RQ1 To what extent do $\mathrm{N}$ and $\mathrm{P}$ loads exceed levels that minimize the risk of harmful algal blooms, and what are the relative shares of sources of $\mathrm{N}$ and $\mathrm{P}$ in rivers of the European Union?

RQ2 What are the potential consequences of large-scale land-based production of biodiesel from cultivated micro-algae in Europe for coastal eutrophication? 
RQ3 Would it possible to cultivate and process micro-algae in a factory, and what is the environmental performance?

RQ4 To what extent can seaweed farming in combination with nutrient management in agriculture and waste water treatment reduce the potential for coastal eutrophication?

\subsection{Outline of the thesis}

A schematic overview of the topics of the thesis is shown in Figure 1. It links the sources of eutrophication of the coastal waters (chapters 2 and 3), to a factory to cultivate micro algae (chapter 4 ) and the possibility of mitigation eutrophication by seaweed farming (chapter 5).

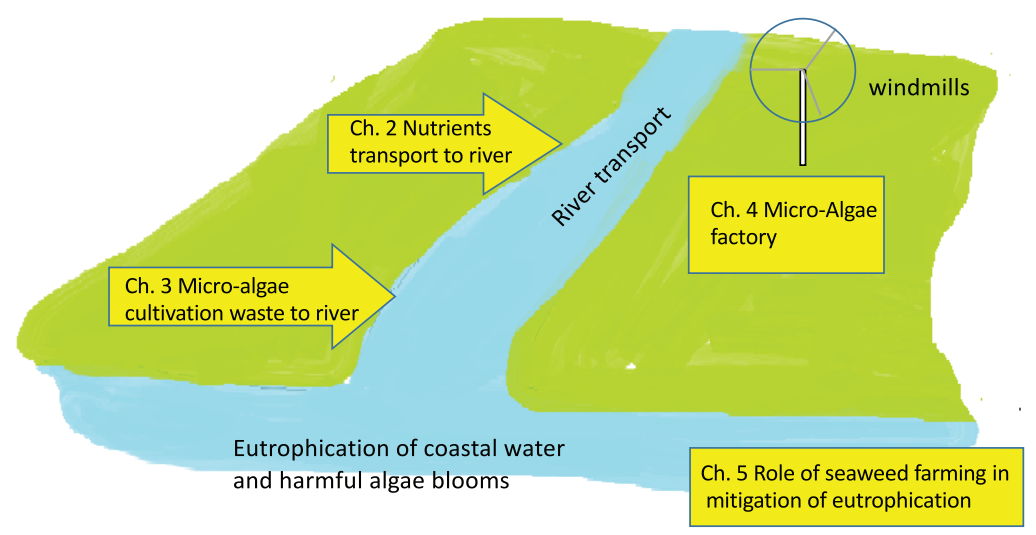

Figure 1. Schematic overview of river export of nutrients from land to sea, and the focus of the four chapters in this thesis.

In chapter 2 of the thesis I answer RQ1 and quantify the extent to which coastal waters of Europe are polluted with the nutrients $\mathrm{N}$ and $\mathrm{P}$ on the basis of Global NEWS results. I also show in the chapter the relative shares of different sources of $\mathrm{N}$ and $\mathrm{P}$. These include agriculture, sewage and other such as natural areas and atmospheric deposition. 
Chapter 3 focuses on the production of micro algae on land. I perform a scenario analysis using Global NEWS to quantify the implications of large-scale cultivation of mirco algae on land for coastal eutrophication. This answers RQ2.

To answer RQ3 I designed a new factory to produce mico-algae. The design is presented in chapter 4 . The factory has closed facades and the cultivation is by artificial light. This makes it possible to reduce losses of nutrients to the environment, and to minimize the area of land needed. I evaluated this design for environmental performances and the energy requirements.

Finally, I estimated possibilities to reduce the risk of coastal eutrophication by efficient agriculture, waste water treatment and seaweed farming. In chapter $5 \mathrm{I}$ present a scenario in which the potential of coastal eutrophication is minimized. The scenario first assumes that nutrient use efficiencies are higher than today, and that waste water treatment is improved. Second, it assumes that all excess $\mathrm{N}$ and $\mathrm{P}$ in coastal waters is taken up by seaweed farming. Using Global NEWS, I analyze where seaweed farming may help to reduce nutrient levels in coastal seas in Europe. 


\section{Chapter 2 Excessive Nitrogen and Phosphorus in European Rivers: 2000- 2050}

Published as:

Blaas H, Kroeze C. 2016. Excessive nitrogen and phosphorus in European rivers: 2000-2050. Ecological Indicators 67, 328-337 http://dx.doi.org/10.1016/j.ecolind.2016.03.004 


\section{Abstract}

Rivers export nutrients to coastal waters. Excess nutrient export may result in harmful algal blooms and hypoxia, affecting biodiversity, fisheries, and recreation. The purpose of this study is to quantify for European rivers (1) the extent to which $\mathrm{N}$ and $\mathrm{P}$ loads exceed levels that minimize the risk of harmful algal blooms and (2) the relative shares of sources of $\mathrm{N}$ and $\mathrm{P}$ in rivers. This may help to identify effective management strategies to reduce coastal eutrophication. We focus on 48 rivers in 27 countries of the European Union (EU27). We used the Global NEWS (Nutrient Export from Watersheds) model to analyze nutrient export by rivers and the associated potentials for coastal eutrophication as reflected by ICEP (Indicator for Coastal Eutrophication Potential). In 2000, 38 of the $48 \mathrm{EU}$ rivers indicated in our study had an ICEP $>0$, indicating a relatively high potential for harmful algal blooms. These 38 rivers cover $60 \%$ of EU 27 land area. Between 2000 and 2050 nutrient export by European rivers is projected to decrease. However, by 2050 still 34 EU rivers, covering 48\% of the land area, have an ICEP $>0$. This indicates that in these scenarios little progress is made in terms of environmental improvement. About one third of the rivers with ICEP $>0$ are $\mathrm{N}$ limited, and about two thirds $\mathrm{P}$ limited. In $\mathrm{N}$-limited rivers reducing $\mathrm{N}$ loads is a more effective way to reduce the risk for coastal eutrophication than reducing $\mathrm{P}$, and vice versa. For $\mathrm{N}$-limited rivers agriculture or sewage are the dominant sources of nutrients in river water. In P-limited rivers, sewage is found to be the dominant source of $\mathrm{P}$, except for rivers draining into the Atlantic Ocean, where agriculture can also be dominant. A basin-specific approach is needed to effectively reduce $\mathrm{N}$ and $\mathrm{P}$ loads. 


\subsection{Introduction}

\subsubsection{Background}

Eutrophication of coastal waters results from an increase in the supply of nutrients, which mostly is related to nutrient enrichment enhancing the primary production. Eutrophication can unbalance ecosystems in coastal waters (Romero et al., 2013). These problems are caused by increased transport of nitrogen $(\mathrm{N})$ and phosphorus $(\mathrm{P})$ from land to sea. Nutrients are from natural and anthropogenic sources. Natural sources include woods and wetlands, and are diffuse sources. Anthropogenic sources include urban, industrial and agricultural areas. Cities and industries can cause point source emissions of nutrients to rivers. Agriculture is among others a diffuse source of $\mathrm{N}$ and $\mathrm{P}$ in rivers, through leaching or runoff of fertilizers.

Increased $\mathrm{N}$ and $\mathrm{P}$ in coastal waters may lead to algal blooms, which in turn may disturb ecosystems in coastal waters. Algal blooms can be harmful when they lead to hypoxia or release for toxins. Eutrophication may thus result in changes in marine ecosystems and reduced biodiversity. It may also lead to reduced natural resources of fish and income in fish industry and affect the attractiveness of coastlines for tourism. Finally, algal toxins may lead to toxicity problems in ecosystems and for humans (EEA, 2001).

Harmful algal blooms have been observed worldwide (Diaz and Rosenberg, 2008; Scheffer, 2010; Seitzinger et al., 2010) . The algal blooms indicate that river export of nutrients has been increasing in many world regions. Algal blooms can be observed by satellite observations (Sutton et al., 2011). Some coastal waters are more sensitive to eutrophication and algal blooms than others. In Europe, most algal blooms occur in the coastal waters of the North Atlantic Ocean and the Baltic Sea. In the North West region of the Black Sea also severe algal blooms have been observed, as well as in the Mediterranean Sea.

European rivers are polluted with nutrients, as a result of human activities on land (Seitzinger et al., 2005). Both point and diffuse sources contribute to this pollution (Howarth et al., 2011; Mayorga et al., 2010). Urban and industrial waste is generally treated by water treatment plants, but not all nutrients are removed and discharged to rivers with the effluent. In Europe, also food production is an 
important source of nutrients in rivers. Both synthetic fertilizers and manure used as fertilizer are partly exported to the coastal waters. Although European policies are expected to reduce $\mathrm{N}$ and $\mathrm{P}$ loads in rivers to some extent, the risk for coastal eutrophication will be considerable during the coming decades (Seitzinger et al., 2010).

In this study, we focus on rivers of 27 European countries that discharge into the coastal waters of the Atlantic Ocean, the Baltic Sea, the Black Sea and the Mediterranean Sea. Several studies exist on nutrient export by European rivers (Kroeze et al., 2002; Kroeze and Seitzinger, 1998). However, no systematic analysis has been published of the relative shares of anthropogenic sources in the excess nutrient export by rivers in Europe, and how these can develop over time. A comprehensive overview of sources of pollution by rivers would help to prioritize policies aimed at reducing coastal eutrophication.

The purpose of this study is to quantify for European rivers (1) the extent to which $\mathrm{N}$ and $\mathrm{P}$ loads exceed levels with no risks of harmful algal blooms and (2) the relative shares of sources of $\mathrm{N}$ and $\mathrm{P}$ in rivers. This may help to identify effective management strategies to reduce coastal eutrophication. We focus on 48 rivers in 27 countries of the European Union (EU27). We use the Global NEWS (Nutrient Export from Watersheds) model to analyze nutrient export by rivers and the associated potentials for coastal eutrophication as reflected by ICEP (Indicator for Coastal Eutrophication Potential). When ICEP values are < 0 this is an indication that the risks of eutrophication are low. We identify the causes of ICEP values that exceed 0 , indicating that there is a risk for harmful algal blooms. The results of our analysis may help to identify effective manage strategies to reduce the risk of algae blooms. We focus on 48 rivers in 27 European countries, in line with earlier studies (Blaas and Kroeze, 2014; Van Wijnen et al., 2015). We used the Global NEWS model for our analyses.

\subsubsection{Global NEWS}

Global NEWS (Nutrient Export from Watersheds) is a global, spatially explicit computer model of the exports of nutrients to coastal waters by more than 6000 exoreic rivers (Mayorga et al., 2010; Seitzinger et al., 2010). In 2002, the model has been developed by an international, interdisciplinary, scientific taskforce by an assignment of UNESCO. After the first development in the year 
2005 the model was updated in 2009 and published as Global NEWS 2. In this new release all the sub models were combined in one integrated interface.

Global NEWS can be used to model river export of nitrogen $(\mathrm{N})$, phosphorus $(\mathrm{P})$, carbon (C) and silica (Si) in different forms, as a function of human activities on land, hydrology and basin characteristics. The model consists of two sub models: for point sources and diffuse source. Point sources include nutrient inputs to rivers from sewage. Diffuse sources include both natural and anthropogenic flows from land to rivers.

Point sources of nutrients include sewage treatment plants. Diffuse sources can be natural or anthropogenic (Mayorga et al., 2010; Van Drecht et al., 2009). Natural sources include $\mathrm{N}$ and $\mathrm{P}$ leaching and runoff from soils. Anthropogenic diffuse sources include leaching and runoff from soils with increased $\mathrm{N}$ and $\mathrm{P}$ levels from, for instance, agriculture and atmospheric $\mathrm{N}$-deposition. Anthropogenic point sources include sewage systems. Waste water treatment can reduce part of nutrients from sewage. In Global NEWS this is simulated using a retention factor. The amount of nutrients transported by rivers to coastal waters depends on retention of nutrient in terrestrial systems, rivers and reservoirs. These different types of retention are also included in Global NEWS (Tysmans et al., 2012). River export of nutrient is expressed in yields (kg/ $\left.\mathrm{km}^{2} / \mathrm{yr}\right)$ or loads at the river mouth $(\mathrm{Mg} / \mathrm{yr})$.

The hydrology is from the WBMplus model, and watersheds are delineated on a grid of $0.5^{\circ} \times 0.5^{\circ}$ latitude by longitude based on the STN-30p river system (Vörösmarty et al., 2000). The input databases are generated by the IMAGE model (Bouwman et al., 2009; Van Drecht et al., 2009) and the Water Balance Plus model (Feteke et al., 2010) The model calculates export of nutrients in different forms (Table 1). The model has been implemented to calculate export of nutrients for the years 1970, 2000, 2030 and 2050. 
Table 1. Nutrients that are included in the Global NEWS model (Seitzinger et al., 2010; Mayorga et al., 2010)

\begin{tabular}{lll}
\hline Nutrient & Form & Abbreviation \\
\hline Nitrogen & dissolved and organic & DON \\
Nitrogen & dissolved and inorganic & DIN \\
Nitrogen & particulate & PN \\
Phosphorus & dissolved and organic & DOP \\
Phosphorus & dissolved and inorganic & DIP \\
Phosphorus & particulate & P \\
Carbon & dissolved and organic & DOC \\
Carbon & particulate & PC \\
Silica & dissolved & DSi \\
\hline
\end{tabular}

The Global NEWS model has been validated in several ways. It was developed and validated at the global scale (Seitzinger et al., 2010; Mayorga et al., 2010). In addition, it was validated for several continents or regions ( $Q u$ and Kroeze, 2010; Sattar et al., 2014; van der Struijk and Kroeze, 2010; Yasin et al., 2010). Also for Europe it has been validated (Kroeze et al., 2002; Strokal and Kroeze, 2013; Thieu et al., 2010)). At the global scale the model performance is assessed through comparing modeled versus measured values, to calculate NashSutcliffe efficiencies $\left(R^{2}\right)$. These efficiencies typically range between 0.5 and 0.9 , indicating that the model can explain the observed variability reasonably well. Validations at the continental scale typically result in similar efficiencies. These different validations build trust in the model, indicating that it cannot only be applied at the global, but also at the continental scale.

The exports of the rivers for the years 2030 and 2050 are predictions based on the Millennium Ecosystems Assessment Scenarios (MA). For a description of the scenarios see below. In this study we use the scenario Global Orchestration (GO) for 2050 as a baseline to analyze the additional inputs of N, P and Si to rivers by using the Global NEWS model. A summary of the main equations used in the Global NEWS model are shown in Table 2. 
Table 2. Summary of Global NEWS equations for the modelling of river export of dissolved nitrogen and Phosphorus from land to sea. For details and other model equations see Mayorga et al., (2010).

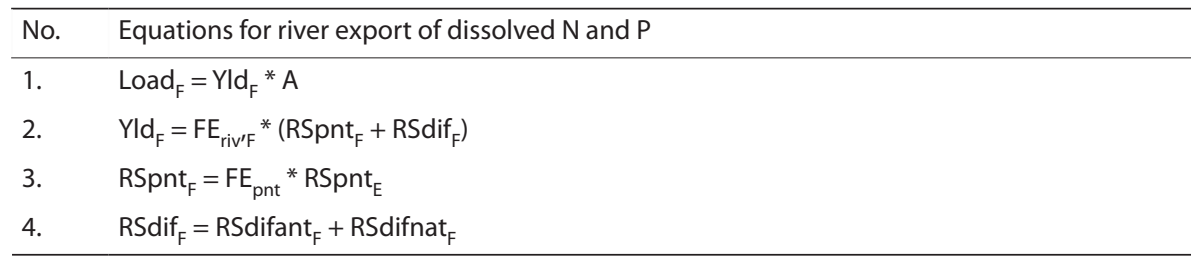

Variables and parameters (Unit) for dissolved $\mathrm{N}$ and $\mathrm{P}$

Load $_{\mathrm{F}}=$ river export of dissolved element form $\mathrm{F}$ from basin $\left(\mathrm{t} \mathrm{y}^{-1}\right)$

$\mathrm{Yld}_{\mathrm{F}}=$ river export of dissolved element form $\mathrm{F}$ per km${ }^{-2}$ of basin area $\left(\mathrm{kg} \mathrm{km}^{-2} \mathrm{y}^{-1}\right)$

$\mathrm{A}=$ basin area $\left(\mathrm{km}^{2}\right)$

$\mathrm{FE}_{\text {riv, } \mathrm{F}}=$ the fraction of nutrient form $\mathrm{F}$ inputs to rivers (point + diffuse sources) that is exported to the river mouth.

$\mathrm{RSpnt}_{\mathrm{F}}=$ the annual point source input of nutrient form $\mathrm{F}$ to rivers from sewage systems $\left(\mathrm{kg} \mathrm{km}^{-2} \mathrm{y}^{-1}\right)$

$\mathrm{FE}_{\mathrm{pnt}, \mathrm{F}}=$ fraction of nutrient form $\mathrm{F}$ in element $\mathrm{E}$ in point source inputs

$\mathrm{RSdif}_{\mathrm{F}}=$ the annual diffuse source input of nutrient form $\mathrm{F}$ to rivers from natural and athropogenic sources $\left(\mathrm{kg} \mathrm{km}^{-2} \mathrm{y}^{-1}\right)$

$\mathrm{RSdifant}_{\mathrm{F}}=$ the annual diffuse source input of nutrient form $\mathrm{F}$ to rivers from athropogenic sources $(\mathrm{kg}$ $\mathrm{km}^{-2} \mathrm{y}^{-1}$ )

$\mathrm{RSdifnat}_{\mathrm{F}}=$ the annual diffuse source input of nutrient form $\mathrm{F}$ to rivers from natural sources $\left(\mathrm{kg} \mathrm{km}^{-2} \mathrm{y}^{-1}\right)$

Global NEWS furthermore includes an Indicator for Coastal Eutrophication (ICEP) (see section 2.2). In this study we use Global NEWS to calculate river exports of N, P in excess over levels that would ensure a low risk for coastal eutrophication (i.e. ICEP=0). We will identify the sources of these nutrients (point sources and diffuse sources) in the watersheds of the rivers.

\subsubsection{Millennium Ecosystem Assessment Scenarios}

There is a strong relationship between ecosystems and human wellbeing. To survive humanity needs the services of the ecosystems. Services are among others water, fishery, wood, soil and air. The knowledge about ecosystems and their relationships with social systems is increasing. The Millennium Ecosystem Assessment (MA) scenarios have been developed to explore the future of ecosystems as affected by social systems. In the year 2000 the United Nations Secretary-General Kofi Annan sent the MA report "We the People: The Role of the United Nations in the 21st Century" to the UN General Assembly. Worldwide nearly 1360 experts from 95 countries contributed to the MA, including scenarios for the year 2050. The MA reports are available online at www.maweb.org. 
The MA scenarios are based on storylines. They differ with respect to the assumed trends towards sustainability, economic growth, social development and dominant social organizations. The scenarios are no predictions but describe possible future developments. Probably the future will be a mixture of the scenarios. The scenarios can be used to quantify possible outcomes of the aspects of the scenarios (Alcamo et al., 2005; Bennett and Carpenter, 2006; Bouwman et al., 2009; Carpenter et al., 2005)

Four MA scenarios exist: Global Orchestration (GO), Order from Strength (OS), Adapting Mosaic (AM) and Technogarden (TG). In this study we use the GO scenario as a basis for analysis. This scenario describes a globalized world with a focus on equity and economic growth, while environmental problems are solved in a reactive way. The MA scenarios have been quantitatively interpreted by the Global NEWS team to create the required output databases for the Global NEWS model for 1970, 2000, 2030 and 2050. This was done for model inputs related to land use (Van Drecht et al., 2009), sewage (Van Drecht et al., 2009) and hydrology (Feteke et al., 2010).

Agricultural production increases worldwide in all scenarios but the fertilizer $\mathrm{N}$ and $\mathrm{P}$ efficiency in Europe will not change much. In the GO scenario the European population increases from 466 million in 2000 to 541 million inhabitants in 2050. In $200079 \%$ of the population were connected to sewage systems increasing to nearly $90 \%$ in 2050 . For sewage there will be a decline in $\mathrm{N}$ and $\mathrm{P}$ flows for Europe (Seitzinger et al., 2010; Strokal and Kroeze, 2013; Van Drecht et al., 2009).

Summarizing, the scenarios have been implemented in Global NEWS to analyze trends over time in human activities and their impacts in watersheds of more than 6000 rivers.

\subsection{Method}

\subsubsection{Selection of rivers}

We selected 48 rivers from the Global NEWS model (Par. 1.2) discharging into the coastal waters of the countries of the 27 European countries (EU27; Table 3). 
All European rivers with an $\mathrm{N}$ load of more than $10 \mathrm{Gg} / \mathrm{yr}$ at the river mouth, and with a river mouth located in one of the EU27 countries are selected (Blaas and Kroeze, 2014). These rivers cover $70 \%$ of the European land area, and export $50 \%$ of the water/nutrients to the coastal waters of Europe. Most of the rivers export to the coastal waters of the North Atlantic Ocean. Only the river Danube drains into the Black Sea but has a large drainage basin $\left(785,306 \mathrm{~km}^{2}\right)$.

Table 3. Rivers included in this study. Modified from Blaas and Kroeze (2014).

\begin{tabular}{|c|c|c|c|}
\hline River * & $\begin{array}{l}\text { Country where the river mouth is } \\
\text { located }\end{array}$ & Basin area $\left(\mathrm{km}^{2}\right)$ & Ocean/Sea \\
\hline Rhine & The Netherlands & 163750 & North Atlantic Ocean \\
\hline Elbe & Germany & 148118 & North Atlantic Ocean \\
\hline Loire & France & 117340 & North Atlantic Ocean \\
\hline Douro & Portugal & 95455 & North Atlantic Ocean \\
\hline Seine & France & 72838 & North Atlantic Ocean \\
\hline Tejo & Portugal & 72290 & North Atlantic Ocean \\
\hline Guadiana & Portugal & 64196 & North Atlantic Ocean \\
\hline Garonne & France & 57858 & North Atlantic Ocean \\
\hline Guadalquivir & Spain & 53249 & North Atlantic Ocean \\
\hline Gota & Sweden & 44107 & North Atlantic Ocean \\
\hline Weser & Germany & 45389 & North Atlantic Ocean \\
\hline Meuse & The Netherlands & 43284 & North Atlantic Ocean \\
\hline Dordogne & France & 25744 & North Atlantic Ocean \\
\hline Humber & UK & 23670 & North Atlantic Ocean \\
\hline Shannon & Ireland & 20831 & North Atlantic Ocean \\
\hline Scheldt & The Netherlands & 20604 & North Atlantic Ocean \\
\hline Minho & Portugal & 17472 & North Atlantic Ocean \\
\hline Thames & UK & 16833 & North Atlantic Ocean \\
\hline Trent & UK & 16948 & North Atlantic Ocean \\
\hline Ems & Germany & 14989 & North Atlantic Ocean \\
\hline Basin no. 885 & UK & 11876 & North Atlantic Ocean \\
\hline Adour & France & 13010 & North Atlantic Ocean \\
\hline Basin no. 1090 & France & 10320 & North Atlantic Ocean \\
\hline Basin no. 1095 & UK & 10066 & North Atlantic Ocean \\
\hline Basin no. 1382 & UK & 5763 & North Atlantic Ocean \\
\hline Basin no. 1405 & Ireland & 7168 & North Atlantic Ocean \\
\hline Basin no. 1434 & Ireland & 6242 & North Atlantic Ocean \\
\hline Basin no. 1448 & Ireland & 6864 & North Atlantic Ocean \\
\hline Basin no. 1456 & UK & 6264 & North Atlantic Ocean \\
\hline Basin no. 1503 & UK & 6508 & North Atlantic Ocean \\
\hline Basin no. 1857 & UK & 5594 & North Atlantic Ocean \\
\hline Basin no. 1870 & Ireland & 4741 & North Atlantic Ocean \\
\hline Basin no. 1875 & UK & 5671 & North Atlantic Ocean \\
\hline Basin no. 1919 & UK & 5036 & North Atlantic Ocean \\
\hline
\end{tabular}


Table 3. continued

\begin{tabular}{llll}
\hline River * & $\begin{array}{l}\text { Country where the river mouth is } \\
\text { located }\end{array}$ & Basin area $\left(\mathrm{km}^{2}\right)$ & Ocean/Sea \\
\hline Basin no. 1941 & UK & 5171 & North Atlantic Ocean \\
Basin no. 1972 & Ireland & 4351 & North Atlantic Ocean \\
Basin no. 2348 & Ireland & 3526 & North Atlantic Ocean \\
Basin no. 4520 & Ireland & 1912 & North Atlantic Ocean \\
Wisla & Poland & 179883 & Baltic Sea \\
Odra & Germany & 118731 & Baltic Sea \\
Nemunas & Lithuania & 95532 & Baltic Sea \\
Daugava & Letland & 83279 & Baltic Sea \\
Narva & Estland & 54374 & Baltic Sea \\
Ume-Vindealven & Sweden & 28923 & Baltic Sea \\
Danube & Romania & 785306 & Black Sea \\
Po & Italy & 100297 & Mediterranean Sea \\
Rhone & France & 98660 & Mediterranean Sea \\
Ebro & Spain & 81901 & Mediterranean Sea \\
\hline
\end{tabular}

* Rivers characteristics are from the Global NEWS model and some of the rivers in Global NEWS have codenames. (Mayorga et al., 2010; Seitzinger et al., 2010)

\subsubsection{ICEP: An Indicator for Coastal Eutrophication Potential}

The average composition of algae can be described by the Redfield equation, $\left(\mathrm{CH}_{2} \mathrm{O}\right)_{106}\left(\mathrm{NH}_{3}\right)_{16} \mathrm{H}_{3} \mathrm{PO}_{4}$. In this equation the $\mathrm{C}: \mathrm{N}: \mathrm{P}$ molecular ratio is 106:16:1. As long as silica is available, increased $\mathrm{N}$ and $\mathrm{P}$ will result in diatoms to grow which are considered harmless. For growth of diatoms an average C:Si ratio of 106:20 is sufficient. So the total Redfield ratio for C:N:P:Si is 106:16:1:20 (Billen and Garnier, 2007). With an excess of $\mathrm{N}$ or $\mathrm{P}$ over $\mathrm{Si}$, there will be a growth of non-siliceous algae. These non-siliceous algae are mainly uni-cellular green algae that may cause algal blooms, and hypoxia. To assess the potential for algae to bloom Billen and Garnier propose the ICEP (Indicator for Coastal Eutrophication Potential) approach:

ICEP $=[\mathrm{Nflx} /(14 * 16)-\mathrm{Sifl} /(28 * 20)] * 106^{*} 12$

If $\mathrm{N}: \mathrm{P}<16$ ( $\mathrm{N}$ is the limiting nutrient)

and

ICEP $=\left[\mathrm{Pflx} / 31-\mathrm{Siflx} /\left(28^{*} 20\right)\right] * 106 * 12$ 
If $\mathrm{N}: \mathrm{P}>16$ ( $\mathrm{P}$ is the limiting nutrient)

(Billen and Garnier, 2007)

Where Pflx, Nflx and Siflx are the fluxes of total phosphorus, nitrogen and silica.

With an ICEP $\geq 0$ conditions are favorable for harmful algal blooms, because Siflx is low relative to Nflx and Pflx (Garnier et al., 2010; Hart et al., 2004).

In this study equations 1 and 2 are used to calculate the river export of $\mathrm{N}$ and $\mathrm{P}$ for which ICEP $=0$. These fluxes represent the maximum levels for river export of $\mathrm{N}$ and $\mathrm{P}$ to ensure that ICEP stays below 0 , indicating a low risk for harmful algal blooms. We refer to these maximum loads as TNmax and TPmax in this study. TNmax and TPmax can be compared with the actual loads of N and P (TN and TP) at the river mouths. We calculate the ratio of actual to maximum loads as an indication of the extent to which nutrient exports by rivers exceed these environmentally sound levels.

\subsection{Results}

\subsubsection{Nutrient export by rivers compared to environmentally sound levels}

The Global Orchestration scenario that we use as a baseline here reflects possible trends in Europe for the coming decades. The total nutrient loads are decreasing between 2000 and 2050 in this scenario (Table 3). This is a result of environmental and agricultural policies in Europe. The decrease, however is moderate $( \pm 10 \%)$. This indicates that policies are not very effective in reducing nutrient levels in coastal waters. The total loads of nitrogen and phosphorus exceed the desired maximum (to ensure that ICEP $=0$ ) considerably. In 2000 the total load is about twice the desired maximum (the surplus is $49-50 \%$ ). By 2050, the surplus is somewhat lower: $45 \%$ for $\mathrm{N}$ and $42 \%$ for P. This is still high and far from zero.

In 200038 of the $48 \mathrm{EU}$ rivers included in our study had an ICEP >0 (high risk for harmful algal blooms). These rivers cover $60 \%$ of EU land area. In 2050 this number of rivers decreases to 34 covering $48 \%$ of EU land area. This moderate 
progress in improvement of the ICEP values is also shown in Figures 1 and 2. In these figures the watersheds of the 48 rivers are shown with their ICEP values. Most of the Europe area is drained by rivers with a positive ICEP $(0-15)$, indicating a risk for coastal eutrophication.

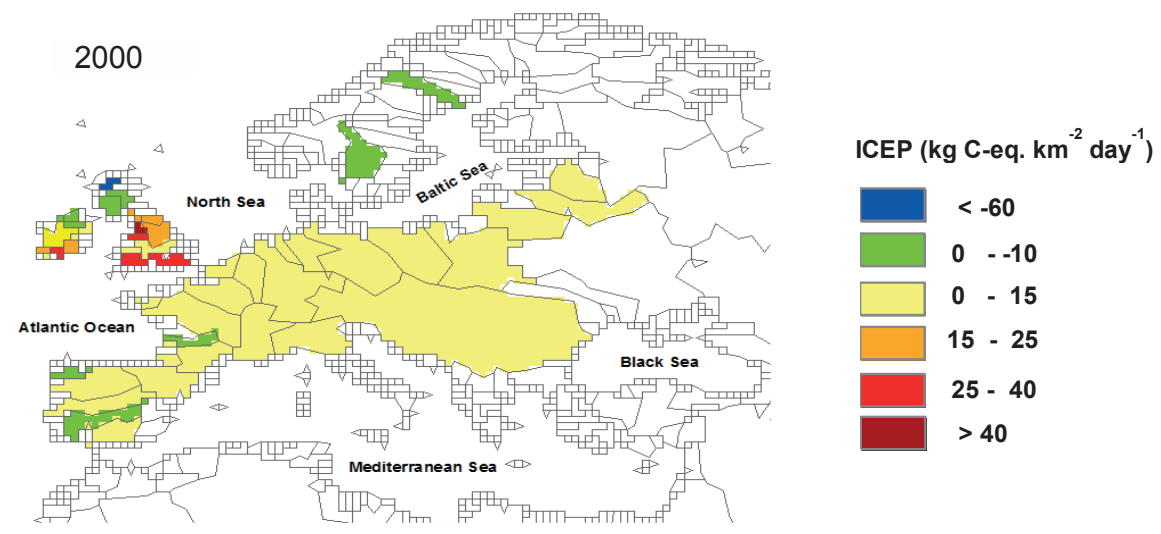

Figure 1. Values of ICEP (Indicator for Coastal Eutrophication Potential) of the 48 rivers considered in this study. The colors indicate the ICEP at the river mouths for the year 2000

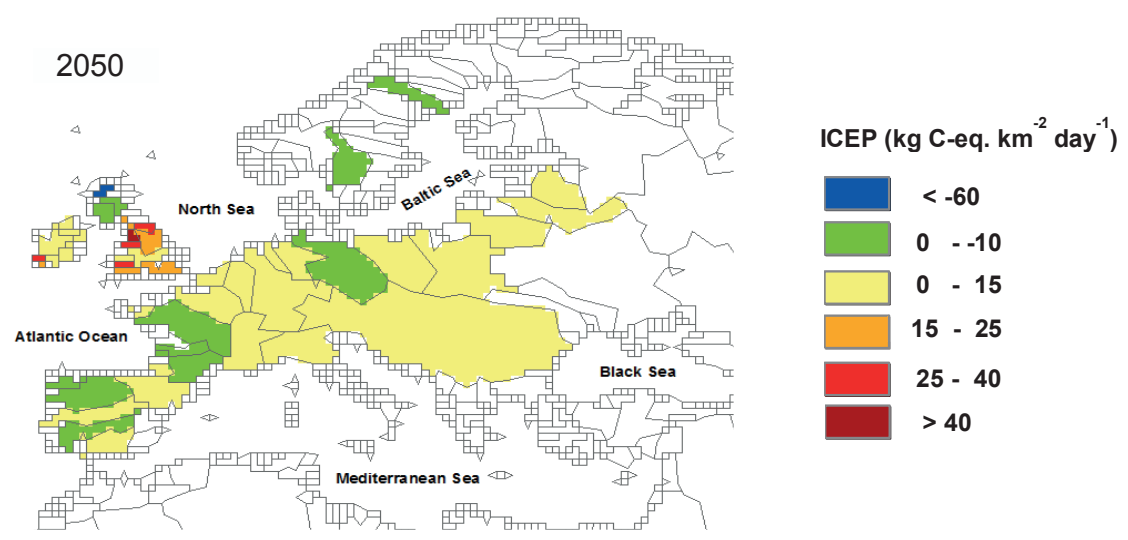

Figure 2. As Fig. 1, but for 2050

River export of nutrients is decreasing over time as a result of agricultural and environmental policies. Not only diffuse sources of nutrients decrease over time, but also point sources. In 2000, $79 \%$ of the European inhabitants were connected to sewage systems and in 2050 almost $90 \%$ in the Global Orchestration scenario (Van Drecht et al., 2009). Meanwhile, waste water 
treatment is projected to become more effective, so that the point sources inputs decrease over time. As a result, nutrient loads at the river mouths decrease (Table 4).

Table 4. Loads at the river mouths of nitrogen and phosphorus (dissolved and particulate) by the 48 rivers included in this study for 2000 and 2050 (scenario GO, see text). The Table shows river export (total load), and the loads associated with fertilizer, manure and sewage (dissolved $\mathrm{N}$ and $\mathrm{P}$ ), other sources (dissolved and particulate $\mathrm{N}$ and $\mathrm{P}$ from natural soils, atmospheric deposition and $\mathrm{N}_{2}$ fixation), as well as the maximum load for which ICEP $=0$ (TNmax and TPmax) and the surplus which is calculated as the total load minus the maximum load. All nutrient exports are in $\mathrm{Gg} / \mathrm{yr}$ (between brackets: \% of total load).

\begin{tabular}{lccllll}
\hline Nutrient & Year & Total load & $\begin{array}{l}\text { Load from } \\
\text { fertilizer, } \\
\text { manure and } \\
\text { sewage }\end{array}$ & $\begin{array}{l}\text { Load from } \\
\text { other sources }\end{array}$ & $\begin{array}{l}\text { TNmax and } \\
\text { TPmax for } \\
\text { ICEP }=0\end{array}$ & Surplus \\
\hline Nitrogen & 2000 & $1833(100 \%)$ & $1183(65 \%)$ & $650(35 \%)$ & $938(51 \%)$ & $895(49 \%)$ \\
Nitrogen & 2050 & $1679(100 \%)$ & $1062(63 \%)$ & $617(37 \%)$ & $923(55 \%)$ & $755(45 \%)$ \\
Phosphorus & 2000 & $256(100 \%)$ & $148(58 \%)$ & $108(42 \%)$ & $130(50 \%)$ & $127(50 \%)$ \\
Phosphorus & 2050 & $222(100 \%)$ & $124(56 \%)$ & $98(44 \%)$ & $128(58 \%)$ & $94(42 \%)$ \\
\hline
\end{tabular}

To minimize the risk of harmful algal blooms, ICEP values at the river mouth should be negative $(<0)$. ICEP is calculated for either $\mathrm{N}$ or $\mathrm{P}$, depending on which of the two is limiting growth. Which nutrient is limiting can be calculated by the ratio of $\mathrm{N}$ and $\mathrm{P}$. If the ratio $\mathrm{N}: \mathrm{P}<16, \mathrm{~N}$ is limiting, otherwise $\mathrm{P}$ is limiting. For the limiting nutrient we can calculate the river load that ensures that ICEP is zero. In this study we refer to this load as the TNmax (maximum Total $\mathrm{N}$ export by the river) or TPmax (maximum Total P export). The difference between the actual loads at the river mouth and TNmax or TPmax is obviously the surplus that causes algal bloom. The actual $\mathrm{N}$ or $\mathrm{P}$ load is the Total $\mathrm{N}$ (TN) or P (TP) load which can be calculated by the Global NEWS model. We calculated the ratios of the actual to maximum loads for the limiting nutrients which are shown in Figures 3 and 4 for the selected rivers. If the ratio is 1 then ICEP is 0 . If the ratio is smaller than 1 then ICEP is negative $(<0)$ indicating a low risk for harmful algal blooms. If the ratio exceeds 1 , then ICEP is positive $(>0)$ and algal blooms may occur.

Figures 3 and 4 show the ratios of the individual rivers of the total to the maximum loads to ensure ICEP $=0$ for the years 2000 and 2050. Not for all the rivers both years are represented, because the limiting nutrient is not always the same for the years 2000 and 2050. 
Figure 3 shows the ratios of total to maximum loads for the $\mathrm{N}$ limited rivers. For 200017 rivers are $\mathrm{N}$ limited of which 15 have a ratio $>1$. The ratios range up to 9. For 205018 rivers are $\mathrm{N}$ limited of which 12 have a ratio $>1$ with a range up to 7.5. Rivers with the largest ratios drain into the Atlantic Ocean. For example, the river Thames is a river with a high ratio of more than 9 in 2000 and 7.5 in 2050. For most of the rivers the ratio is 10\% smaller in 2050 than in 2000, in line with results presented in Table 4.

The $P$ limited rivers are shown in Figures 4 and 5. In 200031 rivers are $P$ limited of which 23 have a ratio $>1$ (ranging from 1 to 13). For 205030 rivers are $P$ limited of which 24 have a ratio $>1$ (ranging from 1 to 11 ). As for $\mathrm{N}$ limited rivers, highest ratios are calculated for rivers draining into the Atlantic Ocean. For instance, large ratios are calculated for the Meuse and Scheldt. The ratio of the Meuse is even larger in 2050 (5.9) than in 2000 (5.8). The river Scheldt has a ratio of 13.3 in 2000 and a ratio of 11.1 in 2050. For most other rivers the 2050 ratios are $10 \%$ lower than in 2000 . For all the rivers together the ratio for 2000 is 2 and for 20501.7 .

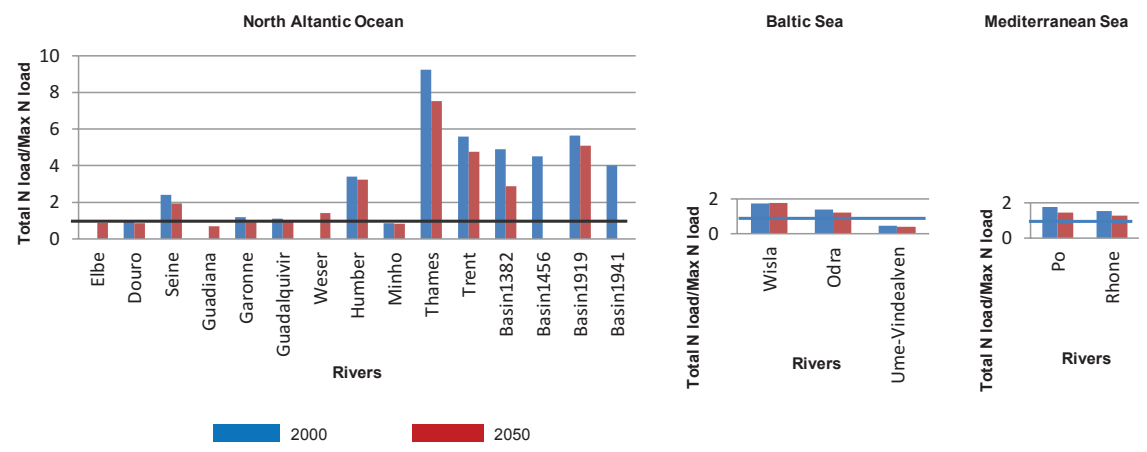

Figure 3. Ratios of total exported N load to maximum N load for ICEP $=0$ for the years 2000 and 2050 at the river mouth. The graph presents ratios for $\mathrm{N}$ limited rivers only. 


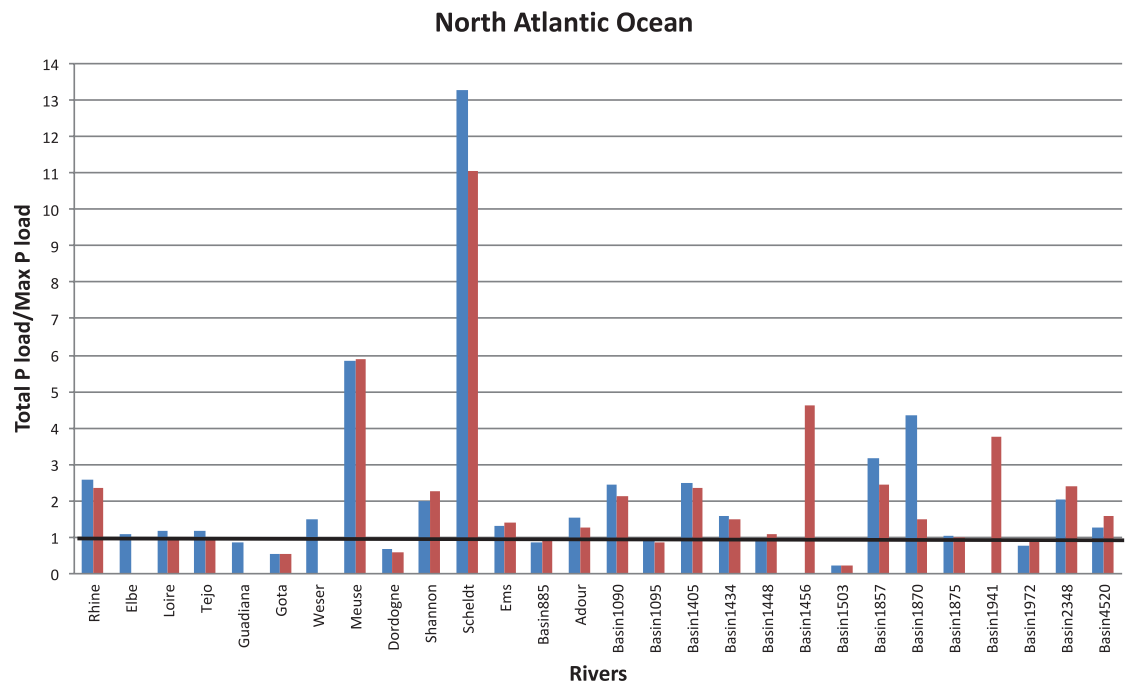

Figure 4. Ratios of total exported P load to maximum $P$ load for ICEP $=0$ for the years 2000 and 2050 at the river mouth. The graph presents ratios for $\mathrm{P}$ limited rivers only.

Baltic Sea

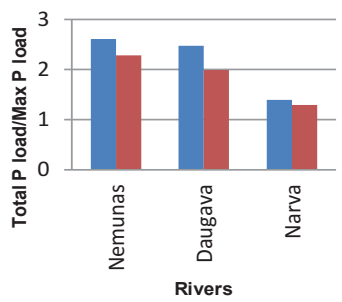

2000
Black Sea

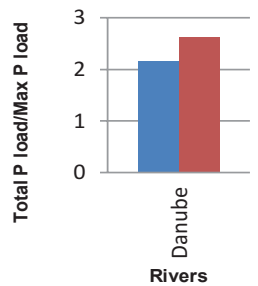

Mediterranean Sea

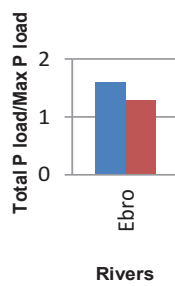

Figure 5. As Figure 4

\subsubsection{Sources of $\mathbf{N}$ and $P$ in rivers}

Next, we identified the sources of $\mathrm{N}$ and $\mathrm{P}$ in rivers. We distinguish between three categories of sources: agriculture, sewage, and other. Agricultural $\mathrm{N}$ and $\mathrm{P}$ includes manure and fertilizers used in agriculture, which are diffuse sources of $\mathrm{N}$ and $\mathrm{P}$ in rivers. Sewage includes urban point sources. The category "other" includes all other sources of nutrients in rivers, which are largely nonanthropogenic. It largely consists of nutrients leaching from natural areas. 
Figures 6,7 and 8 present the shares of these three sources in the export of nutrients by rivers that are either $\mathrm{N}$ or $\mathrm{P}$ limited. In these figures only rivers with a ratio $>1$ are shown. These are the rivers with a relatively high risk of algal blooms.

More than $60 \%$ of the $\mathrm{N}$ exported by rivers to the Atlantic Ocean and the Baltic Sea is from sewage and agriculture (Fig. 6). Some rivers are more dominated by anthropogenic sources than others. Example rivers in which $\mathrm{N}$ is largely from anthropogenic sources are the Thames and Seine. Sewage is the dominant source of nutrients in the Thames, and agriculture in the Seine. For the Atlantic Ocean and the Baltic Sea the share of anthropogenic is in general the same. For the Mediterranean Sea this share is about $40 \%$.

The sources of $\mathrm{P}$ in river export are shown in Figures 7 and 8. There is a large variation among rivers. In some rivers agriculture is the dominant source, and in others sewage. Sewage is an important source of $\mathrm{P}$ in many rivers draining into the North Atlantic Ocean (e.g. the Scheldt) and the Black Sea. This can generally be explained from high levels of urbanization in these watershed. Agriculture is a relatively small source of $P$ in these rivers. It accounts for less than $10 \%$ of $P$ in rivers draining into the Baltic Sea and Black Sea. In several rivers draining into the North Atlantic, however, agriculture is the dominant source of $P$. 


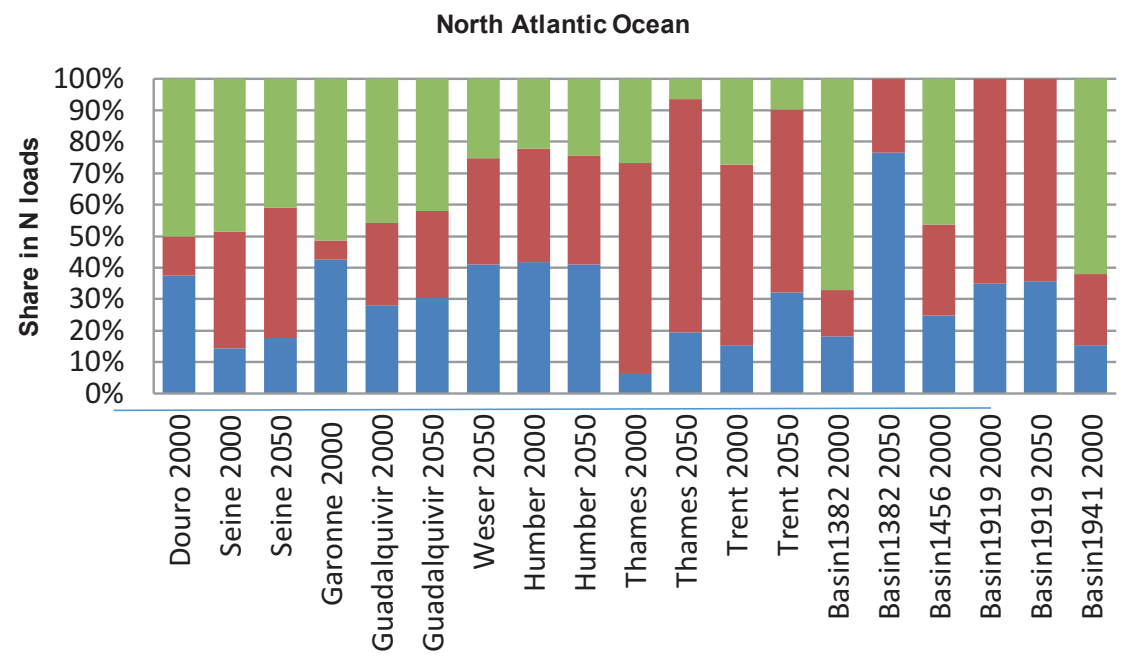

\section{Rivers}

Baltic Sea

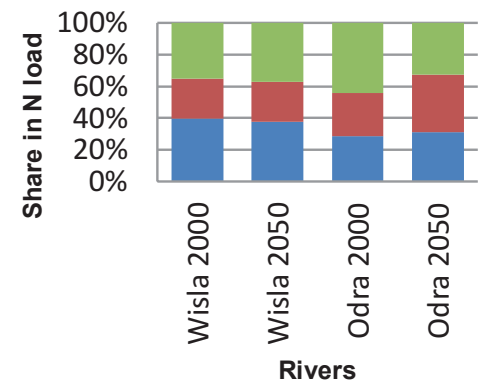

Mediterranean Sea

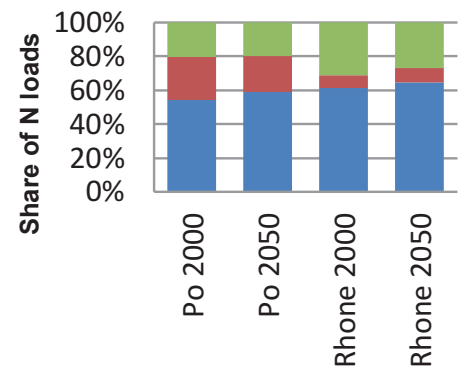

Rivers

Figure 6. Sources N in N-limited rivers for the years 2000 and 2050. The presented shares (in \%) reflect the source attribution at the river mouths. Only rivers with ICEP > 0 in 2000 or 2050 are shown. Results are for total $\mathrm{N}$ (dissolved and particulate). 


\section{North Atlantic Ocean}

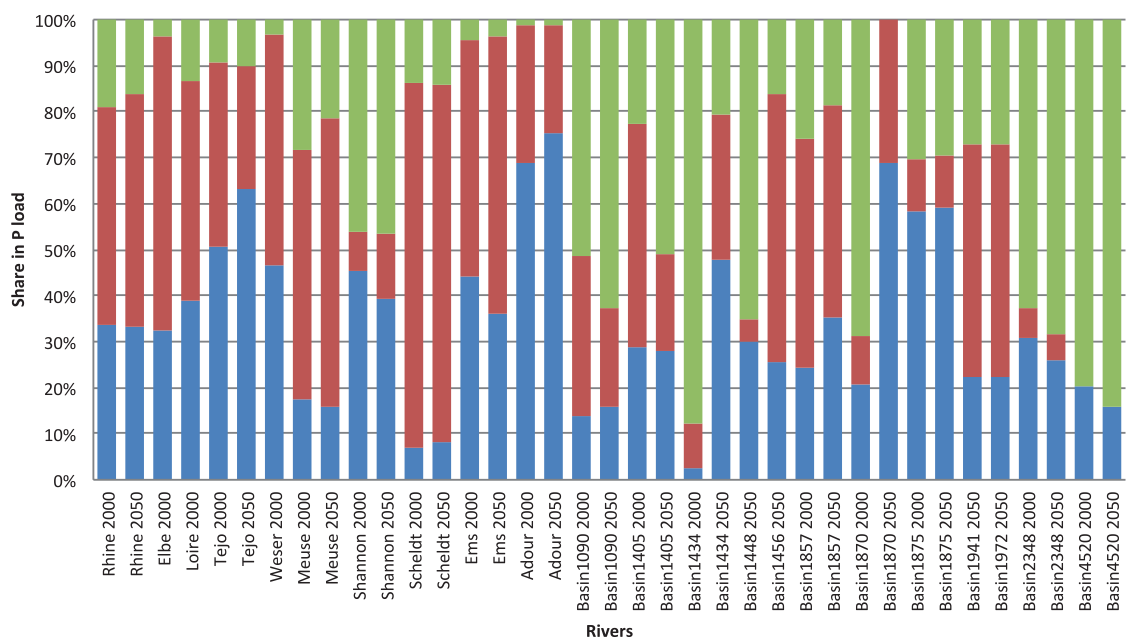

Figure 7. Sources $P$ in P-limited rivers for the years 2000 and 2050. The presented shares (in \%) reflect the source attribution at the river mouths. Only rivers with ICEP $>0$ are shown. Results are for total $P$ (dissolved and particulate).

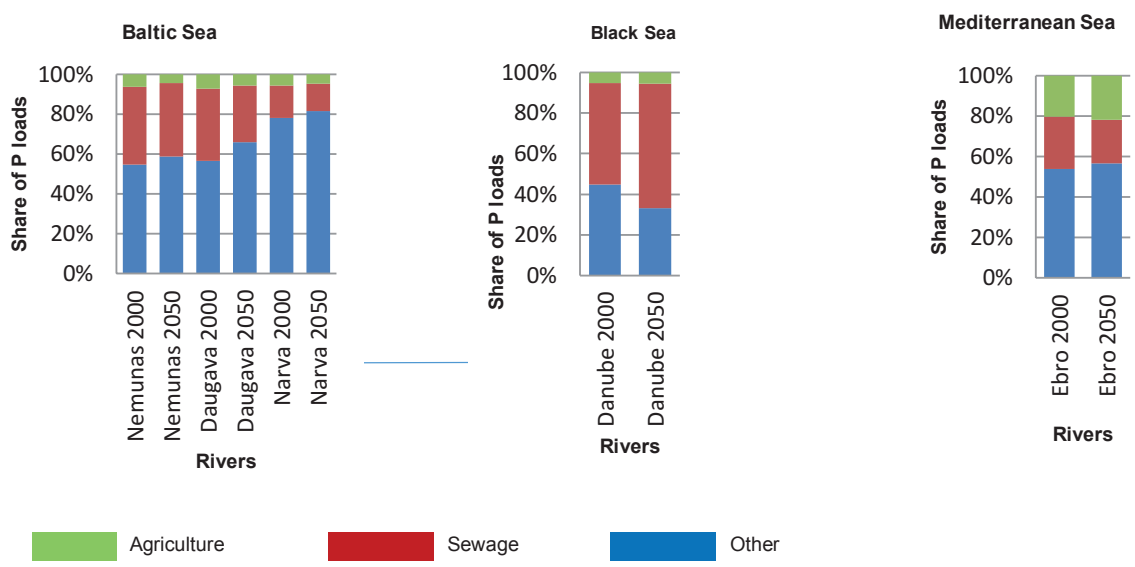

Figure 8. Sources P in P-limited rivers for the years 2000 and 2050. The presented shares (in \%) reflect the source attribution at the river mouths. Only rivers with ICEP $>0$ are shown. Results are for total $P$ (dissolved and particulate).

Table 5 summarizes ICEP values by river, and indicates which nutrient is limiting, N or P. In 200017 of the 48 rivers are N-limited, and 31 are P-limited. In 2050 this is almost the same. Thus more rivers are $P$ limited. The number of rivers with ICEP > 0 is decreasing from 38 in 2000 to 36 in 2050. The reason of this decrease will be that more people are connected at sewage systems. Our ICEP-values of 
rivers of South-West Europe are comparable to those calculated by Romero al. (2013).

Rivers draining into the Atlantic Ocean show a large variation in ICEP value, ranging from -67.9 (basin no. 1503) to 48.1 (basin no. 1941) in 2050. In the southern region of the EU27 the ICEPs of the coastal waters of the Atlantic Ocean range from 7.5 (basin no. 1090) to -4.1 (Dordogne) in 2050. For the rivers draining into the Baltic Sea the ICEP has a value of 2.3 (Wisla) to -8.6 (Ume Vindealven) in 2050. The river mouth of the Danube (Black Sea) has an ICEP of 3.7 for 2000 and 2050. The river mouths at the coastal waters of the Mediterranean Sea have ICEPs ranging between 0.2 and 12.4 and are lower in the year 2050 but still positive.

The rivers with high ICEP values are the most interesting to analyze. For 2050 these rivers are indicated by yellow, orange and red colors in Table 5 . We calculate high ICEP values for rivers draining into all four European seas. Highest values are calculated for rivers draining into the North Atlantic. Table 5 furthermore indicates that rivers differ largely with respect to the causes of the high ICEP value. High ICEP rivers can be either $\mathrm{N}$ or $\mathrm{P}$ limited, and the dominant sources can be either sewage or agriculture.

Table 5. Summary of results by river for 2000 and 2050: Potential Coastal Eutrophication (ICEP); the limiting nutrient ( $\mathrm{N}$ or $\mathrm{P}$ ), and dominant sources of the limiting nutrient. Results are sorted by ICEP 2050. Color codes indicate ICEP categories as Figures 1 and 2.

\begin{tabular}{|c|c|c|c|c|c|c|c|c|}
\hline 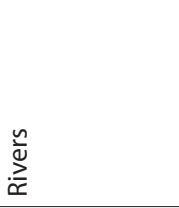 & 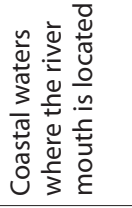 & 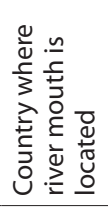 & $\begin{array}{l}\stackrel{8}{0} \\
\text { ․ } \\
\underline{u} \\
\underline{u}\end{array}$ & 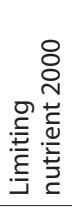 & $\begin{array}{l}\text { 융 } \\
\text { N } \\
\text { 岂 } \\
\underline{u}\end{array}$ & 号 & 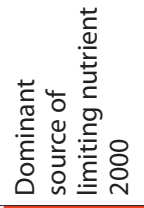 & 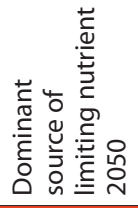 \\
\hline Basin no. 1941 & North Atl. & UK & 48.8 & $\mathrm{~N}$ & 48.1 & $P$ & agriculture & agriculture \\
\hline Basin no. 1919 & Id. & UK & 26.1 & $\mathrm{~N}$ & 26.6 & $\mathrm{~N}$ & sewage & sewage \\
\hline Basin no. 1456 & Id. & UK & 21.7 & $\mathrm{~N}$ & 26.0 & $\mathrm{P}$ & agriculture & sewage \\
\hline Basin no. 1857 & Id. & UK & 36.2 & P & 25.6 & P & agriculture & sewage \\
\hline Thames & Id. & UK & 25.3 & $\mathrm{~N}$ & 22.8 & $\mathrm{~N}$ & sewage & sewage \\
\hline Basin no. 4520 & Id. & Ireland & 10.4 & P & 21.5 & P & agriculture & agriculture \\
\hline Humber & Id. & UK & 16.3 & $\mathrm{~N}$ & 17.2 & $\mathrm{~N}$ & sewage & sewage \\
\hline Basin no. 1382 & Id. & UK & 28.8 & $\mathrm{~N}$ & 15.9 & $\mathrm{~N}$ & agriculture & Sewage \\
\hline Shannon & Id. & Ireland & 8.2 & $\mathrm{P}$ & 12.4 & $P$ & agriculture & agriculture \\
\hline Trent & Id. & UK & 12.1 & $\mathrm{~N}$ & 11.7 & $\mathrm{~N}$ & sewage & sewage \\
\hline Basin no. 1405 & Id. & Ireland & 15.0 & $P$ & 11.3 & $P$ & agriculture & agriculture \\
\hline
\end{tabular}


Table 5. continued

\begin{tabular}{|c|c|c|c|c|c|c|c|c|}
\hline Rivers & 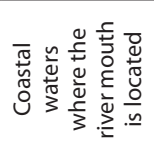 & 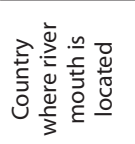 & 岂 옷 & 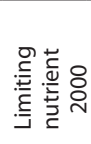 & 岂 융 & 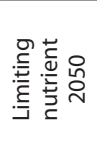 & 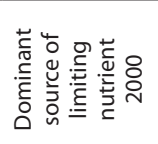 & 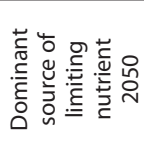 \\
\hline Basin no. 2348 & Id. & Ireland & 20.3 & $P$ & 9.5 & $P$ & agriculture & agriculture \\
\hline Basin no. 1090 & Id. & France & 9.2 & $\mathrm{P}$ & 7.5 & $P$ & agriculture & agriculture \\
\hline Po & Med. Sea & Italy & 12.4 & $\mathrm{~N}$ & 7.4 & $\mathrm{~N}$ & agriculture & agriculture \\
\hline Basin no. 1434 & $\begin{array}{l}\text { North Atl. } \\
\text { Ocean }\end{array}$ & Ireland & 6.6 & $P$ & 6.9 & $P$ & sewage & sewage \\
\hline Basin no. 1870 & Id. & Ireland & 32.9 & $P$ & 5.6 & $P$ & agriculture & sewage \\
\hline Basin no. 1448 & Id. & Ireland & -0.2 & $P$ & 4.6 & $P$ & agriculture & agriculture \\
\hline Scheldt & Id. & The Neth. & 4.5 & $\mathrm{P}$ & 4.2 & $P$ & sewage & sewage \\
\hline Meuse & Id. & The Neth. & 3.8 & $P$ & 3.9 & $P$ & sewage & sewage \\
\hline Seine & Id. & France & 5.2 & $\mathrm{~N}$ & 3.8 & $\mathrm{~N}$ & agriculture & sewage \\
\hline Danube & Black Sea & Romana & 3.7 & $P$ & 3.7 & $P$ & sewage & sewage \\
\hline Rhone & Med. Sea & France & 5.8 & $\mathrm{~N}$ & 3.1 & $\mathrm{~N}$ & agriculture & agriculture \\
\hline Basin no. 1972 & $\begin{array}{l}\text { North Atl. } \\
\text { Ocean }\end{array}$ & Ireland & -2.3 & $P$ & 2.8 & $P$ & agriculture & agriculture \\
\hline Ems & Id. & Germany & 1.9 & $P$ & 2.7 & $P$ & sewage & sewage \\
\hline Wisla & Baltic Sea & Poland & 2.1 & $\mathrm{~N}$ & 2.3 & $\mathrm{~N}$ & agriculture & agriculture \\
\hline Weser & $\begin{array}{l}\text { North Atl. } \\
\text { Ocean }\end{array}$ & Germany & 2.4 & $P$ & 2.1 & $\mathrm{~N}$ & sewage & sewage \\
\hline Nemunas & Baltic Sea & Lithuana & 2.7 & $P$ & 2.1 & $P$ & sewage & sewage \\
\hline Rhine & $\begin{array}{l}\text { North Atl. } \\
\text { Ocean }\end{array}$ & The Neth. & 2.2 & $\mathrm{P}$ & 1.8 & $\mathrm{P}$ & sewage & sewage \\
\hline Adour & Id. & France & 3.8 & $P$ & 1.8 & $P$ & sewage & sewage \\
\hline Daugava & Baltic Sea & Letland & 1.1 & $P$ & 0.9 & $P$ & sewage & sewage \\
\hline Odra & Id. & Germany & 1.1 & $\mathrm{~N}$ & 0.6 & $\mathrm{~N}$ & agriculture & sewage \\
\hline Narva & Id. & Estland & 0.7 & $P$ & 0.6 & $P$ & sewage & sewage \\
\hline Basin no. 1875 & $\begin{array}{l}\text { North Atl. } \\
\text { Ocean }\end{array}$ & UK & 1.1 & $\mathrm{P}$ & 0.5 & $\mathrm{P}$ & agriculture & agriculture \\
\hline Ebro & Med. Sea & Spain & 0.5 & $\mathrm{P}$ & 0.2 & $\mathrm{P}$ & sewage & sewage \\
\hline Tejo & $\begin{array}{l}\text { North Atl. } \\
\text { Ocean }\end{array}$ & Portugal & 0.3 & $P$ & 0.0 & $P$ & sewage & sewage \\
\hline Guadalquiver & Id. & Spain & 0.4 & $\mathrm{~N}$ & 0.0 & $\mathrm{~N}$ & agriculture & agriculture \\
\hline Loire & Id. & France & 1.1 & $\mathrm{P}$ & -0.2 & $P$ & sewage & sewage \\
\hline Elbe & Id. & Germany & 0.5 & $\mathrm{P}$ & -0.4 & $\mathrm{~N}$ & sewage & sewage \\
\hline Douro & Id. & Portugal & 0.1 & $\mathrm{~N}$ & -0.5 & $\mathrm{~N}$ & agriculture & agriculture \\
\hline Basin no. 885 & Id. & UK & -4.2 & $P$ & -0.7 & $P$ & agriculture & agriculture \\
\hline Garonne & Id. & France & 1.4 & $\mathrm{~N}$ & -0.8 & $\mathrm{~N}$ & agriculture & agriculture \\
\hline Guadiana & Id. & Spain & -0.4 & $P$ & -0.8 & $\mathrm{~N}$ & sewage & agriculture \\
\hline Minho & Id. & Portugal & -2.3 & $\mathrm{~N}$ & -2.8 & $\mathrm{~N}$ & sewage & sewage \\
\hline Gota & Id. & Sweden & -3.2 & $P$ & -3.9 & $P$ & sewage & agriculture \\
\hline Dordogne & Id. & France & -3.3 & $\mathrm{P}$ & -4.1 & $P$ & agriculture & agriculture \\
\hline Basin no. 1095 & Id. & UK & -1.5 & $P$ & -5.4 & $P$ & sewage & sewage \\
\hline Ume-Vindealven & Baltic Sea & Sweden & -6.6 & $\mathrm{~N}$ & -8.6 & $\mathrm{~N}$ & agriculture & agriculture \\
\hline Basin no. 1503 & $\begin{array}{l}\text { North Atl. } \\
\text { Ocean }\end{array}$ & UK & -63.4 & $P$ & -67.9 & $P$ & sewage & sewage \\
\hline
\end{tabular}




\subsection{Discussion}

All results presented here have their specific uncertainties. Even though the model has been validated at several scales, as indicated above, the results have to be interpreted with caution. There are uncertainties in de Global NEWS model, but also the future is by definition uncertain. The MA scenarios were developed as possible futures under different social and economic developments. Despite these uncertainties, our results can be considered indications of the causes of coastal eutrophication in specific European rivers. The results indicate that eutrophication can be serious in the future in the European coastal waters if no measures are taken.

We presented loads of nutrients in rivers, and their ICEP values indicating risks of coastal eutrophication. Managing anthropogenic sources may lower ICEP values. Our results indicate that total loads of $\mathrm{N}$ and $\mathrm{P}$ in European rivers exceed desirable levels (to ensure ICEP $=0$ ) on average by a factor of 2 , but for individual rivers the excess of nutrients can be much larger (Table 4 and 5). Anthropogenic sources have a large share of the loads at the river mouths. These anthropogenic sources include agriculture and sewage.

Table 5 indicates that the causes of coastal eutrophication in Europe differ largely among rivers, as well as the extent to which desirable $\mathrm{N}$ and $\mathrm{P}$ levels in rivers are exceeded. This indicates that basin-specific policies to reduce the risk for coastal eutrophication is probably more effective than European-wide policies. Agriculture can be managed by more efficient $\mathrm{N}$ and $\mathrm{P}$ use. Sewage can be more efficient by a higher removal of the nutrients. For example, we calculate that the river Thames is $\mathrm{N}$ limited in 2050 with a high ICEP (22.8), and that sewage is the dominant polluting source. So for this river $\mathrm{N}$ removal in the sewage treatment would be a preferred management strategy. Another example is the river Po, which is also $\mathrm{N}$ limited in 2050 with a high ICEP of 7.4. In this case increased nutrient use efficiency in agriculture may most effectively decrease the risk for coastal eutrophication. These two examples illustrate how basin-specific management may effectively reduce the risk of algal bloom in the coastal waters. 


\subsection{Conclusion}

Future scenario studies indicate that by the year 2050 the river export of nitrogen and phosphorus are 8 and 13\% lower than in 2000, respectively. These decreases are achieved by European policy measures for agriculture and sewage. These decreases are not sufficient to avoid the risk for algal blooms in coastal seas.

In this study we estimated the extent to which $\mathrm{N}$ and $\mathrm{P}$ loads in 48 European rivers exceed levels that can be considered low enough to avoid harmful algal blooms. We calculate that in 2000 current $\mathrm{N}$ and $\mathrm{P}$ loads of 38 rivers exceed such levels In the future, nutrient loads in rivers may decrease to some extent as a result of European policies but still loads of 36 rivers exceed the safe level. However, in our scenarios for 2050 the surplus is reduced by only a few percent. The higher the ratio of actual to maximum river loads for ICEP $=0$, the higher the risk for harmful algal blooms in the coastal water. The highest ratios of actual and harmless loads are found for the rivers with their mouth at the coastal waters of Atlantic Ocean.

Next, we quantified the relative shares of sources of $\mathrm{N}$ and $\mathrm{P}$ in rivers. Our results indicate that the sources of excess nutrient levels differ among rivers. . For some rivers agriculture is dominant and for some rivers sewage. This indicates that basin-specific policies to reduce the risk for coastal eutrophication is probably more effective than European-wide policies.

Our analysis may help to identify effective management strategies to reduce coastal eutrophication. It is important to find strategies that reduce nutrient export by rivers to levels that minimize the potential for coastal eutrophication. Optimal strategies to avoid harmful algal blooms in the future, therefore, need to be basin-specific. In some basins it may be most effective to improve sewage treatment, while in others nutrient use efficiency in agriculture deserves priority.

\section{Acknowledgements}

We thank Maryna Strokal for assisting in the graphics. 


\section{Chapter 3 Possible future effects of large- scale algae cultivation for biofuels on coastal eutrophication in Europe}

Published as:

Blaas $H$, Kroeze C. 2014. Possible future effects of large-scale algae cultivation for biofuels on coastal eutrophication in Europe. Science of Total Environment 496, 45-51. http://dx.doi.org/10.1016/j.scitotenv.2014.06.131 


\section{Abstract}

Biodiesel is increasingly considered as an alternative for fossil diesel. Biodiesel can be produced from rapeseed, palm, sunflower, soybean and algae. In this study, the consequences of large-scale production of biodiesel from microalgae for eutrophication in four large European seas are analysed. To this end, scenarios for the year 2050 are analysed, assuming that in the 27 countries of the European Union fossil diesel will be replaced by biodiesel from algae. Estimates are made for the required fertiliser inputs to algae parks, and how this may increase concentrations of nitrogen and phosphorus in coastal waters, potentially leading to eutrophication. The Global NEWS (Nutrient Export from WaterSheds) model has been used to estimate the transport of nitrogen and phosphorus to the European coastal waters. The results indicate that the amount of nitrogen and phosphorus in the coastal waters may increase considerably in the future as a result of large-scale production of algae for the production of biodiesel, even in scenarios assuming effective waste water treatment and recycling of waste water in algae production. To ensure sustainable production of biodiesel from micro-algae it is important to develop cultivation systems with low nutrient losses to the environment. 


\subsection{Introduction}

\subsubsection{Background}

Biofuels are often mentioned as promising alternatives for fossil fuels. The first generation biofuels can be produced from, for instance, grains, sugar cane and vegetable oils. There are, however, concerns about replacing food crops by these first generation biofuels. The second generation of biofuel production is based on waste residues and makes use of abandoned land (Eisentraut, 2010). However, also the second generation biofuels can be unsustainable in case they compete with food crops for available land.

Lipids from micro-algae can be used to produce biodiesel. Likewise, biodiesel can be produced from lipids from rapeseed, soybean, sunflower and palm. Green micro-algae, such as the single-cell algae belonging to the genus Chlorella can be grown commercially. The process of algae cultivation has been described elsewhere (Wolkers et al., 2011). The productivity per hectare of micro-algae is considerably higher than that of other energy crops. Biodiesel from algae can therefore be considered an example of a third generation biofuel (Ahmad et al., 2010).

Biodiesel is considered environmental friendly because of low greenhouse gas emissions. Also biodiesel from algae has been suggested as a climate friendly alternative for fossil fuels in the future (Ahmad et al., 2010) although several studies indicate that with current technologies the production of biodiesel from algae is not yet energy efficient (Reijnders, 2009). Others, however, argue that biodiesel may be the only renewable alternative for fossil diesel for heavy traffic (Mackay, 2010).

Production of algae is currently mainly taking place at the pilot scale. It is expected that full-scale production sites may be operational in Europe within the coming decades. Algae production usually takes place in so-called algae parks. Such parks may consist of open ponds or raceways, single-layer or horizontal tube reactors, three dimensional tube reactors and flat plate reactors. The open pond is an open system while the other systems are all closed in the sense that there is no open contact with the environment. 
Algae production may have environmental implications. Several life cycle assessments (LCAs) have been published, indicating that these environmental implications are largely associated the use of fertilisers, energy, and water (Brentner et al., 2011; Clarens et al., 2010; Lardon et al., 2009; Liu and Ma, 2009; Yang et al., 2011). Relatively high fertiliser inputs are needed during algae cultivation, resulting potentially high losses of nutrients such as nitrogen $(\mathrm{N})$ and phosphorus $(\mathrm{P})$ to the environment, giving rise to eutrophication. Other LCA studies indicate that nutrient losses as a result of fertiliser use deserve particular attention because of the large amounts that are potentially lost to the environment (Clarens, 2011; Clarens et al., 2010; Lardon et al., 2009; Yang et al., 2011).

This study focuses on the impact of land-based micro-algae production on aquatic systems. The study is a modelling study applying scenario analysis on the basis of hypothetical assumptions, and investigates the environmental consequences of our assumptions on micro-algae cultivation for biodiesel production in Europe. Algae parks require considerable inputs of nutrients, in particular $\mathrm{N}$ and P. These nutrients are only partly incorporated in algae tissue. The remainder is recycled, or leaving the system as waste or loss to the environment. Losses to the environment include gaseous losses such as dinitrogen $\left(\mathrm{N}_{2}\right)$, amonia $\left(\mathrm{NH}_{3}\right)$, nitrogen oxides $\left(\mathrm{NO}_{x}\right)$ and nitrous oxide $\left(\mathrm{N}_{2} \mathrm{O}\right)$, and losses to aquatic systems. Recycling of nutrients is possible, but not yet current practice in operational algae production sites. Recycling can take place by collecting and re-use of the algae biomass after harvesting. The process of recycling is, however, not the subject of this study. The liquid waste streams from algae parks are generally treated as municipal sewage discharging to rivers. Thus part of the $\mathrm{N}$ and $\mathrm{P}$ used in algae production may be lost to the aquatic system.

Increased nutrient levels in streams and rivers may lead to eutrophication in fresh and marine waters (Diaz and Rosenberg, 2008; EEA, 2001; Seitzinger et al., 2010; Sutton et al., 2011). Eutrophication in surface waters may lead to harmful algae blooms which may be toxic for other organisms. In extreme cases aquatic eutrophication may lead to hypoxia. It thus poses a threat to biodiversity, fish stock, and recreation. The risk for coastal eutrophication is not only depending on $\mathrm{N}$ and $\mathrm{P}$ enrichment, but also on the ratio of $\mathrm{N}$ or $\mathrm{P}$ to other elements (Billen 
and Garnier, 2007). Analyses for the coastal waters of the EU27 indicate that the nutrient availability in coastal waters is currently disturbed and a cause of severe eutrophication events (Sutton et al., 2011). In the future, however, this may change. Environmental and agricultural policies aim at a decrease in the export of $\mathrm{N}$ and $\mathrm{P}$ by rivers to coastal waters in Europe. Scenarios exploring future trends in Europe indeed indicate that the risk for coastal eutrophication may decrease in the future (Garnier et al., 2010; Seitzinger et al., 2010; Strokal and Kroeze, 2012). These scenarios, however, do not account for a possible increase in the production of micro-algae on land.

The purpose of this study is to analyse the potential consequences of largescale land-based production of biodiesel from micro-algae in Europe for coastal eutrophication. The main focus is on $\mathrm{N}$ and $\mathrm{P}$ export by major rivers in the 27 countries of the European Union (EU27) to four large European seas: the North Sea, the Mediterranean Sea, the Black Sea and the Baltic Sea. The analysis is based on hypothetical scenarios for the year 2050 assuming that fossil diesel used in EU 27 countries will be replaced by biodiesel from algae.

\subsubsection{Global NEWS}

In this study the focus is on major rivers in the EU27 that discharge into the coastal waters of the Mediterranean Sea, the Baltic Sea, the Black Sea and the Atlantic Ocean. The analysis follows future export of $\mathrm{N}$ and $\mathrm{P}$ by these rivers with the Global NEWS (Nutrient Export from WaterSheds) model (Mayorga et al., 2010; Seitzinger et al., 2010; Seitzinger et al., 2005). The Global NEWS model has been used to analyse future trends in river export of nutrients based on the Millennium Ecosystem Assessment (MA) scenarios (Alcamo et al., 2006; Bennett and Carpenter, 2006; MA, 2005). The use of these scenarios for the year 2050 is as a baseline to analyse the additional inputs of $\mathrm{N}$ and $\mathrm{P}$ to rivers assuming large-scale land-based production of biodiesel from algae, by using the Global NEWS model. The analysis uses different scenarios, that either assumes replacement of fossil diesel for all traffic, or only for heavy traffic such as heavy duty trucks, freight vessels and airplanes in EU27 countries by biodiesel from algae. The focus on heavy traffic reflects the possibility that many private cars may be electric by the year 2050 and do not need fuels. This may be impossible for heavy traffic, making biodiesel an important alternative to fossil diesel (Mackay, 2010). 
The Global NEWS. model simulates the transport N, $\mathrm{P}$ and carbon (C) in multielement form by more than 6000 rivers all over the world (Mayorga et al., 2010; Seitzinger et al., 2005). The first version of the model (Global NEWS.-1) was released in the year 2005. This model system consisted of a set of submodels which estimate dissolved inorganic nitrogen (DIN) and phosphorus (DIP), dissolved organic nitrogen (DON), phosphorus (DOP) and carbon (DOC), particulate nitrogen (PN), phosphorus (PP) and carbon (PC) (Billen G et al., 2010; Bouwman et al., 2009; Fekete et al., 2010; Seitzinger et al., 2005; van der Hoek, 2001). In 2009 a revised Global NEWS. model was released which combines all sub-models in one integrated interface. This Global NEWS.-2 model estimates nutrient export from the watersheds to coastal waters at the mouth of rivers not only for the present, but also for the past and the future. The Global NEWS. model uses global input data with a typical spatial resolution of $0.5 \times 0.5$ degree latitude by longitude. These input databases are generated by the IMAGE model and the Water Balance Plus model (Bouwman et al., 2010; Van Drecht et al., 2009; Fekete et al., 2010). Global NEWS. has been validated at the global scale and not only been used for global analysis, but also for studies at the continental scale including Europe (Kroeze et al., 2002; Kroeze and Seitzinger, 1998; Qu and Kroeze, 2010; Qu, 2011; van der Struijk and Kroeze, 2010; Yasin et al., 2010) and the regional scale (Strokal and Kroeze, 2012; Thieu et al., 2010; Yan et al., 2010)

Global NEWS can be used to quantify the sources of nutrients in rivers. The nutrients in rivers originate from anthropogenic and natural sources. Natural sources are mainly diffuse sources, including $\mathrm{N}$ and $\mathrm{P}$ leaching and runoff from natural areas. The anthropogenic sources include diffuse and point sources. Agriculture, industry and human waste are important anthropogenic sources of nutrients in rivers. Sanitation is an important source of nutrients in many rivers (Van Drecht et al., 2009). In Global NEWS, nutrient inputs from sewage are calculated as a function of population density, sewage connection, and waste water treatment. Basin-specific removal efficiencies of waste water treatment plants are available in the model. The Global NEWS model calculates river export of nutrients while accounting for watershed and river retention. The model output includes the nutrients loads at the river mouths. 
The Global NEWS model is used to calculate the additional river export of nutrients as a result of cultivation algae in river basins of the EU27 countries in the future. Algae parks on land are considered an additional point source of $\mathrm{N}$ and $\mathrm{P}$ to rivers in our study, following the modelling approach of point sources applied in Global NEWS (Van Drecht et al., 2009).

\subsubsection{Millennium Ecosystem Assessment Scenarios}

The Millennium Ecosystem Assessment (MA) scenarios for 2050 function are as a baseline. The MA was initiated by the United Nations in 2000. The objective of the MA was to assess the consequences of ecosystem change for human well-being and provide a rigorous scientific basis for action needed to enhance the conservation and sustainable use of those systems and their contribution to human well-being. The result of the work of 1360 experts was the determination and trends of the world's ecosystems and the services they provide such as clean water, food, forest products, flood control, and natural resources. The reports of MA provide also options to restore, conserve or enhance the sustainable use of ecosystems (MA, 2005). The available products of MA are reports containing four scenarios for possible future developments. The scenarios estimate the developments up to the year 2050.

Four MA scenarios exist: Global Orchestration (GO), Order from Strength (OS), Adapting Mosaic (MA) and Technogarden (TG) (Alcamo et al., 2006) (Table 1). These scenarios differ with respect to the underlying assumptions on socio-economic developments (globalization versus regionalization) and the approach towards ecosystem management (proactive versus reactive).

The MA scenarios have been quantitatively interpreted by the Global NEWS team to create the required input databases for the Global NEWS model for 1970, 2000, 2030 and 2050. This was done for model inputs related to land use (Bouwman et al., 2010), sewage (Van Drecht et al., 2009) and hydrology (Fekete et al., 2010). 
Table 1. Characteristics of the four MA scenarios.

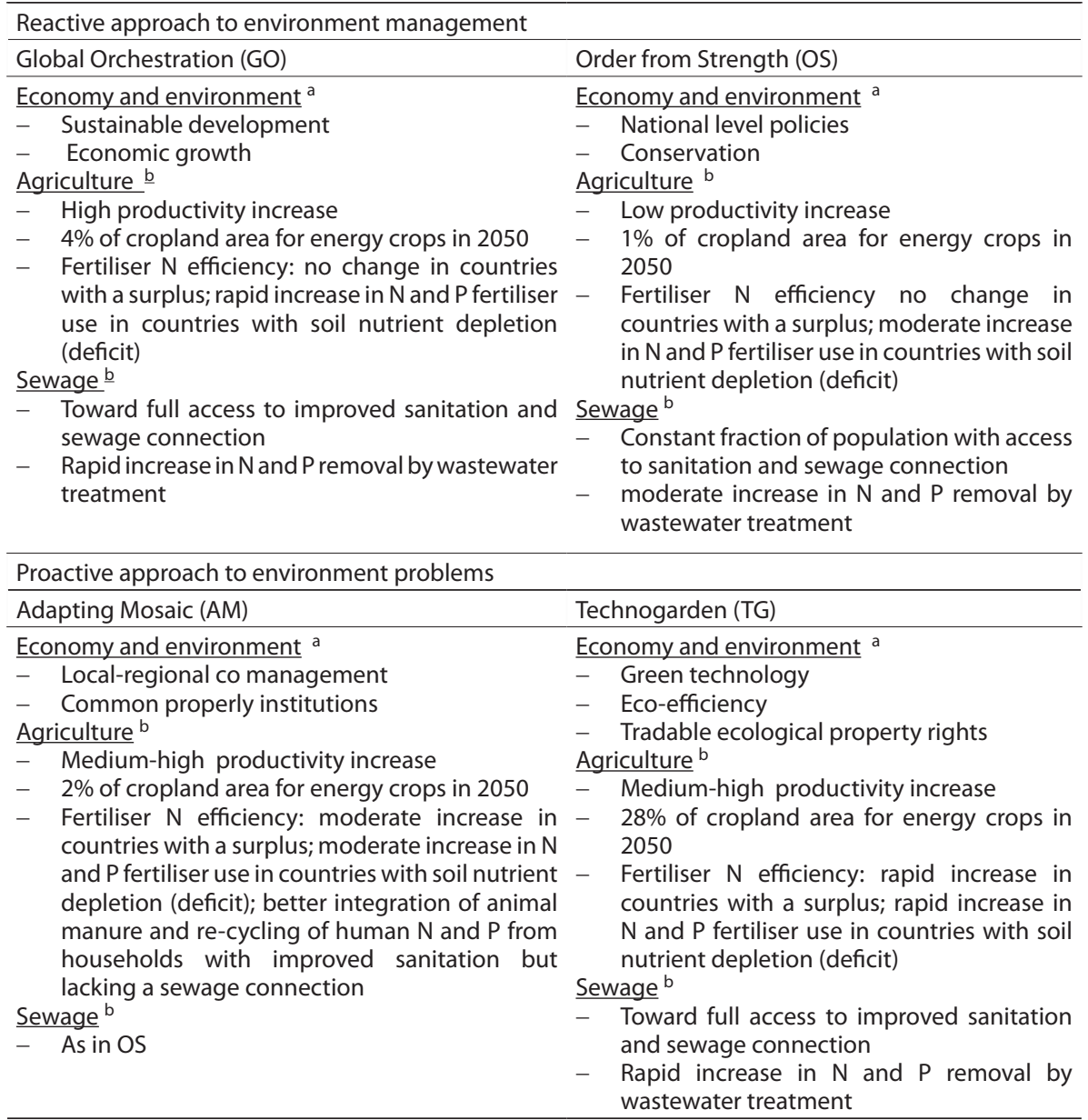

a Alcamo et al., (2006)

b Bouwman et al., (2010), Seitzinger et al., (2010) and Van Drecht et al., (2010)

\subsection{Method}

\subsubsection{Modelling $\mathbf{N}$ and $\mathbf{P}$ inputs from large-scale algae production to coastal seas in EU27 in $\mathbf{2 0 5 0}$}

The MA scenarios as implemented in the Global NEWS model assume zero production of biodiesel from algae (Seitzinger et al., 2010). New scenarios are developed, based on the MA scenarios for the EU27 countries in which is assumed an increased production of micro-algae on land. 
The approach can be summarized as follows. First, rivers are selected from the Global NEWS model discharging into the four major European Seas. Second, estimate has been made for the amount of micro-algae needed to produce sufficient biodiesel to replace fossil diesel in EU 27 countries in 2050. Third, also estimate has been made for the associated $\mathrm{N}$ and $\mathrm{P}$ fertiliser inputs needed to grow these algae in the selected river basins on land. Finally, the Global NEWS model has been run to calculate the additional $\mathrm{N}$ and $\mathrm{P}$ inputs to the coastal seas in 2050 while considering algae parks as additional point sources of $\mathrm{N}$ and $P$ in rivers and while assuming different levels of waste water treatment. In the following these research steps are elaborated.

\subsubsection{Selection of rivers}

48 rivers were selected from the Global NEWS model discharging into the coastal waters of the countries of the EU27 (Table 1). All European rivers with an $\mathrm{N}$ load of more than $10 \mathrm{Gg} / \mathrm{yr}$ at the river mouth, and with a river mouth located in one of the EU 27 countries are selected. The $10 \mathrm{Gg} \mathrm{N} / \mathrm{yr}$ threshold is arbitrary, but the resulting group of rivers are largely responsible for the current nutrient inputs to European coastal waters. Some rivers in Global NEWS have a codename (a basin identification number). For all rivers the coordinates of the river mouth are available in degrees longitude and latitude in Global NEWS. There is a distinguish between rivers draining into the North Atlantic Ocean, the Baltic sea, the Black Sea and the Mediterranean Sea (Figure 1).

Table 2. Rivers included in this study. Source: Global NEWS (Mayorga et al., 2010; Seitzinger et al., 2010).

\begin{tabular}{llll}
\hline River & $\begin{array}{l}\text { Country where the river mouth } \\
\text { is located }\end{array}$ & Basin area $\left(\mathrm{km}^{2}\right)$ & Ocean/Sea \\
\hline Rhine & The Netherlands & 163750 & North Atlantic Ocean \\
Elbe & Germany & 148118 & North Atlantic Ocean \\
Loire & France & 117340 & North Atlantic Ocean \\
Douro & Portugal & 95455 & North Atlantic Ocean \\
Seine & France & 72838 & North Atlantic Ocean \\
Tejo & Portugal & 72290 & North Atlantic Ocean \\
Guadiana & Portugal & 64196 & North Atlantic Ocean \\
Garonne & France & 57858 & North Atlantic Ocean \\
Guadalquivir & Spain & 53249 & North Atlantic Ocean \\
Gota & Sweden & 44107 & North Atlantic Ocean \\
Weser & Germany & 45389 & North Atlantic Ocean \\
Meuse & The Netherlands & 43284 & North Atlantic Ocean \\
Dordogne & France & 25744 & North Atlantic Ocean
\end{tabular}


Chapter 3

Table 2. continued.

\begin{tabular}{|c|c|c|c|}
\hline River & $\begin{array}{l}\text { Country where the river mouth } \\
\text { is located }\end{array}$ & Basin area $\left(\mathrm{km}^{2}\right)$ & Ocean/Sea \\
\hline Humber & UK & 23670 & North Atlantic Ocean \\
\hline Shannon & Ireland & 20831 & North Atlantic Ocean \\
\hline Scheldt & The Netherlands & 20604 & North Atlantic Ocean \\
\hline Minho & Portugal & 17472 & North Atlantic Ocean \\
\hline Thames & UK & 16833 & North Atlantic Ocean \\
\hline Trent & UK & 16948 & North Atlantic Ocean \\
\hline Ems & Germany & 14989 & North Atlantic Ocean \\
\hline Basin no. 885 & UK & 11876 & North Atlantic Ocean \\
\hline Adour & France & 13010 & North Atlantic Ocean \\
\hline Basin no. 1090 & France & 10320 & North Atlantic Ocean \\
\hline Basin no. 1095 & UK & 10066 & North Atlantic Ocean \\
\hline Basin no. 1382 & UK & 5763 & North Atlantic Ocean \\
\hline Basin no. 1405 & Ireland & 7168 & North Atlantic Ocean \\
\hline Basin no. 1434 & Ireland & 6242 & North Atlantic Ocean \\
\hline Basin no. 1448 & Ireland & 6864 & North Atlantic Ocean \\
\hline Basin no. 1456 & UK & 6264 & North Atlantic Ocean \\
\hline Basin no. 1503 & UK & 6508 & North Atlantic Ocean \\
\hline Basin no. 1857 & UK & 5594 & North Atlantic Ocean \\
\hline Basin no. 1870 & Ireland & 4741 & North Atlantic Ocean \\
\hline Basin no. 1875 & UK & 5671 & North Atlantic Ocean \\
\hline Basin no. 1919 & UK & 5036 & North Atlantic Ocean \\
\hline Basin no. 1941 & UK & 5171 & North Atlantic Ocean \\
\hline Basin no. 1972 & Ireland & 4351 & North Atlantic Ocean \\
\hline Basin no. 2348 & Ireland & 3526 & North Atlantic Ocean \\
\hline Basin no. 4520 & Ireland & 1912 & North Atlantic Ocean \\
\hline Wisla & Poland & 179883 & Baltic Sea \\
\hline Odra & Germany & 118731 & Baltic Sea \\
\hline Nemunas & Lithuania & 95532 & Baltic Sea \\
\hline Daugava & Letland & 83279 & Baltic Sea \\
\hline Narva & Estland & 54374 & Baltic Sea \\
\hline Ume-Vindealven & Sweden & 28923 & Baltic Sea \\
\hline Danube & Romania & 785306 & Black Sea \\
\hline Po & Italy & 100297 & Mediterranean Sea \\
\hline Rhone & France & 98660 & Mediterranean Sea \\
\hline Ebro & Spain & 81901 & Mediterranean Sea \\
\hline
\end{tabular}




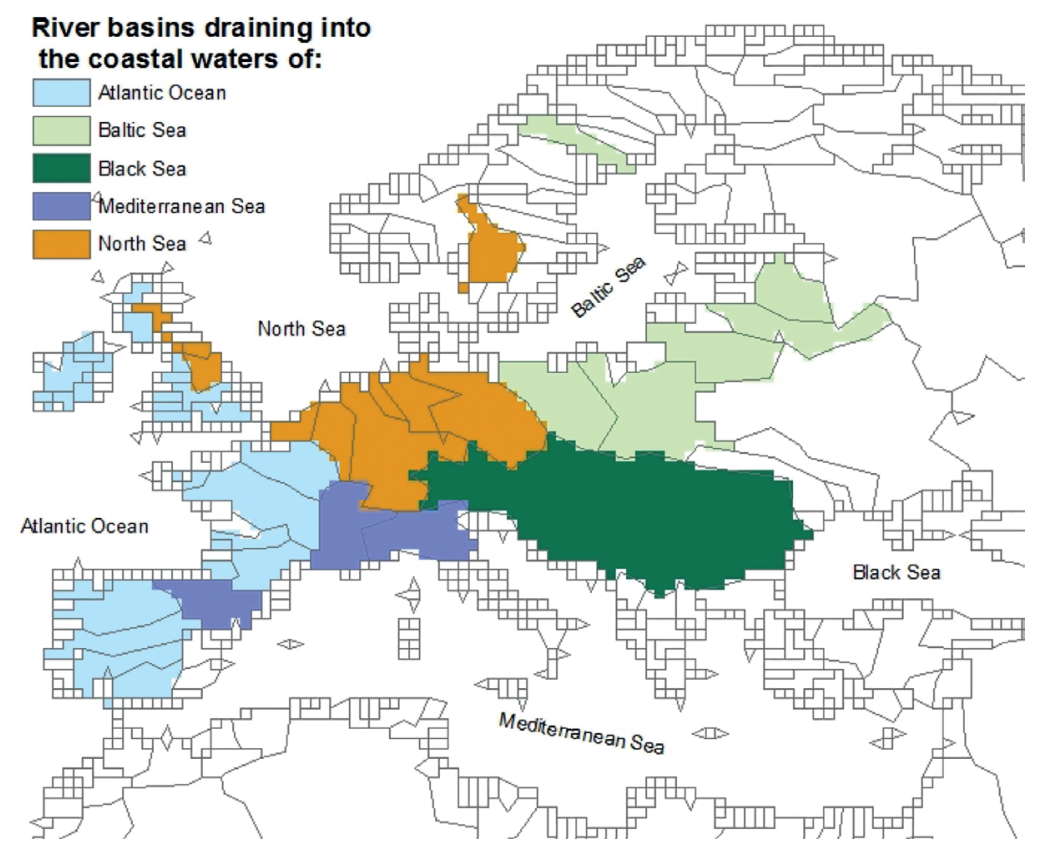

Figure 1. Overview of the selected 48 river basins draining into the coastal waters of Europe.

The total area of the selected basins is 2.9 million $\mathrm{km}^{2}$ while the total area of the EU27 is 4.3 million $\mathrm{km}^{2}$. So the selected river basins in this study cover about two-thirds of the EU27. Most rivers drain into the North Atlantic Ocean (Table 2). These rivers together cover 1.3 million $\mathrm{km}^{2}$, or $44 \%$ of the total study area. The basins draining into the Mediterranean, Baltic and Black Sea cover 10, 19 and $27 \%$ of the study area, respectively.

The total discharge of the 48 rivers considered here is $752 \mathrm{~km}^{3} /$ year. This is about half of the total European river discharge according to Global NEWS.

\subsubsection{Scenarios for biodiesel production from algae}

Six scenarios for the year 2050 are analysed (Table 3). Scenarios 2050GO, 20500S, 2050AM and 2050TG are based on the four MA scenarios, but assume that all diesel used for transport is replaced by biodiesel. Scenarios 2050GO* and 2050GO** are based on 2050GO, but assume that biodiesel is only used for heavy traffic. Scenario $2050 \mathrm{GO}^{* *}$ also assumes a waste water treatment of $80 \%$ on algae parks. The assumption of a removal factor of $80 \%$ is based on the highest percentage of the removal factor used by Global NEWS. 
In this study it is assumed that open ponds have proper liners, so unintentional leakage to the environment can be assumed negligible. It is also assumed that algae parks are stand-alone plants that do not use urban or industrial waste water from waste water treatment plants.

The estimates for algae production in 2050 are based on the current diesel use in Europe. The scenarios do not account for an increase in the demand for fuels between now and 2050 and should therefore be considered a conservative estimate for the demand for diesel. To replace all the current transport fuels by biofuels in the $27 \mathrm{EU}$ countries 0.4 billion $\mathrm{m}^{3}$ biodiesel is needed per year (Wijffels and Bardosa, 2010). This estimate is in line with Eurostat which mentions for the year 2009 an amount of 0.34 billion toe (ton oil equivalent) for motor spirit, diesel oil and jet fuel needed for the 27 countries of the European Union (Eurostat, 2011). Assuming a density of $0.88 \mathrm{~kg} / \mathrm{l}$, an energy density of $37.8 \mathrm{MJ} / \mathrm{l}$ for biodiesel and $41.9 \mathrm{MJ} / \mathrm{kgoe}$ this amount is equivalent to 379 million $\mathrm{Mg}$ or 0.43 billion $\mathrm{m}^{3}$ biodiesel which corresponds with the amount of 0.4 billion $\mathrm{m}^{3}$ biodiesel estimated by Wijffels and Bardosa (2010). The scenarios are hypothetical. They are inspired by the study of Wijffels and Bardosa (2010) who argued that biodiesel from algae could potentially replace all diesel used in European transport. The analysis shows the consequences of such largescale production of micro-algae on land.

Producing 0.4 billion $\mathrm{m}^{3}$ biodiesel per year would require an area of 9.3 million hectare, or about $2 \%$ of the European land surface, for the cultivation of the algae. This estimate assumes a productivity of 40 thousand litre biodiesel per hectare per year, based on the solar conditions of Portugal and a $50 \%$ biomass lipid content of the algae. Current technologies may need to be improved to realize such productivity (Wijffels and Bardosa, 2010). Although the climatic conditions in the south of Europe are better than in the North for growing algae, the assumption is that the production of biodiesel by algae cultivation is evenly spread over the study area.

Scenarios GO2050* and GO2050GO** assume that only heavy traffic will use biodiesel. Heavy traffic includes airplanes, freight vessels and heavy duty trucks. According Eurostat heavy traffic needs 0.25 trillion toe diesel oil and jet fuel (Eurostat, 2011). This amount is equivalent to 269 million Mg. 
Table 3. Scenario assumptions on the use of biodiesel and waste water treatment as used in this study. All other scenario assumptions are as in the interpretation of the Millennium Ecosystem Scenarios: Global Orchestration (GO), Order from Strength (OS), Technogarden (TG) and Adapting Mosaic (AM) (Seitzinger et al., 2010)

\begin{tabular}{|c|c|c|}
\hline Scenario & $\begin{array}{l}\text { Additional assumptions on biodiesel } \\
\text { use }\end{array}$ & $\begin{array}{l}\text { Additional assumptions on wastewater } \\
\text { treatment }\end{array}$ \\
\hline 2000 & No use of biodiesel from algae & $\begin{array}{l}\text { Basin-specific } \mathrm{N} \text { and } \mathrm{P} \text { removal efficiencies } \\
\text { from wastewater as in Global NEWS }\end{array}$ \\
\hline $2050 \mathrm{GO}$ & $\begin{array}{l}\text { Replacement of all diesel used for all } \\
\text { traffic in EU } 27 \text { countries by biodiesel } \\
\text { from algae; algae production in } \\
\text { semi-closed systems }\end{array}$ & $\begin{array}{l}\text { Basin-specific } N \text { and } P \text { removal efficiencies } \\
\text { from wastewater as in Global NEWS } \\
\text { according } 2050 \text { GO scenario }\end{array}$ \\
\hline $20500 S$ & As $2050 \mathrm{GO}$ & $\begin{array}{l}\text { Basin-specific } N \text { and } P \text { removal efficiencies } \\
\text { from wastewater as in Global NEWS } \\
\text { according } 2050 \text { OS scenario }\end{array}$ \\
\hline 2050TG & As $2050 \mathrm{GO}$ & $\begin{array}{l}\text { Basin-specific } N \text { and } P \text { removal efficiencies } \\
\text { from wastewater as in Global NEWS } \\
\text { according } 2050 \text { TG scenario }\end{array}$ \\
\hline 2050AM & As $2050 \mathrm{GO}$ & $\begin{array}{l}\text { Basin-specific } N \text { and P removal efficiencies } \\
\text { from wastewater as in Global NEWS } \\
\text { according } 2050 \text { AM scenario }\end{array}$ \\
\hline $2050 G O^{*}$ & $\begin{array}{l}\text { Replacement of all diesel used for } \\
\text { heavy traffic in EU } 27 \text { countries } \\
\text { by biodiesel from algae; algae } \\
\text { production in semi-closed systems }\end{array}$ & $\begin{array}{l}\mathrm{N} \text { and } \mathrm{P} \text { removal efficiency from wastewater } \\
\text { as in Global NEWS according } 2050 \mathrm{GO} \\
\text { scenario }\end{array}$ \\
\hline $2050 G O^{* *}$ & As 2050GO* & $80 \%$ of $\mathrm{N}$ and $\mathrm{P}$ removed from waste water \\
\hline
\end{tabular}

Algae mass typically consists $25-40 \%$ of protein, $5-30 \%$ of carbohydrate and $10-30 \%$ of lipids/oil (dry weight) (Campbell et al., 2009). The expectation is that by 2050 algae are available with a higher percentage lipids/oil. In this study the assumption is that $40 \%$ of dry weight of algae is lipids/oil. This implies that the production of biodiesel for all transport in EU27 requires 947 million Mg algal biomass per year and for heavy traffic alone 672 million Mg (see Table 4). Based on these assumptions, the fertiliser $\mathrm{N}$ and $\mathrm{P}$ use amounts to 70 and 10 $\mathrm{Mg} / \mathrm{y}$ when biodiesel is used in all transport, respectively. When biodiesel is only used in heavy traffic the $\mathrm{N}$ and $\mathrm{P}$ fertiliser use is 50 and $7 \mathrm{Mg} / \mathrm{y}$, respectively (Table 4). The scenarios do not account for possible future algae strains that are more $\mathrm{N}$ and $\mathrm{P}$ efficient. Such strains could reduce future fertiliser needs. 
Table 4. Assumptions on biodiesel use and production in the year 2050 (Mg/yr).

\begin{tabular}{lll}
\hline & All transport & Heavy traffic \\
\cline { 2 - 3 } & Million Mg/yr & Million Mg/yr \\
\hline Diesel oil use $^{1}$ & 379 & 269 \\
Biomass algae $^{2}$ & 947 & 672 \\
$\mathrm{~N}$ fertiliser use & 70 & 50 \\
P fertiliser use & 10 & 7 \\
N in waste streams $^{3}$ & 3.5 & 2.5 \\
P in waste streams $^{3}$ & 0.5 & 0.4 \\
\hline
\end{tabular}

${ }^{1}$ Based on Eurostat (2011) and Wijffels and Bardosa (2010) see text; ${ }^{2}$ Assuming that all biodiesel is produced by algae cultivation; ${ }^{3}$ before waste water treatment and with an uptake and recycling of $\mathrm{N}$ and $\mathrm{P}$ of $95 \%$.

\subsection{4 $\mathrm{N}$ and $\mathrm{P}$ fertilizer inputs in $\mathbf{2 0 5 0}$}

The Global NEWS model uses fertiliser N and P use as model input. In this study the same estimate of $\mathrm{N}$ and $\mathrm{P}$ fertiliser needs are made to grow algae from the assumption that the algae mass contains $7 \% \mathrm{~N}$ and $1 \% \mathrm{P}$ of the biomass (Wijffels and Bardosa, 2010).This leads to the assumption of fertiliser use per year in EU27 as mentioned in Table 4.

\subsubsection{Recycling of $\mathrm{N}$ and $\mathrm{P}$ and waste water treatment}

Algae can be cultivated in open ponds and in "closed" tubes. In closed systems recycling of $\mathrm{N}$ and $\mathrm{P}$ is more controlled than in open systems. In practice, however, systems are never completely closed; there are always some $\mathrm{N}$ and $\mathrm{P}$ waste streams. In an open system is recycling of $\mathrm{N}$ and $\mathrm{P}$ restricted because of contamination of the system, and a part of the fertiliser $\mathrm{N}$ and $\mathrm{P}$ will be lost as waste water. For this study there is no distinction between cultivation in open ponds or in tube system. In both systems there will be a loss of waste water. The assumption is that $95 \%$ of the fertiliser $\mathrm{N}$ and $\mathrm{P}$ is taken up by micro-algae or recycled in the system, implying that $5 \%$ will be lost as waste from the system (see Table 4). How the recycling will take place is not considered here.

In Figure 2 a schematic overview of the cultivation and production process is given. Two possibilities for waste water treatments are considered. Waste water is either treated on the algae parks (on site) or in public waste water treatment plants. After treatment the waste is discharged into the rivers. In the rivers some retention of nutrients takes place. The remainder is exported to coastal seas. 


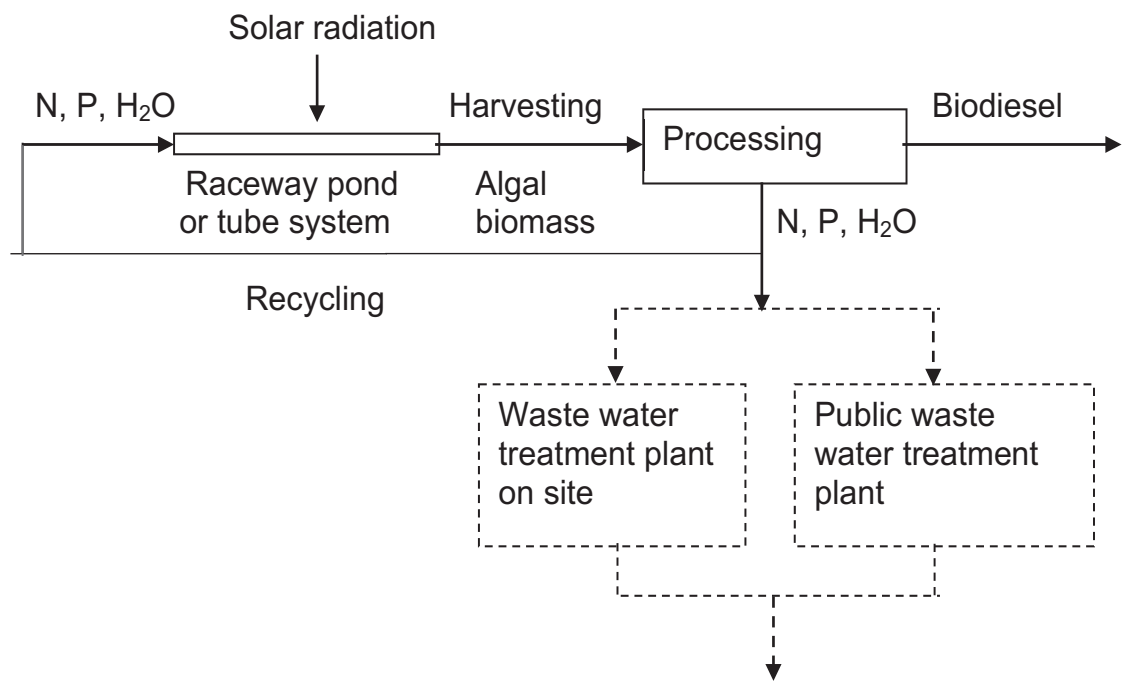

Figure 2. Schematic overview of the $\mathrm{N}$ and flows through the cultivation of algae and the production of biodiesel. The solid lines indicate the biodiesel production process. The dashed lines indicate two possibilities for waste water treatment.

The assumption that $95 \%$ of the $\mathrm{N}$ and $\mathrm{P}$ applied is taken up by algae or recycled (Table 4) is optimistic. Current pilot plants indicate that about $70 \%$ of the fertiliser $\mathrm{N}$ and $\mathrm{P}$ is taken up by micro-algae and that most systems do not (yet) recycle. Without recycling of $\mathrm{N}$ and $\mathrm{P}$, therefore, $30 \%$ of $\mathrm{N}$ and $\mathrm{P}$ inputs to algal cultivation may be discharged as waste water. This $30 \%$ estimate is based on expert judgment and reflects the current and near future status of technology. The 5\% estimate thus reflects advanced recycling techniques. In the literature different estimates of the potential recycling exist. Lundquist (2010) suggests that a recycling of the nutrients of $90 \%$ must be feasible and probably even $95 \%$. This, however, is a theoretical assumption and far from current practice. Other studies seem to assume much lower recycling rates (Brentner et al., 2011; Stephenson et al., 2010). Nevertheless, in this study we consider 95\% technically feasible. To test the sensitivity of the model to this assumption, calculations are also performed for lower recycling rates (Tables 7 and 8).

In the Global NEWS model basin-specific nutrient retention factors and nutrient removal factors for waste water treatment are included for 2050 (Mayorga et al., 2010). The effectiveness of wastewater treatment in terms of $\mathrm{N}$ and $\mathrm{P}$ removal differs among basins in the Global NEWS models. These factors are applied 
to the waste water from algae production in 2050 in all scenarios, except for scenario $2050 \mathrm{GO}{ }^{* *}$. Scenario $2050 \mathrm{GO}{ }^{* *}$ assumes on site waste water treatment for algae production plants with a removal factor for $\mathrm{N}$ and $\mathrm{P}$ of $80 \%$ (Table 3 ). This is for all the river basins higher than as assumed in 2050GO (39-78\%). As can be seen in Figures 3 and 4 and in Tables 5 and 6 the results for the scenario 2050GO** are lower than the results for 2050*.

\subsubsection{Running the Global NEWS model}

The Global NEWS model calculates nutrient export at the river mouth with the equations from Mayorga et al., (2010) as follows:

$\mathrm{Yld}_{\mathrm{F}}=\mathrm{FE}_{\text {riv, F }} *\left(\mathrm{RSpnt}_{\mathrm{F}}+\mathrm{RSdif}_{\mathrm{F}}\right)$

where Yld is the river export (yield, in $\mathrm{kg} / \mathrm{km}^{2} / \mathrm{y}$ ), $\mathrm{F}$ (subscript) is the nutrient form, and river sources (RS) include RSpnt ${ }_{F}$, which is the export of $F$ from the watershed to streams via point sources (sewage) and $\mathrm{RSdif}_{\mathrm{F}}$, which is the export of $F$ from the watershed to streams via diffuse sources. River sources include both natural and anthropogenic inputs and are expressed in $\mathrm{kg}$ (of $\mathrm{N}, \mathrm{P}$ or $\mathrm{C}$ ) per $\mathrm{km}^{2}$ of basin area $\left(\mathrm{km}^{2}\right)$. $\mathrm{FE}_{\mathrm{riv}, \mathrm{F}}$ is the retention factor (0-1) for nutrients in the river (Mayorga et al., 2010).

In this study equation 1 is used to calculate $\mathrm{N}$ and $\mathrm{P}$ export by rivers, but including $\mathrm{N}$ and $\mathrm{P}$ inputs to rivers from algae cultivation as an additional point source:

$\mathrm{RSpnt}_{\mathrm{F}}=\mathrm{RSpnt}_{\mathrm{F} \text {,sewage }}+\mathrm{RSpnt}_{\mathrm{F} \text {,algae }} *\left(1-\mathrm{hW}_{\text {frem, } \mathrm{F}}\right)$

where RSpnt ${ }_{F, \text { sewage }}$ is the export of $\mathrm{F}$ from the sewage point sources to the river $\left(\mathrm{kg} / \mathrm{km}^{2} / \mathrm{yr}\right.$ ) (Mayorga et al., 2010) and $\mathrm{RSpnt}_{\mathrm{F}, \mathrm{algae}}$ is the export of $\mathrm{F}$ from the algae cultivation to the river ( $\mathrm{kg} / \mathrm{km}^{2} / \mathrm{yr}$ ) (this study). $\mathrm{hw}_{\text {frem, } \mathrm{F}}$ is the fraction of $F$ in sewage effluent removed via waste water treatment (Mayorga et al., 2010).

Following these equations $\mathrm{N}$ and $\mathrm{P}$ yields are calculated as a function of point and diffuse sources for all scenarios. For more details on Global NEWS see Mayorga et al., (2010). 

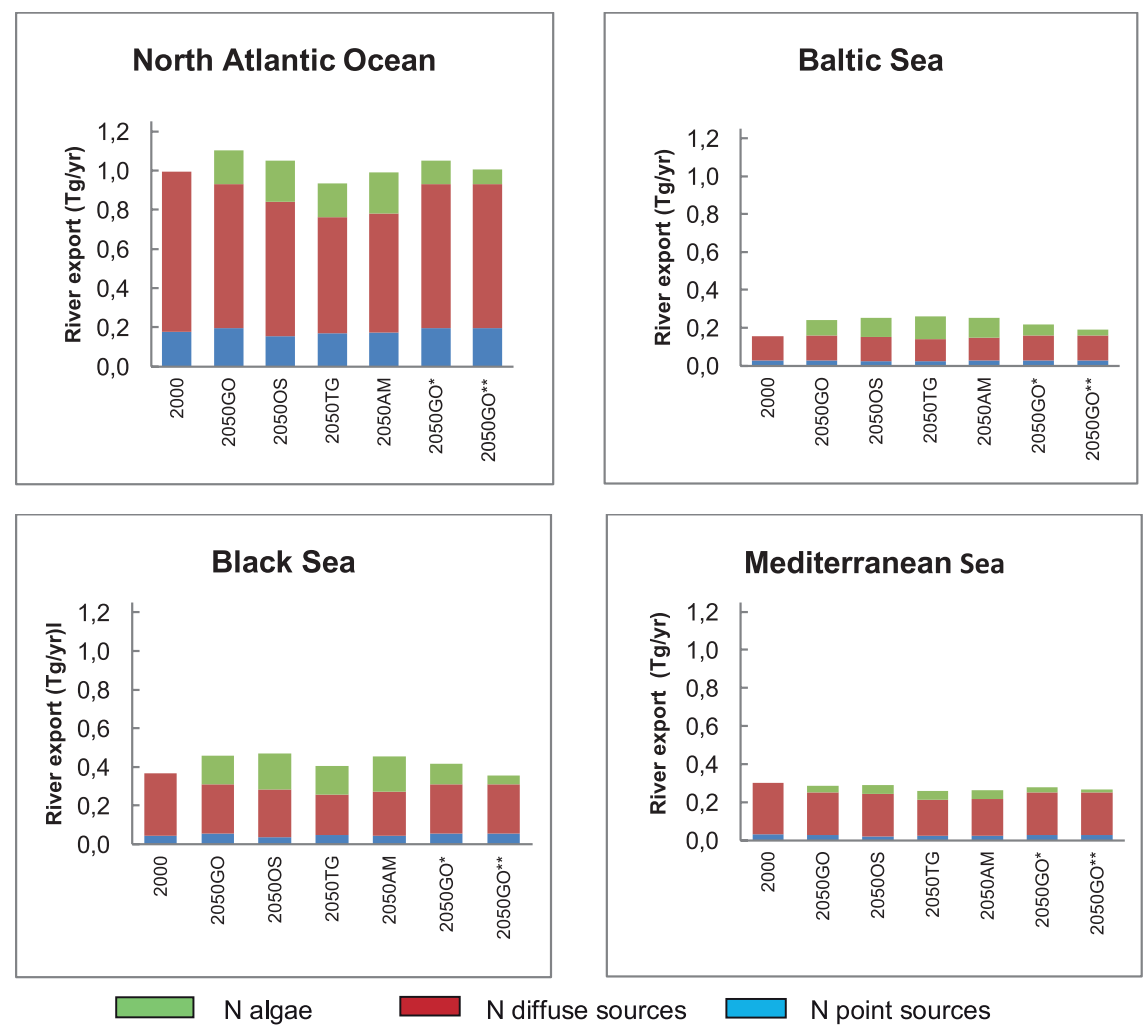

Figure 3. $\mathrm{N}$ export by selected European rivers (in Tg/yr) in 2000, 2050 for the four MEA scenarios (GO, OS, TG, AM) assuming that all transport is based on biodiesel from algae, and in 2050 for two GO scenarios: $2050^{*}$ : assuming that biodiesel is only used for heavy duty trucks, freight vessels and airplanes, and $2050^{* *}$ : assuming that all algae are grown in production sites with improved waste water treatment. For all the scenarios the uptake and recycling of $\mathrm{N}$ before waste water treatment is $95 \%$. 

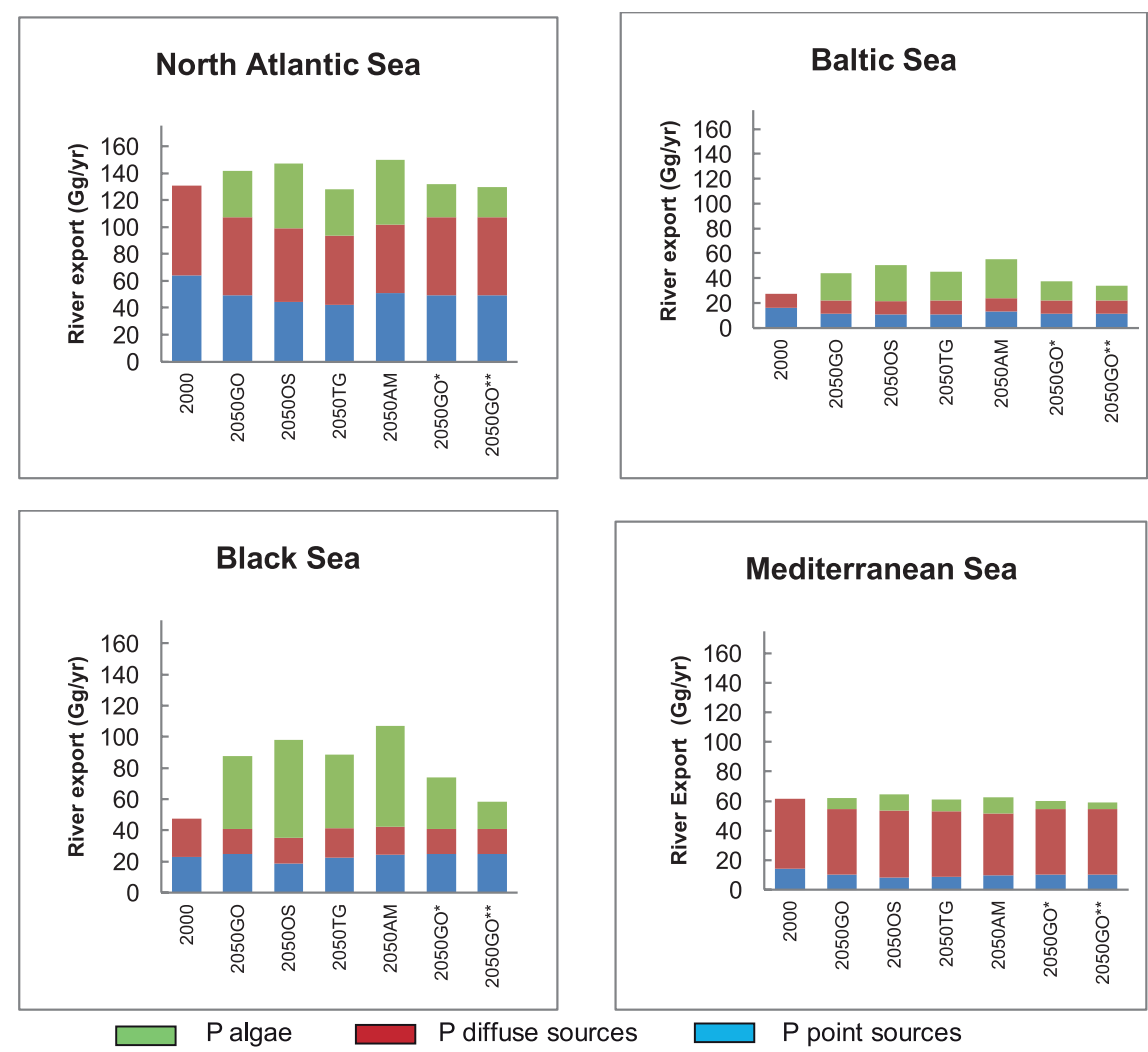

Figure 4. As Figure 3, but for P.

\subsection{Results}

Following the assumptions described in 2.3 the Global NEWS model was used to calculate the effects of micro-algae production for biodiesel on coastal water pollution. Figures 3 and 4 present the calculated river $\mathrm{N}$ and $\mathrm{P}$ export to coastal waters for the years 2000 and 2050 with an assumed uptake and recycling of $\mathrm{N}$ and $\mathrm{P}$ in algae production of $95 \%$.

\section{Nitrogen}

In 2000, river export of $\mathrm{N}$ by all the selected rivers amounted to 1.8 Tg/yr. About half of this amount was exported to the North Atlantic (55\%) (Figure 3).The exports to the other seas are considerably less because of several reasons. First of all, the basin area of the rivers discharging into the North Atlantic covers 
almost half of the total area of the river basins considered in this study (44\%). In addition, there are differences among rivers in human activities on land, landscape, geology, run off, and river retention.

Without algae production, the $\mathrm{N}$ export by rivers to the coastal seas in Europe would in 2050 be lower than in 2000. For instance, in the 2050GO scenario river export of $\mathrm{N}$ amounts to $1.65 \mathrm{Tg} \mathrm{N} /$ year when assuming no algae production (Table 5), which is $9 \%$ lower than in 2000 . This reduction is mainly caused by agricultural and environmental management as assumed in the original MA scenarios (Seitzinger et al., 2010). In addition, changes in hydrology associated with climate change, human water consumption and damming of rivers cause differences among MA scenarios (Seitzinger et al., 2010; Fekete et al., 2010).

Table 5. Total river $\mathrm{N}$ export (load at the mouth) and the part of this river export that can be attributed to point sources (sewage and algae cultivation). Results are shown for the $2050 \mathrm{GO}$ scenario assuming algae cultivation (as in Table 3) with a recycling of $95 \%$ and for the same scenarios but without algae cultivation. Unit: $\mathrm{Gg} / \mathrm{yr}$. n.a. = not applicable

\begin{tabular}{lcccc}
\hline Scenario & \multicolumn{2}{c}{ Total river N export } & \multicolumn{2}{c}{$\begin{array}{c}\text { River N export attributed } \\
\text { to point sources }\end{array}$} \\
\cline { 2 - 5 } & $\begin{array}{c}\text { No algae } \\
\text { cultivation }\end{array}$ & $\begin{array}{c}\text { With algae } \\
\text { cultivation }\end{array}$ & $\begin{array}{c}\text { No algae } \\
\text { cultivation }\end{array}$ & $\begin{array}{c}\text { With algae } \\
\text { cultivation }\end{array}$ \\
\hline 2000 & 1820 & n.a. & 281 & n.a. \\
$2050 G O$ & 1653 & 2088 & 307 & 742 \\
$2050 G O^{*}$ & 1653 & 1962 & 307 & 616 \\
$2050 G O^{* *}$ & 1653 & 1819 & 307 & 473 \\
\hline
\end{tabular}

It is clear that increased algae production for traffic in Europe would counterbalance the effects of environmental and agricultural policies. By 2050 and with algae cultivation the river export for the 2050GO scenario amounts of $2.1 \mathrm{Tg}$ N/year which is higher than in 2000 (Table 5). Thus the potential for coastal eutrophication could be higher than it is today. This $\mathrm{N}$ export by rivers which is attributable to point sources may even double because of algae cultivation (Table 5).

Also for the other scenarios the model calculates higher river export of $\mathrm{N}$ when assuming algae cultivation. In 20500S, 2050TG and 2050AM river export rates are all higher than in 2000 (respectively 2.1, 1.9 and $2.0 \mathrm{Tg} /$ year). 
Lowest $\mathrm{N}$ export rates are calculated for scenarios 2050GO* and 2050GO** (Table 5). This indicates that limiting biodiesel use to heavy transport (scenario 2050GO*) would reduce the $\mathrm{N}$ export by rivers but is still higher relative to 2000 (2.0 Gg/year). Assuming $80 \% \mathrm{~N}$ removal in wastewater treatment (scenario $2050 \mathrm{GO}^{* *}$ ) would reduce river export of $\mathrm{N}$ to the level of the year 2000.

\section{Phosphorus}

For phosphorus the results are similar. In 2000 rivers exported $267 \mathrm{Gg}$ P/year without algae cultivation to coastal seas, of which about $50 \%$ was to the North Atlantic. Without algae cultivation, this river export would by 2050 be $25 \%$ lower than in 2000 as a result of environmental and agricultural policies. In scenarios assuming algae production, the 2050 river export of $P$ exceeds that of 2000 . For the $2050 \mathrm{GO}$ scenario calculation shows a total $\mathrm{P}$ export with algae cultivation of $336 \mathrm{Gg}$ P/year in 2050 which is $25 \%$ higher than in 2000 (Table 6). Likewise, for the scenarios 20500S, 2050TG and 2050AM the river exports of $P$ are higher than in 2000 (respectively 360, 322 and 375 Gg/year).

Table 6. As Table 5, but for P. Unit: Gg/yr.

\begin{tabular}{lcccc}
\hline Scenario & \multicolumn{2}{c}{ Total river P export } & \multicolumn{2}{c}{$\begin{array}{c}\text { River P export attributed } \\
\text { to point sources }\end{array}$} \\
\cline { 2 - 5 } & No algae cultivation & $\begin{array}{c}\text { With algae } \\
\text { cultivation }\end{array}$ & $\begin{array}{c}\text { No algae } \\
\text { cultivation }\end{array}$ & $\begin{array}{c}\text { With algae } \\
\text { cultivation }\end{array}$ \\
\hline 2000 & 267 & n.a. & 118 & n.a. \\
$2050 G O$ & 224 & 336 & 95 & 207 \\
$2050 G O^{*}$ & 224 & 303 & 95 & 174 \\
$2050 G O^{* *}$ & 224 & 281 & 95 & 152 \\
\hline
\end{tabular}

From the above is clear that large-scale algae production in Europe could counterbalance the effects of environmental and agricultural policies in river loads of P. The lowest P export rates are calculated for scenarios 2050GO* and 2050GO**. Limiting biodiesel use to heavy traffic (as assumed on scenario 2050GO*) would reduce the P export by rivers to $303 \mathrm{Gg}$ P/year but is still higher than in 2000. Combined with an $80 \% \mathrm{P}$ removal in wastewater treatment (scenario 2050GO**) P export by rivers is reduced further, but not below 2000 levels (Table 6). Algae cultivation could double $P$ in river export that is attributable to point sources (Table 6). 


\section{Sensitivity Analysis}

The extent to which algae production systems can be considered closed systems is a matter of debate. As explained above, the assumption of a $95 \%$ uptake and recycling of $\mathrm{N}$ and $\mathrm{P}$ is high compared to the current state of art. To test the sensitivity of the calculated $\mathrm{N}$ and $\mathrm{P}$ river export to this assumption, the model also has been run for scenario $2050 \mathrm{GO}$ assuming $\mathrm{N}$ and $\mathrm{P}$ uptake and recycling of 70,80 and $90 \%$ (Tables 7 and 8 ).

Table 7. Increase in total N export to the coastal seas of the EU7 as calculated for scenario 2050GO, assuming different percentages uptake and recycling of fertiliser $\mathrm{N}$ and $\mathrm{P}$. Unit: \% increase relative to 2050GO without algae cultivation.

\begin{tabular}{lccccc}
\hline \multirow{2}{*}{$\begin{array}{l}\text { Assumed \% uptake } \\
\text { and recycling }\end{array}$} & \multicolumn{5}{c}{$\begin{array}{c}\text { Calculated increase in N export to coastal seas } \\
\text { (\% relative to 2050GO without algae cultivation) }\end{array}$} \\
\cline { 2 - 5 } & North Atl. & Baltic sea & Black sea & Med. Sea & All seas \\
\hline 95 & 18 & 52 & 47 & 14 & 26 \\
90 & 39 & 109 & 100 & 29 & 56 \\
80 & 87 & 246 & 225 & 65 & 125 \\
70 & 150 & 422 & 380 & 111 & 214 \\
\hline
\end{tabular}

Table 8. As Table 7, but for $P$.

\begin{tabular}{lccccc}
\hline \multirow{2}{*}{$\begin{array}{l}\text { Assumed \% uptake } \\
\text { and recycling }\end{array}$} & \multicolumn{5}{c}{$\begin{array}{c}\text { Calculated increase in P export to coastal seas } \\
\text { \% relative to } 2050 G O\end{array}$} \\
\cline { 2 - 6 } & North Atl. & Baltic sea & Black sea & Med. sea & All seas \\
\hline 95 & 33 & 101 & 114 & 15 & 50 \\
90 & 69 & 213 & 241 & 31 & 90 \\
80 & 155 & 479 & 541 & 69 & 236 \\
70 & 265 & 821 & 928 & 118 & 405 \\
\hline
\end{tabular}

Tables 7 and 8 indicate that the calculated river export of $\mathrm{N}$ and $\mathrm{P}$ is largely affected by the assumed uptake and recycling in algae parks. In the $2050 \mathrm{GO}$ scenario, assuming $95 \%$ uptake and recycling of $\mathrm{N}$ and $\mathrm{P}$ in algae parks, the river $\mathrm{N}$ export in 2050 for the different coastal waters is up to $50 \%$ higher than in the GO scenario without algae cultivation, and the river $\mathrm{P}$ export for some coastal waters is up to twice as high (Tables 7 and 8). These increases are considerably larger when we assume lower $\mathrm{N}$ and $\mathrm{P}$ uptake and recycling. In case of $70 \%$ uptake and recycling river export of $\mathrm{N}$ would increase by a factor of 2 to 5 , and that of $\mathrm{P}$ by a factor of 2 to 10 (Tables 7 and 8 ). It should be noted that a $70 \%$ uptake and recycling of $\mathrm{N}$ and $\mathrm{P}$ is current practice in pilot plants today. The sensitivity analysis shows how important recycling of $\mathrm{N}$ and $\mathrm{P}$ in the production of micro-algae on land is. Even small losses of fertiliser $\mathrm{N}$ and 
P from algae parks can have large consequences for coastal eutrophication in European seas.

\section{Limitations}

This study is the first to analyse the effect of large-scale production of biodiesel from micro-algae on coastal waters of Europe. It should be noted that this study is based on a number of hypothetical assumptions. Most importantly, the assumption that in EU27 fossil diesel would be replaced by biodiesel may not be impossible, but current policies do not foresee a leading role of algae in this. Moreover, unforeseen future technological developments may reduce the need for biodiesel. On the other hand, algae are increasingly proposed as important alternative for first and second generation biodiesel, in particularly for heavy traffic. A large advantage of micro-algae is that they can be produced anywhere. Cultivation of algae is independent of the type of soil. Algae cultivation can, for instance, take place on land that is not suitable for agriculture or at sea.

A second issue is that the question is ignored where exactly algae production would take place in Europe. In this study algae production is simply distributed evenly over the considered basins. Another spatial distribution of algae production in Europe clearly would affect the distribution of increased $\mathrm{N}$ and $\mathrm{P}$ loads to rivers. This study demonstrates the possible eutrophication in the coastal waters if the recycling of the nutrients is not $100 \%$. In reality, the location of algae production would probably depend on the specific requirements and characteristics of algae cultivation such as light needed and land availability. This, however, would change the distribution of the $\mathrm{N}$ and $\mathrm{P}$ pollution, because $\mathrm{N}$ and $\mathrm{P}$ inputs to rivers differ, as well as $\mathrm{N}$ and $\mathrm{P}$ retentions in the rivers. However, in all cases the level of pollution will likely be high. We also ignore the possible use of urban and industrial waste water, which could reduce the need for synthesised fertiliser and the availability of $\mathrm{CO}_{2}$. This would be an interesting topic for further study. This study assumes that production of micro-algae takes place with nutrient inputs as in current pilot plants. It could be possible that in the future micro-algae strains become available that are more $\mathrm{N}$ and $\mathrm{P}$ efficient, requiring less fertiliser. This would reduce the nutrient losses to the environment accordingly. 
Third, the scenarios explore a future in which the biodiesel from algae is virtually the only fuel used for transport. The simple assumption is made that the amount need equals the current diesel use. This is in line with earlier analyses by Wijffels and Bardosa (2010). This approach could be considered as a first step conservative assumption in view of the uncertainties linked to scenarios for the year 2050. To estimate biodiesel demand for different MAE scenarios is outside the scope of this paper. The conservative estimate is already reason for serious concerns about the potential environmental implications. It should be realized, however, that the demand for diesel in the future is probably underestimated. The need for biofuels is probably largest for heavy traffic biodiesel. At this moment there are no other energy sources available for heavy traffic than diesel. This study shows that also in scenarios where algae are only produced biodiesel for heavy traffic, large amounts are needed. Since biodiesel use is identical in the four scenarios, the differences between the scenarios are caused by differences in the assumed waste water treatment, and differences in nutrient retention in rivers, caused by changing hydrology and human water consumption.

\subsection{Conclusion}

In 2050 coastal eutrophication in Europe may be less than today as a result of agricultural and environmental policies (Seitzinger et al., 2010). Such scenarios, however, do not account for the use of biodiesel from micro-algae produced on land. Widespread production of algae could more than counterbalance the envisaged reduction in $\mathrm{N}$ and $\mathrm{P}$ export to coastal seas.

Assuming that all diesel in EU27 countries will be replaced by biodiesel from algae, the total $\mathrm{N}$ and $\mathrm{P}$ export to European seas and depending on the scenarios may be 2-40\% higher in 2050 than in 2000 (Figure 3 and 4). Inputs of $\mathrm{N}$ and $\mathrm{P}$ to rivers from point sources may even double. In scenario GO2050 (assuming algae production) river export of $\mathrm{N}$ and $\mathrm{P}$ in 2050 is $15-27 \%$ higher than in 2000 (Tables 5 and 6). Without algae cultivation it would be 9-16\% lower than in 2000. Limiting biodiesel use to vessels, heavy duty trucks and airplanes (scenario 2050GO*) would limit the increase in river export of $\mathrm{N}$ and $\mathrm{P}$ between 2050 and 2000 to $8 \%$ and $13 \%$, respectively. Only in scenarios assuming waste 
water treatment with an efficiency of $80 \% \mathrm{~N}$ and $\mathrm{P}$ removal (scenario GO2050**) a future increase in river export of $\mathrm{N}$, and that of $\mathrm{P}$ could be avoided.

This study is a first analysis of the possible effects of large-scale algae production on river water quality. In the scenarios that assume no recycling of $\mathrm{N}$ and $\mathrm{P}$ the risk for increased eutrophication of the coastal waters of Europe increases considerably. Even though algae parks are generally considered relatively closed systems, there may always be small leaks of nutrients to the environment. The scenarios presented here show that without efforts to close nutrient cycles in algae parks and without efficient waste water treatment, the impact of large-scale algae production on the environment may be considerable. These conclusions hold for all our scenarios. One may, therefore, argue that micro-algae can only become a sustainable basis for biodiesel, in case the losses of $\mathrm{N}$ and $\mathrm{P}$ to the environment are minimized.

\section{Acknowledgements}

We greatly acknowledge Prof. R.H. Wijffels, R. Bosma and T. van Boxtel for providing information on algae cultivation and for their advice on our approach. 
Chapter 4 Conceptual Factory Design for Micro-Algae Cultivation and Processing 


\section{Abstract}

Micro-algae are a valuable source of proteins, fatty acids, pigments, carbohydrates, vitamins and minerals. These in turn can serve as raw materials for bioplastics, biodiesel, and food. In this study a conceptual design is presented of a factory for indoor cultivation and processing of micro-algae. Our design has the following characteristics: (1) indoor cultivation and processing of micro-algae, (2) algae are produced for proteins, fatty acids, pigments and/ or carbohydrates, (3) it is a closed system, (4) there are no fossil energy inputs, (5) losses to the environment are minimized, and (6) the factory is independent of weather conditions. The factory design is formalized in mathematical equations and evaluated with respect to environmental performance. This work illustrates the performance of the factory for biodiesel production, which is compared to the performance of an outdoor cultivation system. In this hypothetical indoor factory of 1 hectare per year 745 ton algae are produced, in 12 stories. Our study shows that indoor production of algae is possible with minimum environmental impact and low land requirements. However, the renewable energy demand is high. In outdoor production the energy demand can be lower, but land use is much higher. 


\subsection{Introduction}

Micro-algae are increasingly considered as an interesting resource for a variety of products. Algae mass consists mainly of proteins (25-40\%), carbohydrates (5-30\%) and lipids (10-30\%; on a dry weight basis (Campbell et al., 2009). Many species of algae can produce even larger amounts of lipids under stress conditions (Guo et al., 2013; lia et al., 2014; Tredici, 2010). Chlorella is among the species that seem to be a good option for this (Mata et al., 2010). Lipids from algae can be used to produce biodiesel. Biodiesel is considered attractive as an environmentally friendly alternative to fossil diesel. Since there are no easy alternatives, diesel will likely remain important for the transport sector in the coming decades, in particular for heavy duty trucks, aircrafts and vessels (Mata et al., 2010; Mackay, 2010). Diesel has the advantage of a high energy density per liter. The biomass components of algae can also be used for other products such as bioplastics, fine chemicals, food, and fertilizers.

Nowadays algae cultivation is typically taking place under outdoor conditions with different types of installations such as ponds, tubes and panels (Acién Fernández et al., 2013; Bosma et al., 2014). Cultivation in the open air generally means that algae are produced in a single story and thus cover a relatively large land area (but not arable land). The demand for diesel in European Union could be met by biodiesel from algae cultivated (single story) on a surface as large as Portugal (Wijffels and Bardoso, 2010). Cultivation of algae can also take place indoors. Indoor cultivation has the advantage of being independent of climate and weather, and in a building the production process can be controlled in even the smallest details. Indoor cultivation also allows for algae cultivation in multiple stories. In literature this has been referred to as vertical farming (VF) (Besthorn, 2013; Despommier, 2011; Germer et al., 2011; Winiwarter et al., 2014), i.e. indoor production of crops in several stories with artificial light. VF is generally considered relatively expensive and energy intensive. On the other hand, VF is lower in water use and waste generation than traditional farming systems. In the near future there may be a worldwide shortage of arable land (Ibarrola, 2015). An important advantage of cultivation of algae is that there is no arable land needed. Both indoor and outdoor cultivation of algae can take place on non-arable land. However, outdoor cultivation requires an appropriate level of sun energy (Slegers et al., 2014). 
Several studies present life cycle assessments (LCA) of biodiesel produced from different crop types (Brentner et al., 2011a; Clarens et al., 2010; Reijnders, 2013). These LCAs reveal possible advantages and disadvantages of the production process. However, existing studies typically focus on energy use only, and compare the energy content of the produced biodiesel and the energy needed to produce the diesel. Waste production and the use of resources is often ignored in these studies, while it is an essential part of the impact of such systems (Blaas and Kroeze, 2014; Brentner et al., 2011a; Clarens et al., 2010; Lardon et al., 2009; Liu and Ma, 2009; Reijnders, 2013; Yang et al., 2011).

In this study we present a conceptual design of a factory for indoor cultivation and processing of algae, and evaluate this with respect to its environmental performance. Existing practices in the cultivation of algae and processing of biodiesel are the starting point of our study (Slegers et al., 2013). Sustainable pathways for indoor cultivation and processing of algae biomass are investigated. We focus in particular on reducing the fossil energy input and waste production during the production process, as well as on the land used. All electricity use is therefore assumed to be renewable. In this study we present and describe the conceptual factory design, and the design is formalized in mathematical equations for a specific case in biodiesel production. The quantitative environmental evaluation considers energy input, outflows to the environment (waste) and land use.

\subsection{Materials and Methods}

In this section the conceptual design of an indoor facility for micro-algae cultivation and processing is presented. The factory is designed such that no fossil energy inputs are consumed. The electricity used is renewable and assumed to be produced by wind mills. To minimize the material inputs a maximum recycling of waste streams is implemented. This conceptual design was used as basis for the quantitative environmental assessment.

\subsubsection{Conceptual design of a factory producing micro-algae}

The factory has two main departments: one for cultivation and one for processing. At the cultivation department the algae are cultivated indoors using 
artificial lighting in the building. There is also some algae cultivation outside of the building (on the roof and along façades) where algae are cultivated in sunlight. At the process department the algae are harvested and processed to obtain the raw materials, e.g. lipids, carbohydrates, proteins, vitamins and minerals. These molecules can be processed into a variety of products. In this work the focus is on the extraction of lipids and the production of diesel. Fig. 1 gives an overview of the main components of the factory, as well as the installations on the roof and facades. These installations are comparable with the outdoor installations of algae cultivation. Roofs and facades of buildings are generally suitable for installation of tubes or flat panels to cultivate algae. The tubes or panels get direct sunlight and do not need energy from other sources.

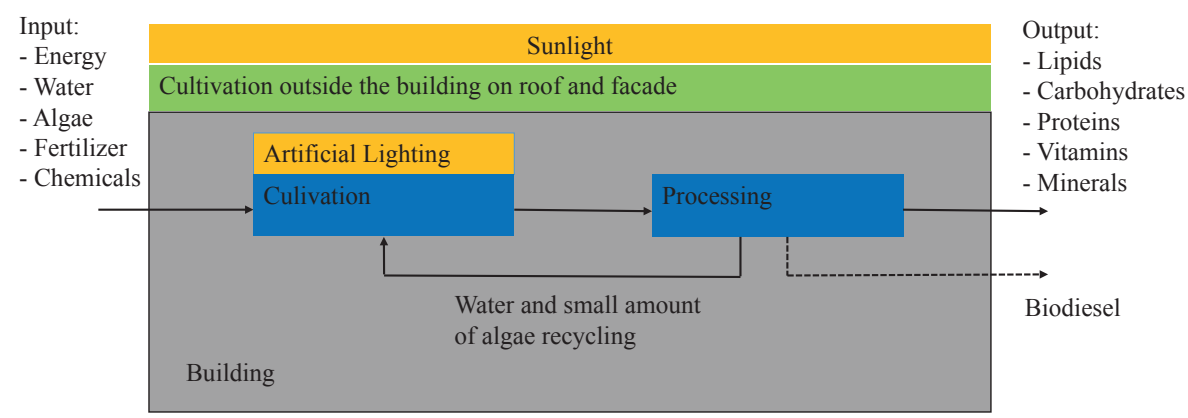

Figure 1. Conceptual design of a factory for indoor cultivation and processing of algae.

The algae cultivation on the roof, facade and inside the factory are further illustrated in Figure 2. The cultivation on the façade is located on the side that receives most sunlight during the day. The algae production on the roof and façade takes place in closed photobioreactors. The specific height of the building depends on the number of stories inside to grow algae. In case stories are $1 \mathrm{~m}$ high, a building with 12 stories has a height of $12 \mathrm{~m}$. In our design the cultivation department has 12 stories with trays filled with water to cultivate algae, in thin layer ponds. Each story has trays with a depth of $50 \mathrm{~mm}$, filled with water with algae. We assume that a depth of $50 \mathrm{~mm}$ gives optimal result in indoor cultivation. This is lower than in outdoor cultivation, for which (Mata et al., 2010) propose an operational depth of the trays between 160 and $210 \mathrm{~mm}$. In the presented design the cultivation department has a surface of one hectare. 

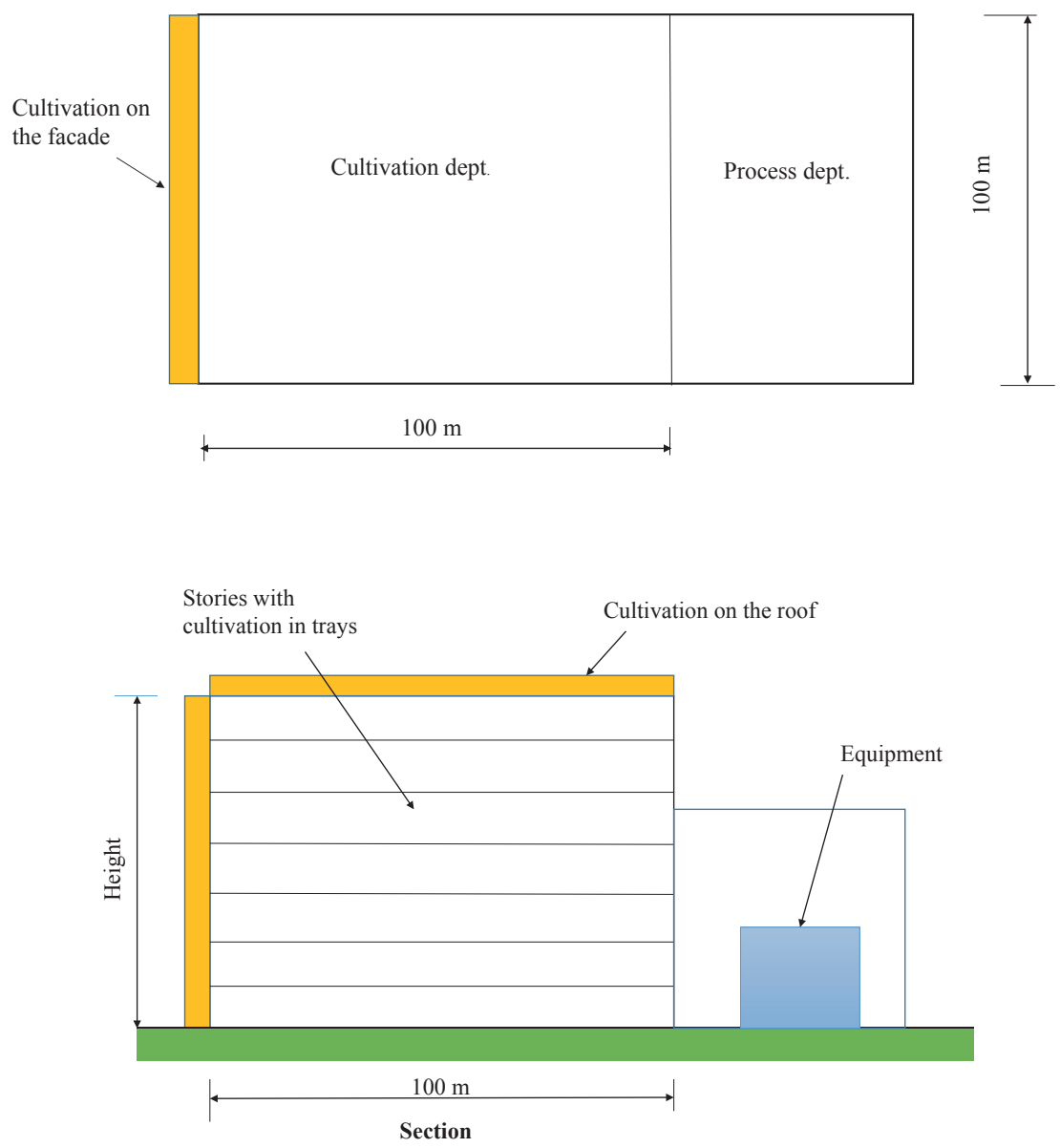

Figure 2. Floor plan and section of the factory for indoor cultivation and processing of algae

Obviously, it is important that the conditions within the factory are optimal for algae growth. Light and temperature are important variables in this respect. The light efficiency of the algae is also an important factor, and depends on the species-specific growth characteristics. This in turn affects the need for electricity and the duration of the cultivation. In the design, the combination of artificial light indoors with direct sunlight outdoors (on the façade and roof) results in optimal use of energy. In addition, light emitting diodes (LED) give the possibility for true light spectrum control (Hemming, 2011). Lamps with PAR light (Photosynthetic Active Radiation) are located above the trays (Figure 3). PAR light has a wave length of $400-700 \mathrm{~nm}$ and it represents 
the photosynthetic active region of light. The light spectrum could be even further optimised, as each species has specific optimal wave length (Blanken et al., 2013). In our design the artificial light period is $16 \mathrm{~h}$ per day, to ensure a minimum dark period of $8 \mathrm{~h}$. The water temperature also affects the growth, as enzymatic cellular processes are temperature regulated. For algae the water temperature should not be higher than $15^{\circ} \mathrm{C}$ above this optimum temperature and not $2-4{ }^{\circ} \mathrm{C}$ below it (Mata et al., 2010). The water temperature in the factory is therefore set to a range of $20-26^{\circ} \mathrm{C}$. The building is connected with a water supply system and an energy supply system. Depending on the algae species, fresh water or seawater can be used. Fresh water creates less problems with corrosion of installations. The disadvantage is the limited availability of fresh water at certain locations. We assume that water in the factory is recycled, so there will be no waste water. The recycling can be done because no chemicals are used during cultivation and processing. Some water is lost by cultivation and processing; there is always a need for addition.

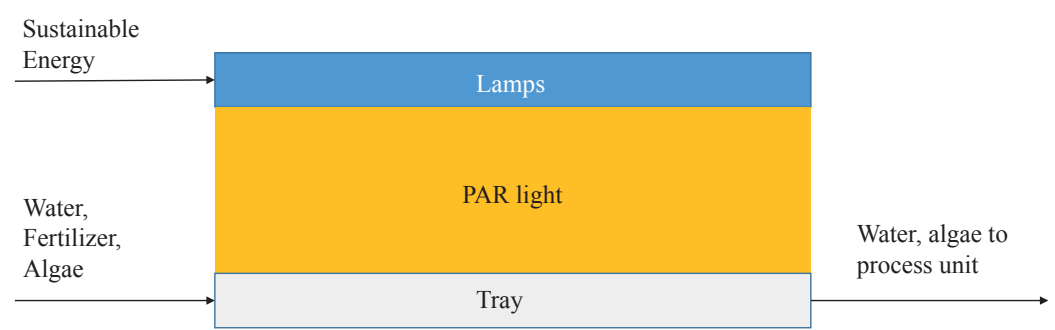

Figure 3. Lighting: schematic overview of the twelve stories with trays in which algae are cultivated

The produced algae biomass is assumed to consist of $50 \%$ lipids, $40 \%$ proteins and carbohydrates, and $10 \%$ of minerals. The biomass is harvested and processed in the processing department. To improve the environmental performance we chose to harvest the algae in one step by pressure filtration. This has as advantage that no chemicals are used for harvesting. Chemicals would make it more difficult to recycle the water, which should be treated before discharge. Furthermore, the presence of chemicals in the harvested biomass can affect the performance of the further downstream processing. After harvesting, cells are disrupted and the lipids are extracted from the algal biomass. After extraction part of the lipids are transesterified. The lipids that can be transesterified into biodiesel which are esters of long-chain carboxylic 
acids with 1, 2, 3-trihydroxypropane (glycerol), so-called triacylglycerides. Transesterification is the chemical reaction in which the organic groups $\mathrm{R}$ of triglyceride exchange with the organic group of an alcohol. The reaction of algal lipids with alcohol (e.g. methanol) results in the end products: the ester biodiesel and glycerol (Figure 4).

Through this chemical reaction in theory from $1000 \mathrm{~kg}$ Lipids, $123 \mathrm{~L}$ Methanol, and $45 \mathrm{~L} \mathrm{NaOH}$ can be produced $1165 \mathrm{~L}$ diesel and $79 \mathrm{~L}$ Glycerol. We consider $4 \%$ sodium hydroxide $(\mathrm{NaOH})$ as a catalyst following the literature for similar processes (Mata et al., 2010; Vyas et al., 2010).

In our factory a 1-step extraction and conversion technique is applied, called supercritical methanol conversion (SC-methanol). This method combines disruption, extraction and conversion (Patil et al., 2012). There is no drying of the biomass required, as it has a tolerance to high moisture contents (Alchris et al., 2016). This solvent-free method has also been applied successfully to other biomass sources (Glisic and Skala, 2009). For micro-algae the Net Energy Ratio of processing chains with SC-methanol are expected to be around 1.0 (Slegers et al., 2014). Given that the technique is being further developed for processing at larger scales, the energy requirement is expected to further improve (Patil et al., 2012).

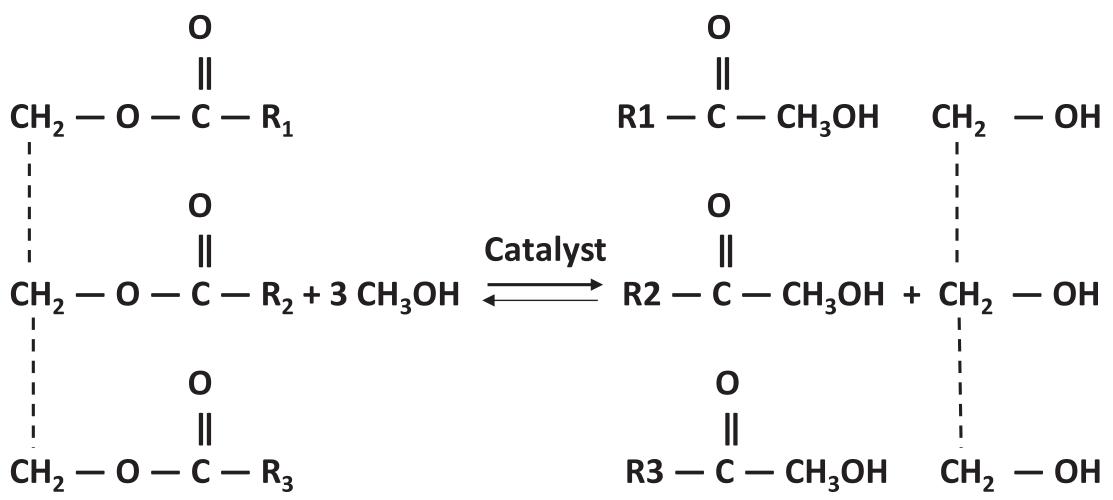

\section{Algal lipids \\ methanol \\ Biodiesel \\ Glycerol}

Figure 4. Chemical reaction producing biodiesel. $R, R$ and $R$ are long-chain carboxylic acids (Mata et al., 2010). In this study the chosen catalyst is $\mathrm{NaOH}^{\prime}{ }^{1}$ 
In short, the inputs of the factory are water, energy, fertilizer and chemicals for the extraction and conversion. These resources are produced elsewhere, and considered external inputs; the production of these resources is not part of the design of the factory. The electricity used is from renewable and produced by wind mills. The outputs of the factory are the main product, i.e. biodiesel, and residual biomass that can be processed further.

\subsubsection{Model calculations}

We simulated the cultivation and processing of algae for our factory design in a computer model that quantifies the growth, harvesting and processing of lipids.

\subsubsection{Cultivation}

The calculations for indoor growth of the algae are described in Appendix A, Box 1 and 2. Algae production takes place in trays with a height of $50 \mathrm{~mm}$ filled with water. The water in the trays is divided in 5 horizontal layers and for each layer the algae concentration is calculated. In practice this water is pumped continuously to create turbulence. To mimic the turbulence and the ideal mixing of the biomass, the water is 'mixed' every $2.5 \mathrm{~h}$ in the calculation. This frequency is in line with the shortest total exposure time in the calculation to reach the desired concentration of algae. Above the trays are led lamps with red light with a wavelength of $660 \mathrm{~nm}$ and a power of $100 \mathrm{~W} \mathrm{~m}^{-2}$.The initial concentration of algae is $0.1 \mathrm{~kg} \mathrm{~m}^{-3}$ and we simulate batch growth until a biomass concentration of $2.1 \mathrm{~kg} \mathrm{~m}^{-3}$ is reached (after 5.8 days). At that concentration the algae are harvested. After harvesting of $2.0 \mathrm{~kg} \mathrm{~m}^{-3}$, the cycle starts again with an initial concentration of $0.1 \mathrm{~kg} \mathrm{~m}^{-3}$. The resulting algae productivity under artificial light can be validated with the photosynthetic efficiency (PE) calculation: assuming that algae consists of lipids (50\%), carbohydrates and protein (40\%) and minerals (10\%). Experts consider $50 \%$ lipids content is achievable. With the energy content of lipids of $35 \mathrm{MJ} \mathrm{kg}^{-1}$ and of carbohydrates of $17 \mathrm{MJ} \mathrm{kg}^{-1}$ the energy content of algae is $24.3 \mathrm{MJ} \mathrm{kg}^{-1}$. With an exposure time of 5.8 days of 16 hours, $100 \mathrm{~W} \mathrm{~m}^{-2}$ light on a $10,000 \mathrm{~m}^{2}$ area, the total exposure energy per batch is $334 \mathrm{GJ}$. Under these conditions $1000 \mathrm{~kg}$ algae are produced, so the indoor $\mathrm{PE}=1000 * 24.3 / 334,000 * 100 \%=7.3 \%$. Experts consider $7.3 \%$ as a reliable value for algae growth under artificial illumination. Outdoors there is algae cultivation on the roof and one of the façades of the factory. The roof has a 
surface of 1 ha and the façade 0.12 ha, where algae are grown in horizontal and vertical tubular photo bioreactors. We assume a productivity that is achievable under Dutch weather conditions. Algae growth is calculated based on Slegers et al (Slegers et al., 2013) (Figure 6 and Table 2). The calculation of fertilizer and water requirements are described in Appendix A Box 3.

\subsubsection{Processing}

For harvesting of algae, and for the production of diesel equipment is needed. In our factory, the algae mass is harvested through pressure filtration. This technique has the advantage of lower energy consumption compared to centrifugation (Slegers et al., 2014) and does not require additional chemicals. The mathematical equations used to model the harvesting are given in Appendix B. The extraction and conversion processes require methanol, $\mathrm{NaOH}$, and energy. These inputs are based on Slegers et al., (Slegers et al., 2014) and are given as well in the Appendix. The yield in the conceptual factory results in $386,400 \mathrm{~L}^{\text {biodiesel }} \mathrm{yr}^{-1}$, and with this amount of biodiesel stoichiometrically $25,500 \mathrm{~L}$ glycerol is produced. From these results the Net Energy Ratio can be determined, i.e. the ratio between the energy contained in the biomass divided by the energy input.

\subsubsection{Scenarios}

The performance of the factory is compared to outdoor production using open ponds ( state-of-the-art). The algae production, fertiliser input, water consumption, and electricity demand are based on Tredici (2010) and Slegers et al., (2013; 2014). A detailed calculation is given in the appendix. For the outdoor production two scenarios for biodiesel production are analysed, i.e. 'hexaneacidic' (wet solvent extraction followed by conventional conversion) and 'SC Methanol' (promising 1-step processing). The calculations of these scenarios are based on Slegers et al. (2014). The hexane-acidic scenario is included to illustrate the impact of solvent and chemical use in the downstream processing.

\subsection{Results}

The annual algae production in the factory, and outdoors on the roof and facade are illustrated in Table 1. The total calculated algae production for a factory with 
1 ha ground area for cultivation leads to a total biomass productivity of $810 \mathrm{t}$ $y^{-1}$. The indoor production is much larger, since effectively 12 ha of surface is available for growth, in contrast to 1.12 ha on the outside of the factory.

Table 1 Model results for indoor cultivation of algae in a factory as designed in Fig. 2 (1 ha ground floor area for cultivation)

\begin{tabular}{llll}
\hline & Indoor & Roof & Facade \\
\hline $\begin{array}{l}\text { Reactor area (ha) } \\
\text { Reactor type }\end{array}$ & 12 (in 12 stories) & 1 & 0.12 (vertical) \\
& Thin layer pond & $\begin{array}{l}\text { Horizontal tubular } \\
\text { reactor }\end{array}$ & $\begin{array}{l}\text { Vertical tubular } \\
\text { reactor }\end{array}$ \\
Light & LED light, $100 \mathrm{~W} \mathrm{~m}^{-2}, 16 \mathrm{~h} \mathrm{~d}^{-1}$ & $\begin{array}{l}\text { Sunlight, Dutch } \\
\text { conditions }\end{array}$ & $\begin{array}{l}\text { Sunlight, Dutch } \\
\text { conditions }\end{array}$ \\
Electricity use (GJ $\mathrm{yr}^{-1}$ ) & 248,832 & 0 & 0 \\
Production (ton $\left.\mathrm{yr}^{-1}\right)$ & 745 & 60 & 5 \\
\hline
\end{tabular}

The algae produced in our conceptual factory are used for biodiesel production. The energy needed for harvesting 810 ton of algal biomass is $42,000 \mathrm{GJ}$. The energy needed for extraction and transesterification of 810 ton algae biomass is $12,400 \mathrm{GJ}$. In total $386,400 \mathrm{~L}$ is produced. The lipids are half the weight of the biomass, therefore half of the cultivation and process energy is allocated to the lipids. The resulting NER is therefore 0.1 , which means that only $10 \%$ of the ingoing energy is contained in the biodiesel product. This low NER can nevertheless be overcome, either by refinery of the products, and by employing renewable energy sources. For example, if we assume energy supply by wind mills, the total energy required can be delivered by four wind turbines with a power of $4 \mathrm{MW}$ each.

We compared the environmental performance of biodiesel produced in our factory to that from algae produced in outdoor ponds. We accounted for the land area needed, fertilizer use, water use, energy use and waste water production. In Table 2, these indicators are quantified for $1000 \mathrm{~L}$ of biodiesel produced. For outdoor production two scenarios for the lipid processing are analysed, i.e. 'hexane-acidic' and 'SC Methanol', based on Slegers et al. (2014). The results in Table 2 are for biomass cultivation and processing. Note, the electricity use for cultivation of algae in Table 2 is not the total demand, but the part that can be allocated to biodiesel. Inputs of water are corrected for water recycling. The factory does not produce waste water, ignoring small inevitable losses of waste water from the process system. The two cases for 
algae production in outdoor ponds in Table 2 assume the use of chitosan flocculation for preconcentration, following Slegers et al. (2014). This is required for the very dilute solution coming from outdoor ponds $\left(0.5 \mathrm{~kg} / \mathrm{m}^{3}\right)$. It is not yet known whether the water with traces of chitosan can be recycled, therefore it was assumed that process water with chitosan is not suitable for recycling. Alternatively, two steps of mechanical harvesting could be chosen, thereby enabling recycling of the waste water but increasing the energy demand. For this work we chose to focus on extreme, though pragmatic cases, i.e. for the factory design no chemical use and full water recycling, and for the outdoor situation a preference for chemical use over additional energy inputs.

Table 2 Environmental performance of indoor algae cultivation and processing for $1000 \mathrm{~L}$ diesel production in the factory (as designed in this study) compared with outdoor production in a pond in 5.8 days

\begin{tabular}{|c|c|c|c|c|}
\hline $\begin{array}{l}\text { Eq. } \\
\text { Box } 7\end{array}$ & & $\begin{array}{l}\text { Case I } \\
\text { Factory (SC } \\
\text { Methanol } \\
\text { conversion) }\end{array}$ & $\begin{array}{l}\text { Case II } \\
\text { Outdoor pond } \\
\text { (Hexane - acidic }_{\text {conversion) }}{ }^{\mathrm{a}}\end{array}$ & $\begin{array}{l}\text { Case III } \\
\text { Outdoor pond } \\
\text { (SC Methanol } \\
\text { conversion) }^{\mathrm{a}}\end{array}$ \\
\hline 17 & Water input $I_{w}\left(m^{3}\right)$ & 104 & 1851 & 1724 \\
\hline 18 & Land Area A (m²) & 1736 & 21421 & 21421 \\
\hline 19 & Fertilizer N (kg) & 121 & 376 & 346 \\
\hline 20 & Fertilizer P (kg) & 17 & 54 & 49 \\
\hline 21 & Methanol (L) & 216 & 121 & 216 \\
\hline 22 & Chitosan (kg) & 0 & 0.41 & 0.38 \\
\hline 23 & Hexane (L) & 0 & 288 & 0 \\
\hline 24 & Catalyst (kg) & 49 & 4 & 49 \\
\hline 25 & Energy use for cultivation (GJ) & 289 & 7 & 7 \\
\hline 26 & Upstream ${ }^{c}$ energy use for processing (GJ) & 64 & 22 & 35 \\
\hline 27 & Waste-water $\left(\mathrm{m}^{3}\right)$ & 0 & 1751 & 1624 \\
\hline 28 & Waste-water recycling $\left(\mathrm{m}^{3}\right)$ & 938 & 0 & 0 \\
\hline 29 & Fertilizer waste after processing (kg) & 0 & 129 & 119 \\
\hline
\end{tabular}

a) From Slegers et al. (2014) (Figure 7 with outdoor cultivation)

b) Energy use for biodiesel production only.

c) The upstream energy use of producing the required heat and electricity is considered

The area needed for algae cultivation in a factory differs considerably from that for ponds (Table 2). Cultivation of algae in factories with stories spares land. The factory has 12 stories of 1 ha to produce 810 ton algae biomass per year. The productivity of this factory can be compared with outdoor productivity 
on a similar land area. Outdoor productivity under Dutch conditions in vertical tubular photobioreactors is about 60 ton $\mathrm{ha}^{-1} \mathrm{yr}^{-1}$, and in ponds about 25 ton $\mathrm{ha}^{-1} \mathrm{yr}^{-1}$ (Slegers et al., 2013). So the indoor productivity is about 13 - 30 times higher depending on the type of cultivation. This explains why for $1000 \mathrm{~L}$ of biodiesel the land requirement for outdoor ponds is about 15 times as high as for the factory.

Fertilizer inputs are also considerably lower when algae are produced in a factory compared to ponds (Table 2). This is because the cultivation waste water still contains considerable amounts of nutrients. In the factory this water is recycled, however in the outdoor scenario the water is send to a treatment to prevent any problems with the chitosan circulation. As a result, the demand for water in the factory is less than $5 \%$ of that for outdoor ponds.

Summarizing, the factory scores better on almost every environmental indicator listed in Table 2, except for energy use. The energy use is high and therefore results in unfavourable NER. However, when this is energy from renewable sources, the environmental impact of it may be small.

\subsection{Conclusion}

We presented a conceptual design of a factory for indoor cultivation and processing of algae. The characteristics of this design are:

- Indoor cultivation and processing

- Algae produced for proteins, lipids, carbohydrates and minerals.

- Closed system

- No fossil energy inputs

- Minimum losses to the environment

- Independent of climate and weather conditions

We evaluate this design with respect to environmental loads. From the evaluation we conclude that our design performs well in terms of water, fertilizer and land use. Water and fertilizer are minimised as a result of recycling, moreover, land use is minimised because cultivation takes place in a building 
with stories. On the other hand, energy use is high, but without the use of fossil fuels. We argue that with efficient energy production our factory is achievable and environmentally sound. For comparing indoor versus outdoor algae production the electricity use and land use are the two important decision variables to consider. Either electricity use is minimized by choosing outdoor cultivation which increases demand for land, or land-use is minimized and as consequence additional electricity is needed for lighting the systems.

In this study the design is based on the contemporary knowledge of cultivation and processing of algae. Before the realisation of such a factory more experimental studies are needed on the processes involved. A next step would be experiments at the laboratory and pilot scale to proof our concept.

Our study is the first to present and evaluate a design of a factory for cultivation of micro-algae for biodiesel and other products. It can serve as a base for next steps toward large scale production of micro-algae. Our design can be implemented using available technology. Practical experience will help to further optimise the processes within the factory. 


\section{Appendix A. Calculations for algae cultivation}

Box 1. Model equations for cultivation of algae

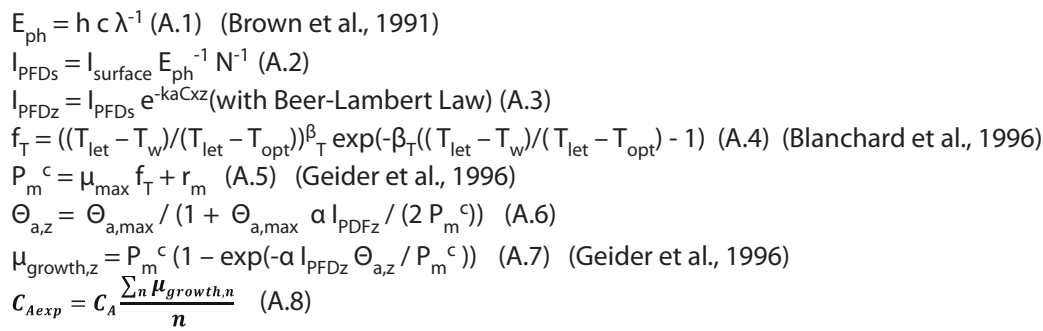

Box 2. Description of parameters and variables present in Box 1

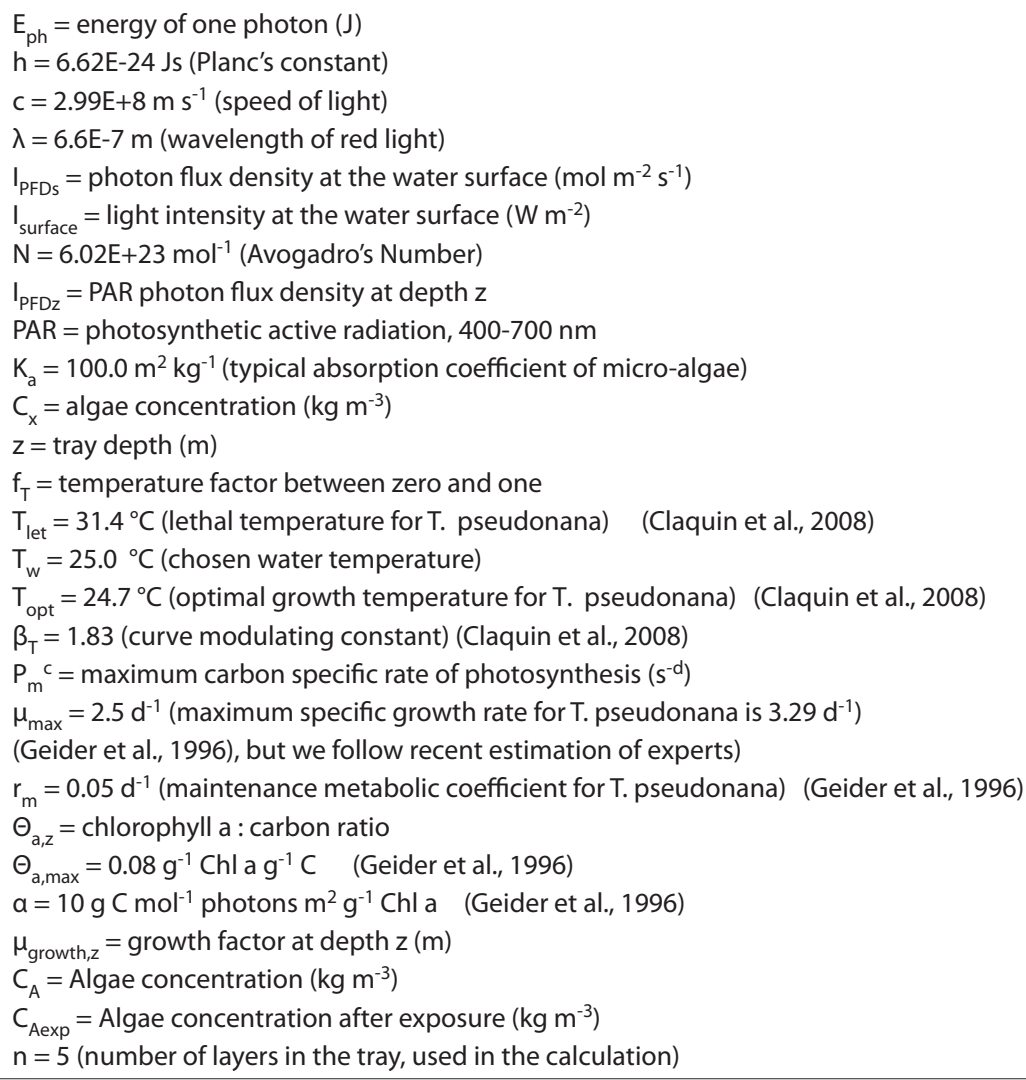


Box 3. Mathematical formulation of Table 2

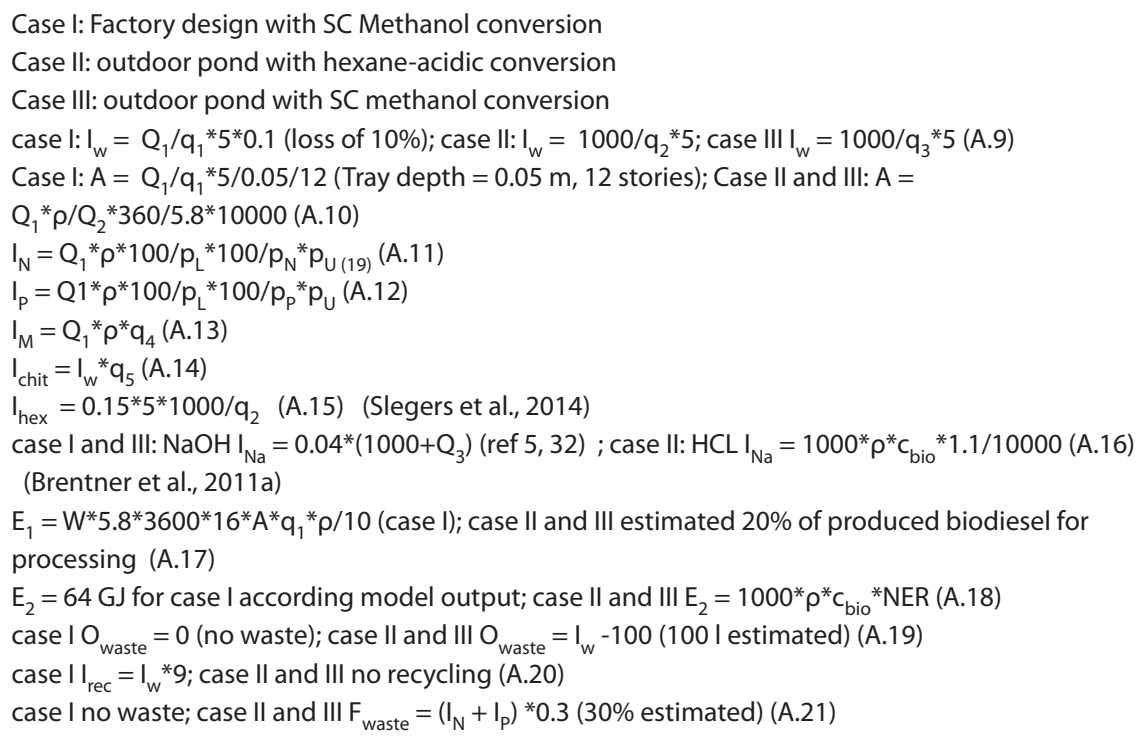

Box 4. Description of parameters and variables presented in Box 3

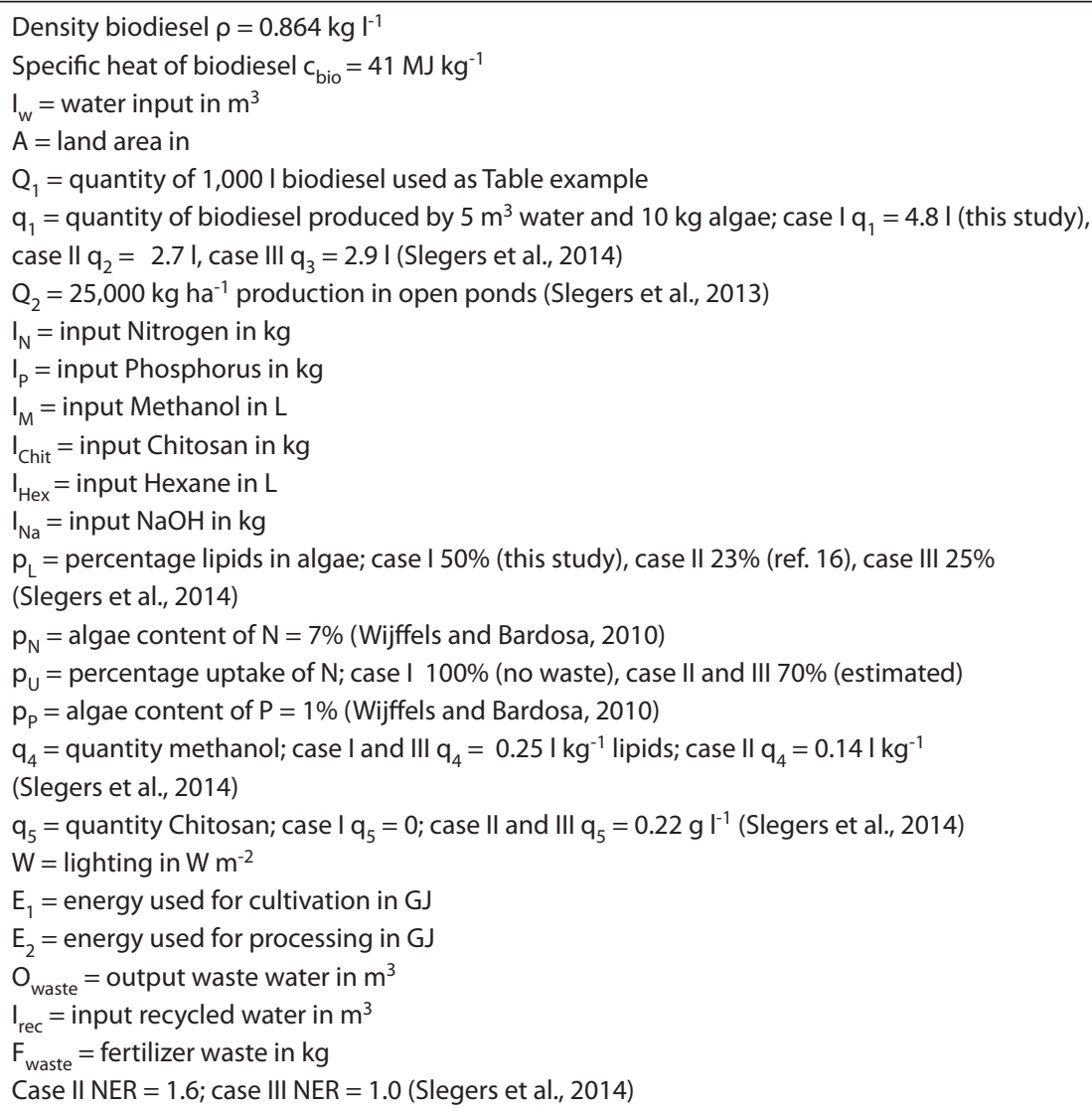




\section{Appendix B. Calculations processing into biodiesel}

Box 1. Model equations for harvesting

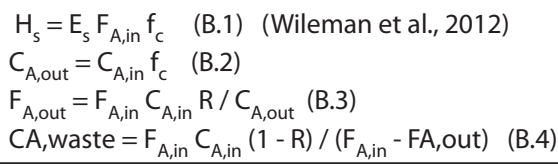

Box 2. Description of parameters and variables present in Box 3

$\mathrm{H}_{\mathrm{s}}=$ energy input $\left(\mathrm{J} \mathrm{m}^{3}\right)$

$\mathrm{E}_{\mathrm{s}}=1.7 \mathrm{MJ} \mathrm{m}^{-3}$ (required energy) (Wileman et al., 2012)

$\mathrm{F}_{\mathrm{A}, \text { in }}=$ in flow of water containing algae $\left(\mathrm{m}^{3} \mathrm{~h}^{-1}\right)$

$\mathrm{f}_{\mathrm{c}}=50$ (concentration factor)

$\mathrm{R}=95 \%$ (recovery factor) (Brentner et al., 2011b)

$\mathrm{C}_{\mathrm{A} \text { out }}=$ algae concentration out flow $\left(\mathrm{kg} \mathrm{m}^{-3}\right)$

$C_{A, \text { in }}=2.0 \mathrm{~kg} \mathrm{~m}^{-3}$ (algae concentration in flow)

$C_{A \text {,waste }}=$ algae concentration of waste flow $\left(\mathrm{kg} \mathrm{m}^{-3}\right)$

Box 3. Mathematical formulation of supercritical methanol conversion

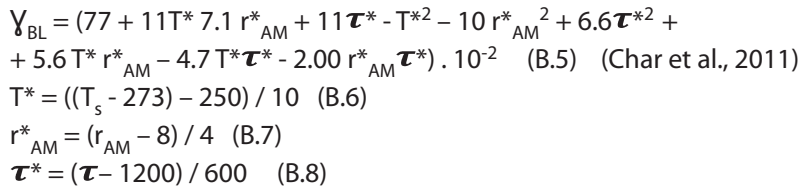

Box 4. Description of parameters and variables presented in Box 5

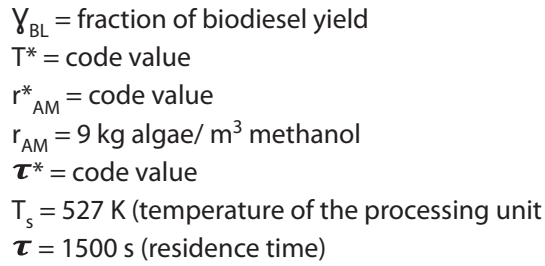





\section{Chapter 5 Eutrophication Control in European Seas: The Role of Nutrient Management, Waste Water Treatment and Seaweed Production}




\section{Abstract}

Coastal waters in Europe are polluted with nitrogen $(\mathrm{N})$ and phosphorus $(\mathrm{P})$. Scenario studies indicate that current policies do not result in a considerable reduction of this pollution in the coming decades. The consequences of longterm nutrient enrichment include a loss of biodiversity, fish mortality and disadvantages for tourism. In this study we explore possibilities to reduce the risk of coastal eutrophication by seaweed farming in combination with nutrient management in agriculture and sewage treatment on land. We present a scenario in which the potential of coastal eutrophication is minimized. The scenario first assumes that nutrient use efficiencies in agriculture are higher than today, and that sewage treatment on land is improved. Second, it assumes that all excess $\mathrm{N}$ and $\mathrm{P}$ in coastal waters is taken up in seaweed farms. In our scenario there is seaweed farming in the coastal waters of 34 rivers mouths in Europe. The farm areas range from 0 to $952 \mathrm{~km}^{2}$. Our conclusion is that eutrophication in the coastal waters of Europe can be minimised in the future with a combination of measures on land (in agriculture and sewage) and in the coastal waters itself (seaweed farming). 


\subsection{Introduction}

Coastal waters of the European Union are highly polluted with nutrients such as nitrogen (N) and phosphorus (P) (Diaz and Rosenberg, 2008; EEA, 2001; Seitzinger et al., 2010; Sutton et al., 2011). Human activities on land, such as agriculture and sewage systems, add to the nitrogen loading of rivers and coastal waters. Algal blooms are an important consequence of nutrient pollution in the coastal waters. These blooms have several negative effect for the coastal waters, such as loss of biodiversity, oxygen decrease, fish mortality and, decrease of tourism.

Scenario studies for the future indicate that environmental policies in Europe may reduce nutrient pollution of rivers to some extent, but not enough to avoid eutrophication (Blaas and Kroeze, 2016; Garnier et al., 2010; Seitzinger et al., 2010; Strokal and Kroeze, 2012). The most important causes of nutrient inputs to European rivers are agriculture and sewage (Seitzinger et al., 2010; Blaas and Kroeze, 2016).

Several options exist to mitigate algal blooms in the coastal waters. Important options are (1) increased nutrient use efficiency in agriculture on land, and (2) improved sewage treatment.

Nutrient use efficiency can be improved by, for instance, precision agriculture (Baltissen 2014; Bongiovanni et al., 2004; Chen et al., 2014; Keller et al., 2002). Latest technologies use Global Positioning Systems (GPS) in combination with high-tech agricultural machines to use fertilizers more efficiently. Precision Agriculture aims for secure monitoring of soil and crop growth. Through this monitoring the farmer is informed about which land needs water or nutrients, in which quantities, and when. This helps to maximize yields while minimizing the use of water and fertilizers. Reducing fertilizer inputs can reduce leaching of fertilizers to groundwater, rivers and coastal waters considerably (Bongiovanni et al., 2004). Nutrient inputs in crop production can be both synthetic fertilizer or animal manure. More effective use of manure will also reduce nutrient losses to the environment. 
Sewage is another important cause of nutrient pollution in rivers and coastal seas. In Europe most people are connected to sewage systems that drain into rivers after sewage treatment (Van Drecht et al., 2010). However, the effectiveness of sewage treatment varies among European countries. Technically, it is possible to reduce the $\mathrm{N}$ and $\mathrm{P}$ content of sewage by up to $90 \%$, but this is not current practice in many European regions (Van Drecht et al., 2010).

Current scenario analyses do not consider possibilities to remove nutrients from coastal seas as an option for control. This could be done by, for instance, harvesting seaweed from coastal waters. Growing seaweed is increasingly considered one of the promising developments to feed the world population in the future. Seaweed is a marine plant from which food, feed, chemicals and pharmaceutical products can be fabricated. In 2005 the worldwide production was about 18 million tons. Apart from these products seaweed is also interesting to produce $\mathrm{CO}_{2}$ neutral energy (Koning et al., 2008; Reith et al., 2005). Seaweed needs nutrients such as $\mathrm{N}$ and $P$ for growth. In nutrient-rich coastal waters $\mathrm{N}$ and $\mathrm{P}$ are available. Harvesting seaweed will result in a removal of $\mathrm{N}$ and $\mathrm{P}$ from the water.

In this study we explore possibilities to reduce the risk of coastal eutrophication by seaweed farming in combination with nutrient management in agriculture and sewage treatment on land.

We present a scenario in which the potential of coastal eutrophication is minimized. The scenario first assumes that nutrient use efficiencies in agriculture are higher than today, and that sewage treatment on land is improved. Second, it assumes that all excess $\mathrm{N}$ and $\mathrm{P}$ in coastal waters is taken up in seaweed farming. We estimate what area of seaweed farming would be needed for that.

We use the computer model Global NEWS (Nutrient Export from WaterSheds) to analyse river export of nutrients, as affected by human activities on land. We build on an earlier application of Global NEWS to European Seas (Blaas and Kroeze, 2016). This study quantifies rivers export of $\mathrm{N}$ and $\mathrm{P}$ to the coastal waters, and the associated coastal eutrophication based on ICEP (Indicator Coastal Eutrophication Potential. If ICEP is positive $(>0)$ at the river mouth nutrient levels are in excess over dissolved silica (Si), making conditions favourable for harmful algal blooms (Garnier et al., 2007; 2010). 


\subsection{Method}

In this study we use the computer model Global NEWS (Seitzinger et al., 2010; Mayorga et al., 2010). This model has been developed to analyse past and future trends in nutrient export by rivers, as affected by human activities on the land. It estimates the river transport of the Carbon (C), Nitrogen (N), Phosphorus (P) and Silica (Si) for more than 6000 rivers worldwide, and for the years 1970, 2000, 2030 and 2050. The model has been validated at the global and continental scale (Mayorga et al., 2010; Kroeze et al., 2002; Qu and Kroeze, 2010, 2011; van der Struik and Kroeze, 2010; Yasin et al., 2010) and regionally (Strokal and Kroeze, 2012; Thieu et al., 2010; Yan et al., 2010). It has been successfully applied to study river export of nutrients to European seas (Blaas and Kroeze, 2016)

Future trends in Global NEWS are interpretations of the Millennium Ecosystem Assessment (MA) scenarios for the years 2030 and 2050 (Mayorga et al., 2010). The MA scenarios were developed after the United Nations assigned in 2000. More than 1300 scientists contributed to the MA. The MA resulted in scenarios for ecosystem changes in connection with human well-being up to the year 2050 (Carpenter etal., 2005;MA, 2005) The scenarios are based on different assumptions on future socio-economic trends that affect ecosystem. The scenarios differ with respect to socio-economic developments (global or regional) and with respect to environmental management (proactive of reactive). In Global NEWS all four MA scenarios were implemented. Here we use the scenario Global Orchestration (GO) as a basis for our scenario analysis, which describes a globalizing world, with a reactive approach towards environmental management.

The Global NEWS model calculates river transport of nutrients from land to sea in terms of yields ( $\mathrm{kg} \mathrm{km}^{-2}$ of watershed $\left.\mathrm{yr}^{-1}\right)$ or loads $\left(\mathrm{Mg} \mathrm{yr}^{-1}\right)$. It is spatially explicit. Most model inputs are derived from gridded datasets $(0.5 \times 0.5$ degree) (Bouwman et al., 2010; Van Drecht et al., 2010). Model outputs are at the basin scale. The model accounts for nutrient retention on land and during river transport, and accounts for the effects of human water consumption and dams (Fekete et al., 2010).

In Global NEWS the ICEP for the rivers is calculated as an indicator for negative implications of coastal eutrophication. The calculated ICEP is based on the 
Redfield ratio for $\mathrm{C}: \mathrm{N}: \mathrm{P}: \mathrm{Si}$, which is 106:16:1:20. This ratio reflects the nutrient composition algal biomass that are not harmful. At sufficient levels of silica, silica skeletons are formed and dead algae sink to the bottom of the sea and cause no blooms. If the ratio of $\mathrm{N}$ or $\mathrm{P}$ to $\mathrm{Si}$ is below the Redfield ratio, harmful algal blooms may develop.

ICEP kg km${ }^{-2} \mathrm{~d}^{-1}$ is calculated as follows:

ICEP $=\left[\mathrm{Yld}_{\mathrm{N}} /(14 * 16 * 365)-\mathrm{Yld}_{\mathrm{Si}} /(28 * 20 * 365)\right] * 106 * 12$

If $\mathrm{N}: \mathrm{P}<16$ ( $\mathrm{N}$ is the limiting nutrient for growth of algae)

ICEP $=\left[Y d_{p} /(31 * 365)-Y_{\text {Id }} /(28 * 20 * 365)\right] * 106 * 12$

If $\mathrm{N}: \mathrm{P}>16$ ( $\mathrm{P}$ is the limiting nutrient for growth of algae)

(Billen and Garnier, 2007)

$\mathrm{Yld}_{\mathrm{N}^{\prime}} \mathrm{Yld}_{\mathrm{P}}$ and $\mathrm{Yld}_{\mathrm{Si}}$ are the yields of total phosphorus, nitrogen and silica at the river mouth and are calculated with the Global NEWS equations as follows:

$\mathrm{Yld}_{\mathrm{F}}=\mathrm{FE}_{\text {riv, F }} *\left(\mathrm{RSpnt}_{\mathrm{F}}+\mathrm{RSdif}_{\mathrm{F}}\right)$

$\mathrm{RSpnt}_{\mathrm{F}}=\mathrm{FE}_{\text {pnt,E }} * \mathrm{RSpnt}_{\mathrm{E}}$

$\mathrm{RSdif}_{\mathrm{F}}=\mathrm{RSdifant}_{\mathrm{F}}+\mathrm{RSdifnat}_{\mathrm{F}}$

Variables and parameters (unit) for dissolved N and P (Mayorga et al., 2010):

$\mathrm{Yld}_{\mathrm{F}}=$ river export of dissolved element form $\mathrm{F}$ per km${ }^{-2}$ of basin area $\left(\mathrm{kg} \mathrm{km}^{-2}\right.$ $\mathrm{yr}^{-1}$ )

$\mathrm{FE}_{\text {riv, }}=$ the fraction of nutrient form inputs to rivers (point + diffuse sources) that is exported to the river mouth

$\mathrm{RSpnt}_{\mathrm{F}}=$ the annual point source input of nutrient form $\mathrm{F}$ to rivers from sewage systems $\left(\mathrm{kg} \mathrm{km}^{-2} \mathrm{yr}^{-1}\right)$

$\mathrm{RSdif}_{\mathrm{F}}=$ the annual diffuse source input of nutrient form $\mathrm{F}$ to rivers from natural and anthropogenic sources $\left(\mathrm{kg} \mathrm{km}^{-2} \mathrm{yr}^{-1}\right)$ 
$\mathrm{FE}_{\mathrm{pnt}, \mathrm{E}}=$ fraction of nutrient form $\mathrm{F}$ in element $\mathrm{E}$ in point source units

$\mathrm{RSpnt}_{\mathrm{E}}=$ the annual point source input of element $\mathrm{E}$

$\mathrm{RSdifant}_{\mathrm{F}}=$ the annual diffuse source input of nutrient form $\mathrm{F}$ to rivers from anthropogenic sources $\left(\mathrm{kg} \mathrm{km}^{-2} \mathrm{yr}^{-1}\right)$

$\mathrm{RSdifnat}_{\mathrm{F}}=$ the annual diffuse source input of nutrient form $\mathrm{F}$ to rivers from natural sources $\left(\mathrm{kg} \mathrm{km}^{-2} \mathrm{yr}^{-1}\right)$

$L_{F}$ is the load of total phosphorus, nitrogen and silica at the river mouth and are calculated with the Global NEWS equation as follows:

$\operatorname{Ld}_{\mathrm{F}}=\mathrm{Yld}_{\mathrm{F}} * \mathrm{~A}$

$\mathrm{Ld}_{\mathrm{F}}=$ river export of dissolved element form $\mathrm{F}$ from basin $\left(\mathrm{Mg} \mathrm{yr}^{-1}\right)$

$A=$ basin area $\left(\mathrm{km}^{2}\right)$

In a recent study we used the GO scenario for the year 2050 and 48 rivers of 27 European countries. These were the countries of the European Union as of 2015 (EU27) (Blaas and Kroeze, 2016). These rivers were also chosen based on loads at the river mouth of more than $10 \mathrm{Gg} \mathrm{yr}^{-1}$. Of these, 34 rivers have a positive ICEP and a risk of algae blooms (Table 1). If ICEP is positive there is an excess of $\mathrm{N}$ or $\mathrm{P}$ over $\mathrm{Si}$ and a risk of algal blooms. Table 1 indicates whether $\mathrm{N}$ or $\mathrm{P}$ is limiting for growth, and it shows also the main source of the limiting nutrient. The dominant source of pollution is often agriculture or sewage. Here, we take these results as a starting point for our analyses. 
Table 1. Summary of European rivers with a positive ICEP (Indicator for Coastal Eutrophication Potential) in the year 2050; the limiting nutrient ( $\mathrm{N}$ or P), and dominant sources of the limiting nutrient (modified from Blaas and Kroeze, 2016).

\begin{tabular}{|c|c|c|c|c|c|c|}
\hline 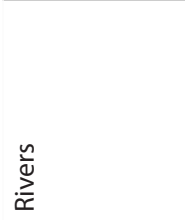 & 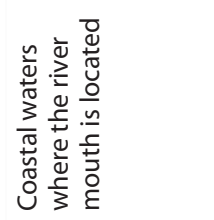 & 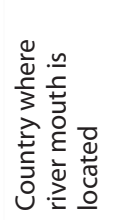 & $\begin{array}{l}\text { 윳 } \\
\text { i } \\
\text { 㟧 }\end{array}$ & 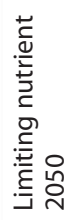 & 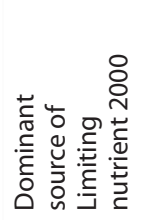 & 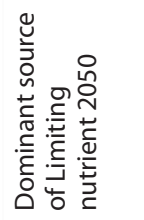 \\
\hline Basin no. 1941 & North Atl. Ocean & UK & 48.1 & $P$ & agriculture & Agriculture \\
\hline Basin no. 1919 & Id. & UK & 26.6 & $\mathrm{~N}$ & Sewage & Sewage \\
\hline Basin no. 1456 & Id. & UK & 26.0 & $P$ & Agriculture & Sewage \\
\hline Basin no. 1857 & Id. & UK & 25.6 & $\mathrm{P}$ & Agriculture & Sewage \\
\hline Thames & Id. & UK & 22.8 & $\mathrm{~N}$ & Sewage & Sewage \\
\hline Basin no. 4520 & Id. & Ireland & 21.5 & $\mathrm{P}$ & Agriculture & Agriculture \\
\hline Humber & Id. & UK & 17.2 & $\mathrm{~N}$ & Sewage & Sewage \\
\hline Basin no. 1382 & Id. & UK & 15.9 & $\mathrm{~N}$ & Agriculture & Sewage \\
\hline Shannon & Id. & Ireland & 12.4 & $P$ & Agriculture & agriculture \\
\hline Trent & Id. & UK & 11.7 & $\mathrm{~N}$ & Sewage & sewage \\
\hline Basin no. 1405 & Id. & Ireland & 11.3 & $P$ & Agriculture & Agriculture \\
\hline Basin no. 2348 & Id. & Ireland & 9.5 & $\mathrm{P}$ & Agriculture & Agriculture \\
\hline Basin no. 1090 & Id. & France & 7.5 & $\mathrm{P}$ & Agriculture & Agriculture \\
\hline Po & Med. Sea & Italy & 7.4 & $\mathrm{~N}$ & Agriculture & Agriculture \\
\hline Basin no. 1434 & North Atl. Ocean & Ireland & 6.9 & $P$ & Sewage & Sewage \\
\hline Basin no. 1870 & Id. & Ireland & 5.6 & $P$ & Agriculture & Sewage \\
\hline Basin no. 1448 & Id. & Ireland & 4.6 & $P$ & Agriculture & Agriculture \\
\hline Scheldt & Id. & The Neth. & 4.2 & $\mathrm{P}$ & Sewage & Sewage \\
\hline Meuse & Id. & The Neth. & 3.9 & $\mathrm{P}$ & Sewage & Sewage \\
\hline Seine & Id. & France & 3.8 & $\mathrm{~N}$ & Agriculture & Sewage \\
\hline Danube & Black Sea & Romana & 3.7 & $P$ & Sewage & Sewage \\
\hline Rhone & Med. Sea & France & 3.1 & $\mathrm{~N}$ & Agriculture & Agriculture \\
\hline Basin no. 1972 & North Atl. Ocean & Ireland & 2.8 & $P$ & Agriculture & Agriculture \\
\hline Ems & Id. & Germany & 2.7 & $P$ & Sewage & Sewage \\
\hline Wisla & Baltic Sea & Poland & 2.3 & $\mathrm{~N}$ & Agriculture & Agriculture \\
\hline Weser & North Atl. Ocean & Germany & 2.1 & $\mathrm{~N}$ & Sewage & Sewage \\
\hline Nemunas & Baltic Sea & Lithuana & 2.1 & $P$ & Sewage & Sewage \\
\hline Rhine & North Atl. Ocean & The Neth. & 1.8 & $P$ & Sewage & Sewage \\
\hline Adour & Id. & France & 1.8 & $\mathrm{P}$ & Sewage & Sewage \\
\hline Daugava & Baltic Sea & Letland & 0.9 & $\mathrm{P}$ & Sewage & Sewage \\
\hline Odra & Id. & Germany & 0.6 & N & Agriculture & Sewage \\
\hline Narva & Id. & Estland & 0.6 & $\mathrm{P}$ & Sewage & Sewage \\
\hline Basin no. 1875 & North Atl. Ocean & UK & 0.5 & $\mathrm{P}$ & Agriculture & Sgriculture \\
\hline Ebro & Med. Sea & Spain & 0.2 & $\mathrm{P}$ & sewage & Sewage \\
\hline
\end{tabular}


In this study we present results for two scenarios: the abovementioned GO scenario (Blaas and Kroeze, 2016; Seitzinger et al., 2010; Mayorga et al., 2010), and a new Optimistic (OPT) scenario. This OPT scenario takes the GO scenario as a starting point, and assumes that it is possible to reduce $\mathrm{N}$ and $\mathrm{P}$ excess to zero. We identify three options to achieve this:

Improving nutrient use efficiency in agriculture: the OPT scenario assumes that fertilizers and water are used as exactly as possible: the right amount on the right place so that plants can optimally use it. This requires that before applying fertilizers, the quality of the soil must be known. During growth the crop can be monitored by GPS, aircrafts or drones and on different spots an adequate amount of fertilizer and water can be applied. The result will be that fertilizer uptake by crops is maximized, and losses to the environment minimized. To what extent leaching of nutrients from soils to groundwater and rivers can be reduced is uncertain. Some studies indicate that precision agriculture may reduce fertilizer needs by up to $50 \%$ (Bongiovanni et al., 2004). In our OPT scenario we assume that fertilizer use is reduced by $30 \%$ by improved agricultural practices.

Improved sewage treatment: Global NEWS accounts for nutrient discharge to rivers from sewage as a point source. It calculates the total $\mathrm{N}$ and $\mathrm{P}$ inputs to rivers from sewage as a function of population, sewage connection and nutrient removal in sewage treatment. It includes scenarios for the removal rates in sewage plants for the period 1970 - 2050. For the GO scenario for the year 2050, it indicates that 14 to $88 \%$ of the $N$ and $P$ is removed from sewage draining into the rivers considered in this study. In our OPT scenarios we assume that all sewage plants apply technologies that remove $90 \%$ of $\mathrm{N}$ and $\mathrm{P}$ from wastewater. This means that less nutrients will be discharged to rivers, and thus are transported to the coastal waters. A $90 \%$ removal rate is technically possible with current technology (Van Drecht et al., 2010).

Seaweed farming: Abundance of nutrients in coastal waters promotes the growth of seaweed in sea farms. For instance, in the North Sea a production of $20 \mathrm{Mg} \mathrm{ha}^{-1} \mathrm{yr}^{-1}$ dry weight of seaweed is possible without additional nutrient inputs (Reith et al., 2005). A possibility would be to grow seaweed in windmill parks. The windmills can be used to attach seaweed installations (Reith et al., 
2005). In the OPT scenario we assume that seaweed can take up $55.2 \mathrm{mg} \mathrm{N}$ $\mathrm{g}^{-1}$ and $3.8 \mathrm{mg} \mathrm{P} \mathrm{g}^{-1}$ of dry weight seaweed (Bouwman et al., 2011) The OPT scenario assumes that excess $\mathrm{N}$ and $\mathrm{P}$ is taken up by seaweed. In other words, the area of seaweed farms is large enough to ensure that ICEP $=0$.

The Seaweed farm Area (SA) required to reduce ICEP to zero is calculated assuming a production of 20 tons dry weight per hectare per year (Reith et al., 2005) with an $\mathrm{N}$ and $\mathrm{P}$ content of 5.5\% and 0.38\% (Bouwman et al., 2011), respectively:

$$
\begin{aligned}
& \mathrm{SA}=\left(\mathrm{Ld}_{\text {excess }}-\mathrm{R}_{1}-\mathrm{R}_{2}\right) /\left(\mathrm{p}_{1} * \mathrm{SP}\right) \\
& \mathrm{Ld} d_{\text {excess }}=\mathrm{Ld}_{\mathrm{F}}-\mathrm{Ld}_{1 \mathrm{ICEP}} \\
& \mathrm{R}_{1}=\mathrm{Ld}_{\text {sew }} *\left(90-\mathrm{p}_{2}\right) / 100 \\
& \mathrm{R}_{2}=0.3 * \mathrm{Ld}_{\mathrm{fer}}
\end{aligned}
$$

where

$\mathrm{SA}=$ seaweed production area in $\mathrm{km}^{2}$

$\mathrm{Ld}_{\text {excess }}=$ excess load in $\mathrm{Mg} \mathrm{yr}^{-1}$

$L d_{F}$ see eq. 6

$\operatorname{Ld}_{\text {ICEP }}=$ load for ICEP is 0 , calculated with eq. 1 and 2

$\mathrm{R}_{1}=$ Reduction in sewage load at river mouth by $90 \% \mathrm{~N}$ and $\mathrm{P}$ removal in $\mathrm{Mg} \mathrm{yr}^{-1}$

$\mathrm{R}_{2}=$ Reduction of fertilizer load at river mouth by precision agriculture $\mathrm{Mg} \mathrm{yr}^{-1}$

$\mathrm{p}_{1}=\mathrm{N}$ or $\mathrm{P}$ in seaweed (Mg nutrient/Mg dry weight of seaweed: 0.055 and 0.0038 for $\mathrm{N}$ and $\mathrm{P}$, respectively).

$\mathrm{SP}=$ Seaweed production (2000 $\mathrm{Mg} \mathrm{km}^{-2} \mathrm{yr}^{-1}$ dry weight of seaweed)

$\mathrm{Ld}_{\text {sew }}=$ Sewage load at river mouth in $\mathrm{Mg} \mathrm{yr}^{-1}$

$\mathrm{p}_{2}$ = percentage $\mathrm{N}$ and $\mathrm{P}$ removed by sewage treatment in $\mathrm{GO}$ scenario.

$\mathrm{Ld}_{\text {fer }}=$ Fertilizer load at river mouth in $\mathrm{Mg} \mathrm{yr}^{-1}$ 


\subsection{Results}

The rivers considered in this study transported $560 \mathrm{Gg} \mathrm{N}$ and $60 \mathrm{Gg} P$ to the coastal seas of Europe in the year 2000. In the BAU scenario for 2050, these export rates are somewhat lower than in 2000 (Figure 1 and 2). This is a result of European policies (Seitzinger et al., 2010). However, this modest result is not enough to prevent coastal eutrophication.

In the GO scenario 34 river mouths have an ICEP $>0$, indicating a risk for harmful algal blooms (Table 2). The total excess river export of nutrients in $\mathrm{GO}$ is $197 \mathrm{Gg}$ $\mathrm{N}$ and $44 \mathrm{Gg}$ P. Thus the excess load of $\mathrm{N}$ is about 4 times higher than that of $\mathrm{P}$, but for the sewage load the load of $\mathrm{P}$ is about 3 times higher than of $\mathrm{N}$. The most important sources of excess nutrients are fertilizers and sewage effluents. Less important sources of excess $\mathrm{N}$ and $\mathrm{P}$ are natural soils and atmospheric deposition. The percentages of $\mathrm{N}$ and $\mathrm{P}$ removal in sewage treatment plants in the GO scenario range from 14 till $88 \%$, and are mostly at the lower end of the range.

In the OPT scenario the ICEP values and excess N loads are zero. The OPT scenario indicates how this can be achieved. Table 2 presents the calculated reductions in river export of nutrients that originate from fertilizers and sewage following from our scenario assumptions. Improved sewage treatment is more effective in reducing excess $\mathrm{N}$ and $\mathrm{P}$ than improved nutrient use efficiency in agriculture (Figure 1 and 2). However, measures in agriculture and sewage alone will not avoid all excess nutrients in rivers. We calculated how much seaweed is needed to reduce nutrient loads to the level that ICEP $=0$. We estimate this area to be $3260 \mathrm{~km} 2$ in 2050, of which $51 \%$ in the North Atlantic Ocean, 11\% in the Mediterranean Sea, 29\% in the Black Sea and 9\% in the Baltic Sea. The required areas vary among rivers, depending on the extent to which $\mathrm{N}$ and $\mathrm{P}$ in rivers exceed the desired level. The seaweed production areas range from 0 till 952 $\mathrm{km}^{2}$. The largest area is calculated for the river Danube draining into the coastal waters of the Black Sea. 
Table 2. Model results for GO and OPT for the year 2050. For GO the table presents ICEP values (indicator for coastal eutrophication), the limiting nutrient, excess $\mathrm{N}$ or $\mathrm{P}$, fertilizer and sewage load at the river mouth, and the \% nutrient removal in sewage treatment. In OPT the ICEP values and excess loads are zero, and the table shows how this is achieved: by reducing fertilizer loads, sewage loads and seaweed farming.

\begin{tabular}{|c|c|c|c|c|c|c|c|c|c|c|c|}
\hline \multirow[t]{2}{*}{ River } & \multicolumn{2}{|c|}{$\begin{array}{l}\text { Global } \\
2050^{1}\end{array}$} & \multicolumn{3}{|c|}{ Orchestration scenario } & \multicolumn{6}{|c|}{ GO for Optimistic scenario OPT (this study) ${ }^{2}$} \\
\hline & 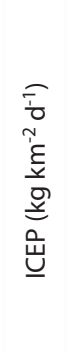 & 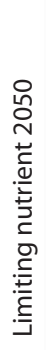 & 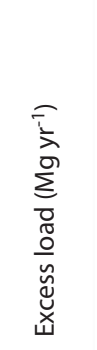 & 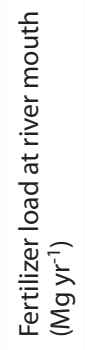 & 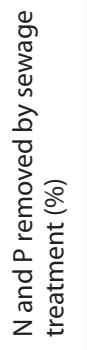 & 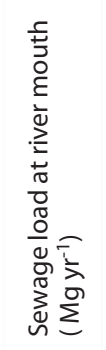 & 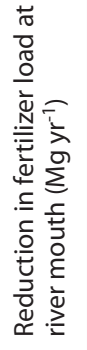 & 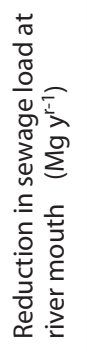 & 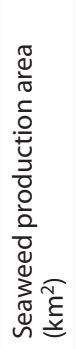 & 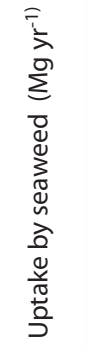 & 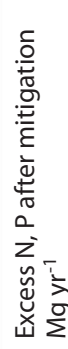 \\
\hline Basin no. 1941 & 48.1 & $\mathrm{P}$ & 2205 & 295 & 71 & 1472 & 89 & 965 & 152 & 1152 & 0 \\
\hline Basin no. 1919 & 26.6 & $\mathrm{~N}$ & 8491 & 0 & 62 & 6790 & 0 & 5003 & 32 & 3487 & 0 \\
\hline Basin no. 1456 & 26.0 & $P$ & 1451 & 116 & 71 & 1056 & 35 & 692 & 95 & 724 & 0 \\
\hline Basin no. 1857 & 25.6 & $\mathrm{P}$ & 1267 & 150 & 71 & 970 & 45 & 635 & 77 & 587 & 0 \\
\hline Thames & 22.8 & $\mathrm{~N}$ & 24590 & 821 & 62 & 21013 & 246 & 15484 & 81 & 8860 & 0 \\
\hline Basin no. 4520 & 21.5 & $P$ & 366 & 243 & 46 & 0 & 73 & 0 & 39 & 293 & 0 \\
\hline Humber & 17.2 & $\mathrm{~N}$ & 26209 & 4614 & 62 & 13116 & 1384 & 9665 & 138 & 15160 & 0 \\
\hline Basin no. 1382 & 15.9 & $\mathrm{~N}$ & 5461 & 0 & 62 & 1970 & 0 & 1451 & 36 & 4009 & 0 \\
\hline Shannon & 12.4 & $P$ & 2278 & 804 & 23 & 570 & 241 & 496 & 203 & 1541 & 0 \\
\hline Trent & 11.7 & $\mathrm{~N}$ & 12753 & 750 & 62 & 9400 & 225 & 6926 & 51 & 5601 & 0 \\
\hline Basin no. 1405 & 11.3 & $P$ & 711 & 295 & 45 & 248 & 89 & 203 & 55 & 419 & 0 \\
\hline Basin no. 2348 & 9.5 & $\mathrm{P}$ & 911 & 310 & 45 & 81 & 93 & 66 & 99 & 752 & 0 \\
\hline Basin no. 1090 & 7.5 & $P$ & 693 & 361 & 82 & 280 & 108 & 124 & 61 & 460 & 0 \\
\hline Po & 7.4 & $\mathrm{~N}$ & 46651 & 10826 & 63 & 18668 & 3248 & 13636 & 271 & 29767 & 0 \\
\hline Basin no. 1434 & 6.9 & $P$ & 348 & 79 & 52 & 310 & 24 & 245 & 10 & 79 & 0 \\
\hline Basin no. 1870 & 5.6 & $\mathrm{P}$ & 225 & 0 & 46 & 211 & 0 & 172 & 7 & 54 & 0 \\
\hline Basin no. 1448 & 4.6 & $\mathrm{P}$ & 229 & 414 & 65 & 85 & 124 & 61 & 6 & 44 & 0 \\
\hline Scheldt & 4.2 & $P$ & 773 & 35 & 70 & 662 & 11 & 442 & 42 & 321 & 0 \\
\hline Meuse & 3.9 & $\mathrm{P}$ & 1497 & 110 & 64 & 1128 & 33 & 814 & 85 & 649 & 0 \\
\hline Seine & 3.8 & $\mathrm{~N}$ & 17456 & 6172 & 72 & 14781 & 1852 & 9540 & 55 & 6065 & 0 \\
\hline Danube & 3.7 & $\mathrm{P}$ & 25535 & 494 & 62 & 24638 & 148 & 18154 & 952 & 7232 & 0 \\
\hline Rhone & 3.1 & $\mathrm{~N}$ & 19116 & 19096 & 72 & 7595 & 5729 & 4901 & 77 & 8486 & 0 \\
\hline Basin no. 1972 & 2.8 & $P$ & $<0$ & 308 & 40 & 171 & 92 & 143 & n.a. & & $<0$ \\
\hline Ems & 2.7 & $\mathrm{P}$ & 349 & 12 & 88 & 719 & 4 & 120 & 30 & 225 & 0 \\
\hline Wisla & 2.3 & $\mathrm{~N}$ & 26164 & 12713 & 65 & 14936 & 3814 & 10656 & 106 & 11694 & 0 \\
\hline Weser & 2.1 & $\mathrm{~N}$ & 6015 & 2653 & 78 & 6844 & 796 & 3733 & 14 & 1486 & 0 \\
\hline Nemanus & 2.1 & $P$ & 1770 & 58 & 64 & 1147 & 17 & 828 & 122 & 925 & 0 \\
\hline Rhine & 1.8 & $P$ & 2630 & 166 & 87 & 2303 & 50 & 531 & 270 & 2049 & 0 \\
\hline Adour & 1.8 & $\mathrm{P}$ & 204 & 0 & 82 & 225 & 0 & 100 & 14 & 104 & 0 \\
\hline Daugava & 0.9 & $P$ & 645 & 7 & 74 & 360 & 2 & 221 & 55 & 422 & 0 \\
\hline Odra & 0.6 & $\mathrm{~N}$ & 4516 & 4734 & 68 & 9251 & 1420 & 6405 & 0 & 0 & $<0$ \\
\hline Narva & 0.6 & $P$ & 285 & 12 & 67 & 163 & 4 & 113 & 22 & 168 & 0 \\
\hline Basin no. 1875 & 0.5 & $P$ & 25 & 118 & 14 & 103 & 35 & 91 & n.a. & & $<0$ \\
\hline Ebro & 0.2 & $\mathrm{P}$ & 129 & 40 & 67 & 108 & 12 & 75 & 3 & 26 & 0 \\
\hline Total N & & & 197422 & 62379 & & 37010 & 18714 & 87400 & 861 & 94615 & \\
\hline Total P & & & 44526 & 4427 & & 124364 & 1329 & 25291 & 2399 & 18226 & \\
\hline
\end{tabular}

${ }^{1}$ From Global NEWS (Seitzinger et al., 2010)

${ }^{2}$ Assumptions for sewage and agriculture are based on expert judgment and literature (see text); Seaweed production area is calculated in such a way to ensure that excess N and P (last column) is zero 


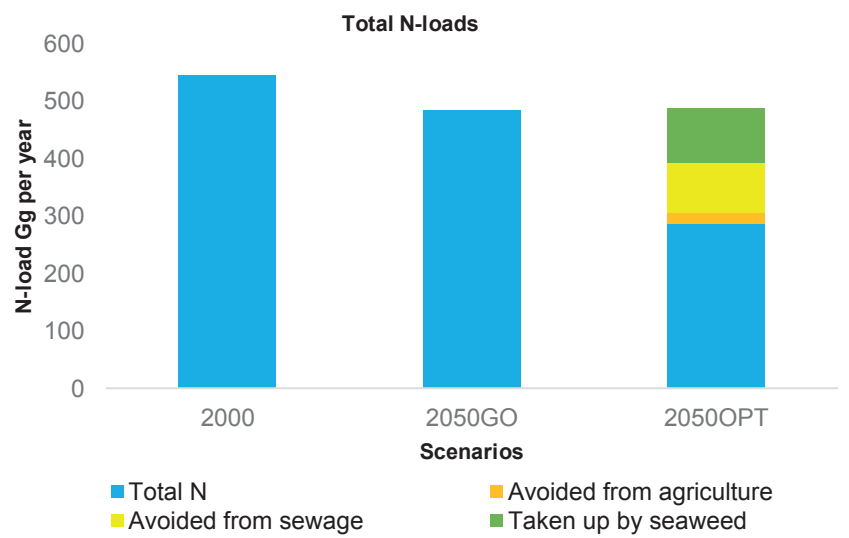

Figure 1. Total $\mathrm{N}$-loads by $11 \mathrm{~N}$-limited rivers in 2000, 2050GO and 2050OPT

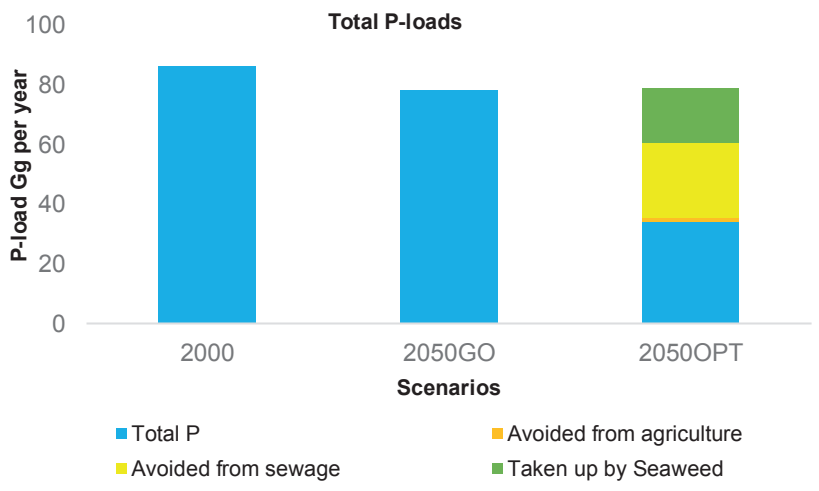

Figure 2. Total P-loads by 23 P-limited rivers in 2000, 2050GO and 2050OPT

\subsection{Conclusion}

$\mathrm{N}$ and $\mathrm{P}$ export by European rivers is high and causing coastal eutrophication. In this study we explored two scenarios for future $\mathrm{N}$ and $\mathrm{P}$ loadings; a business as usual scenario (GO), and an optimistic scenario (OPT) for the year 2050.

The GO scenario shows that current policies in Europe may reduce $\mathrm{N}$ and $\mathrm{P}$ loadings of rivers to some extent between 2000 and 2050, but not enough to avoid potentially harmful algal blooms. We calculate that 34 rivers have an ICEP $>0$, indicating that conditions are favourable for harmful algae to 
bloom. Agriculture and sewage remain important pollutants, although for agriculture the contribution of $\mathrm{N}$ is almost two times higher and for sewage the contribution of $\mathrm{P}$ is 28 times higher.

We present an OPT scenario, assuming increased nutrient use efficiency and improved sewage treatment on land. In this scenario the assumed nutrient use efficiency may reduce $\mathrm{N}$ and P excess loads by $106 \mathrm{Gg}(54 \%)$ and $27 \mathrm{Gg}(60 \%)$ in 2050, respectively. This, however, is not enough to avoid potentially harmful algal blooms in coastal waters in Europe.

Next, we calculated how much area of seaweed farming would be needed to remove the remaining excess $\mathrm{N}$ and $\mathrm{P}$ in coastal seas. We estimate this area to be $3260 \mathrm{~km}^{2}$ in 2050, of which about half in the North Atlantic Ocean, and one third in the Black Sea. For individual rivers these areas range from 0 to $952 \mathrm{~km}^{2}$. We conclude that seaweed farming may help to avoid algal blooms. Our results indicate that seaweed farming and sewage management are more effective in reducing nutrient pollution in rivers than measures in agriculture. In many countries the sewage treatment can be improved.

Our study is the first to analyze the effect of large-scale production of seaweed on coastal eutrophication. It is a first assessment, that could serve as a starting point for further analyses of pollution management in European rivers and coastal waters, taking into account not only mitigation measures on land, but also in the sea. 
Chapter 6 General Discussion 



\subsection{Introduction}

This thesis focuses on harmful and useful algae. Harmful algal blooms may occur as a result of pollution of the coastal waters by nutrients originating from agriculture, sewage and other human activities on land. Rivers are the most important sources of nutrients in coastal waters. Especially rivers with watersheds that are urbanising and/or with intensive agricultural production tend to transport relatively large loads of nutrients to the coastal waters. This pollution is environmentally harmful because of the potential loss of biodiversity, fish mortality and disadvantages for tourism. If nothing is done the pollution will likely increase in the future in many world regions, as a result of increased urbanisation and food production.

The objective of this study was to analyse past and future trends in nutrient export by rivers to European seas with a focus on the role of algae. Three types of algae were distinguished: (1) harmful algal blooms in coastal seas, (2) cultivation of micro-algae on land for the production of proteins, lipids and fatty acids, and (3) cultivation of multi cellular algae in seaweed farms for human consumption or other products.

To meet this objectives, four research questions were addressed:

1. To what extent do $\mathrm{N}$ and $\mathrm{P}$ loads exceed levels that minimize the risk of harmful algal blooms, and what are the relative shares of sources of $\mathrm{N}$ and $\mathrm{P}$ in rivers of the European Union?

2. What are the consequences of large-scale land-based cultivation of micro-algae for the production of biodiesel in Europe for coastal eutrophication?

3. Would it possible to cultivate and process micro-algae in a factory, and what is the environmental performance?

4. To what extent can seaweed farming in combination with nutrient management in agriculture and waste water treatment reduce the potential for coastal eutrophication?

In this chapter I will discuss the results and draw conclusions. 


\subsection{Sources of excess $\mathrm{N}$ and $\mathrm{P}$ in European rivers}

In chapter 2, I used the Global NEWS model to calculate the extent to which $\mathrm{N}$ and $P$ loads exceed levels that minimize the risk of harmful algal blooms, and the relative shares of sources of $\mathrm{N}$ and $\mathrm{P}$ in European rivers. The Global NEWS model and one of the Millennium Ecosystem Assessment scenarios (Global Orchestration) are used to predict the situation in 2050 (Alcamo et al., 2005; Bennett, 2006; Bouwman, 2009; Carpenter et al., 2005; Mayorga et al., 2010; Seitzinger et al., 2010). With the Global NEWS model the transports of nutrients by the rivers to the coastal waters are estimated. The Indicator for Coastal Eutrophication Potential (ICEP) is used to quantify critical nutrient loadings: when ICEP values exceed 0 there is a risk of harmful algae to bloom. When ICEP values are below 0 the nutrient to dissolved silica (Si) are such that the risks of harmful algal blooms are low.

From this analysis the following conclusions can be drawn:

_ In 2000, 38 of the 48 EU rivers indicated in our study had an ICEP $>0$, indicating a relatively high potential for harmful algal blooms. These 48 rivers cover about $70 \%$ of the European basins area considered in the study.

- Between 2000 and 2050 nutrient export by European rivers is projected to decrease. However, by 2050 still 34 rivers, covering $48 \%$ of the land area, have an ICEP $>0$. This indicates that in these scenarios little progress is made in terms of environmental improvement.

- $\quad$ About one third of the rivers with ICEP $>0$ are $\mathrm{N}$ limited, and about two thirds $\mathrm{P}$ limited. In $\mathrm{N}$-limited rivers reducing $\mathrm{N}$ loads is a more effective way to reduce the risk for coastal eutrophication than reducing $\mathrm{P}$, and vice versa.

- For N-limited rivers agriculture or sewage are the dominant sources of nutrients in river water. In P-limited rivers, sewage is found to be the dominant source of $\mathrm{P}$, except for rivers draining into the Atlantic Ocean, where agriculture can also be dominant. 
- A basin-specific approach is needed to effectively reduce $N$ and $P$ loads.

In this chapter, I used the Global NEWS model to compare the transports of nutrients by 48 European rivers to critical nutrient loads in seawater. Global NEWS has not been used earlier for such type of analyses. Moreover, I analysed which sources of nutrients dominate in rivers with ICEP $>0$. The analysis reveals the relative importance of agriculture and sewage in coastal eutrophication. Natural sources such as leaching and runoff from natural soils are generally not dominant.

For highly polluted rivers it is important to investigate the possible sources of the polluting nutrients. Global NEWS may help to identify the largest sources of pollution. This may help policymakers to decide how to improve the situation. For other parts of the world it would be useful to estimate with the same method.

\subsection{Potential coastal eutrophication by land-based cultiva- tion of micro-algae in Europe}

In chapter 3 I studied algae as a resource. Micro-algae can be used to produce biodiesel and other useful products (Wijffels and Bardosa, 2011). It is likely that in the coming decades diesel will be needed, because there is no good alternative foreseen for diesel use in heavy transport (Mackay, 2010). Biodiesel is considered by many a good alternative for fossil diesel. Currently, microalgae cultivation on land is only taking place in small-scale demonstration sites, but this may change in the future (Acién Fernández et al., 2013; Bosma et al., 2014). I present scenarios showing that large-scale cultivation of micro-algae on land may result in pollution of coastal waters. This has not been quantified before. Some life cycle assessments of micro-algae production or biodiesel exist (Brentner et al., 2011; Clarens et al., 2010; Lardon et al., 2009; Liu and Ma, 2009; Yang et al., 2011). However, these studies do not quantify water pollution in a spatially explicit way as I did. My results show that if the production takes place as currently practiced, the pollution may be considerable. Large-scale production of micro-algae production is not yet realised, so there is time to rethink the method of implementation. 
From chapter 3 the following conclusions can be drawn:

- If biodiesel would become an alternative for fossil diesel in Europe, the demand for biodiesel could increase to 0.4 billion $\mathrm{m}^{3}$ diesel in Europe in the future.

- This amount can be produced from micro-algae grown on $2 \%$ of the European Union land area (assuming a productivity of 40 thousand litre of biodiesel per hectare and weather conditions of Portugal).

- Large-scale cultivation of micro-algae on land can become a source of nutrient pollution in rivers.

- Efficient recycling of waste water during production is needed to avoid additional eutrophication of the coastal waters.

In this chapter I used the Global NEWS model from a new perspective: I focused on micro-algae as a source of water pollution. Biodiesel can be produced on a large scale by cultivation of micro-algae on land in the open air and closed systems. I presented scenarios for the year 2050 that assume production in open ponds and closed systems from which $30 \%$ of the water used to cultivate micro-algae is wasted. If this waste is transported by the rivers the pollution in the coastal waters will be roughly $25 \%$ higher than in the year 2000 . This illustrates why efficient recycling of waste water is important. In my scenarios assuming a recycling of $80 \%$ of waste water, sufficient fertilizer is reused to avoid an increase in eutrophication.

\subsection{A factory design for the cultivation and processing of mi- cro-algae}

In chapter 4, I focused on new algae producing industries that do not harm the environment. A sustainable factory to produce biodiesel by cultivating micro-algae would have minimum waste production or pollution, and use sustainable energy. In this chapter a factory has been designed to cultivate algae to produce raw materials. Although several procedures for production of 
cultivation of micro algae exist (Mata et al., 2010), I found no other designs in the literature of such factories. The emphasis in my study was on the production of diesel, although the algae are also feedstock for other products.

From this chapter I draw the following conclusions:

- It is possible to design a factory for indoor cultivation and processing of micro-algae in an environmentally sound way.

- The design has the following characteristics:

1) indoor cultivation and processing of micro-algae;

2) production of algae for proteins, fatty acids, pigments and/or carbohydrates;

3) production in a closed system;

4) no fossil energy inputs;

5) losses to the environment are minimized;

6) the factory is independent of weather conditions;

7) no need for arable land; land requirement is small.

- Besides other products, in this hypothetical factory of 1 hectare and 12 stories, 386 tons biodiesel are produced per year.

- Indoor production of algae is possible with minimum environmental impact and low land requirements. However, the renewable energy demand is high. The factory can, therefore, be only considered sustainable if all energy is from renewable sources.

The novel aspect of this chapter is my design for factory producing micro algae. In the factory the whole cultivation and processing procedure can be controlled. 
The design of the factory allows for control of the cultivation procedure. The result is a production procedure that is relatively environmentally friendly if we assume that the energy is provided by renewable sources of energy. Some details, such as the specific algae species, require more research.

The challenge will be to make a complete and confident design for local realization. A pilot plant for indoor cultivation of algae could prove the feasibility of the design. Factories can be realised in different regions in Europe. The factories are independent of climate and no arable land is needed. So the factories can also be realized in urban or industrial regions. The factories also need relatively low amounts water and nutrients. A disadvantage is the high demand for energy. Future research is needed to investigate whether it is possible to reduce the energy demand. My design assumes that all electricity is from windmills. One could argue that the net energy ratio is too low to make biodiesel from micro algae energetically interesting. However, there will be a need to produce diesel for heavy traffic until better alternatives are available (Mackay, 2010). In this thesis the costs of a factory to produce biodiesel are not estimated.

\subsection{Seaweed farming as a means to reduce coastal eutrophi- cation}

Macro-algae are being produced mainly because they are edible (Koning et al., 2009; Reith et al., 2005). When harvested from sea farms they may reduce nutrient loads in coastal seas. Sea farms could be among the measures to reduce pollution of coastal waters. Other mitigation options include improved agricultural practice and improved sewage treatment.

From chapter 5 the conclusions are:

- I developed an optimistic scenario in which the potential of coastal eutrophication is minimized. The scenario first assumes that nutrient use efficiencies in agriculture are higher than today, and that waste water treatment in sewage systems is improved. In this scenario the $\mathrm{N}$ and $\mathrm{P}$ excess loads are reduced by $106 \mathrm{Gg}$ (54\%) and $27 \mathrm{Gg}(60 \%)$ in 2050, respectively. This, however, is 
not enough to avoid potentially harmful algal blooms in coastal waters in Europe. There are still 34 rivers where $\mathrm{N}$ or $\mathrm{P}$ loads exceed critical levels.

- Seaweed farms could help to remove $\mathrm{N}$ and $\mathrm{P}$ from the coastal waters to a level that minimizes the risks for harmful algal blooms (i.e. ICEP =0). I estimated for my optimistic scenario, that a sea farm area of $3260 \mathrm{~km}^{2}$ is needed for that, of which $51 \%$ in the North Atlantic Ocean, $11 \%$ in the Mediterranean Sea, 29\% in the Black Sea and $9 \%$ in the Baltic Sea. The farm areas range from 0 to 952 $\mathrm{km} 2$, depending on the extent to which $\mathrm{N}$ and $\mathrm{P}$ are exceeding environmental limits in the river mouth.

- The effects of eutrophication in the coastal waters of Europe can be minimised in the future by a combination of measures in agriculture, sewage and sea farms.

The novelty of this chapter is the quantitative analysis of seaweed as a means to reduce coastal eutrophication. My scenarios show that it will be difficult to reduce excess $\mathrm{N}$ and $\mathrm{P}$ in the European coastal waters by pollution reduction on land. Measures in agriculture and sewage alone cannot avoid future coastal eutrophication. Agriculture is a source of increased nutrients in groundwater and surface waters. If agricultural losses are minimized the transport of nutrients to the coastal waters are reduced. Reduction of $\mathrm{N}$ and $\mathrm{P}$ losses from agriculture can be achieved with, for instance, precision agriculture, in which fertilizer needs are determined by GPS and soil sampling. This is not current practice yet. I also show that if improved sewage treatment may reduce nutrients transport by rivers to coastal seas. Currently, not all households and industries are connected to sewage systems, and the waste water treatment plants are not everywhere applying latest technology. In my optimistic scenario I assume that all sewage is treated very efficiently.

I argue that effective reduction of coastal eutrophication requires measures on land as well as in the sea. Seaweed farming may help to reduce excess nutrients that are difficult to control on land. The areas needed are large, but not impossible to realise. In this thesis the economic feasibility of the proposed 
measures such as the mitigation of the eutrophication of the coastal waters and the indoor diesel production is not discussed. Although less pollution will cost more, more study is needed to determine these costs. If mitigation of the eutrophication of the coastal waters will be feasible and carried out other compounds causing pollution in the coastal waters will also be minimised. This is a logical and simple conclusion, but research has to be carried out to confirm this conclusion.

Not only for the coastal waters of the European Union are eutrophic. It is known that other continent have the same pollution (Seitzinger et al., 2010; Sutton et al., 2011). Seaweed farming may also be useful in eutrophication control in other continents. It would be interesting to explore this in future research.

\subsection{Strengths and weaknesses of the study}

\section{Strengths}

In this chapter I will discuss the strengths and weaknesses of my study. There are several strengths that I would like to emphasize.

First, a strength of this study is the use of Global NEWS to analyse eutrophication of coastal waters. The Global NEWS model is widely accepted, and has been validated worldwide and regionally. Global NEWS can be used to calculate river export by nutrients and the ICEP indicator at the river mouths. This is important to assess future trends in potential eutrophication problems in coastal waters.

Second, the rivers that I selected cover a large part of Europe. The 48 rivers cover about two-thirds of Europe and discharge about half of the total European river discharge. Of these rivers, 44\% discharge into the Atlantic Ocean, 10\% into the Mediterranean, 19\% into the Baltic Sea and 27\% into the Black Sea (chapter 2).

Third, Global NEWS integrates all the causes and processes of discharging N, P and $\mathrm{Si}$ to the coastal waters (Mayorga et al., 2010). Anthropogenic sources are included, as well as natural. Moreover, the model distinguishes between point and diffuse sources. And it does this for different forms of $\mathrm{N}$ and P. I do not know of any other global model with such a comprehensive assessment of sources. 
Fourth, Global NEWS can be used to calculate ICEP, an indicator for coastal eutrophication potential. ICEP is calculated for the river mouth and indicates the possibility of harmful algal blooms to develop in coastal waters (Billen and Garnier 2007). If the ICEP value of Global NEWS of a river is positive harmful algal blooms could develop. Based on the modelled nutrient export by rivers in Global NEWS the limiting nutrient can be identified. This nutrient determines the value of ICEP. I calculated ICEP values for European rivers, and I used ICEP to quantify the extent to which river export of nutrients need to be reduced (chapter 2).

Fifth, this is the first study to integrate knowledge on harmful and useful algae. In the coastal waters of Europe algal blooms can be harmful. However, algae can also be cultivated on land to produce raw materials such as diesel. I present possibilities for environmentally friendly production of algae on land (chapter 3). Moreover, sea farms can yield macro-algae. By doing so nutrients are removed from eutrophied sea water (chapter 4). This study can be a starting point for such actions. My study is the first to show how harmful algae are polluting rivers and coastal waters on the one hand, but can also be part of sustainable pathways on the other hand.

\section{Weaknesses}

There are also weaknesses of the study.

First, Global NEWS has been validated at the global scale (Mayorga et al., 2010) and at the continental scale for Europe, China, Bay of Bengal, Black Sea, South America and Africa (Kroeze et al., 2002; Qu and Kroeze, 2010; Sattar et al., 2014; Strokal and Kroeze, 2013; van der Struijk and Kroeze, 2010; Yasin et al., 2010). For all these world regions the model was found to be appropriate. Nevertheless, there will always be uncertainties, in particular for individual rivers. These uncertainties in the study have not specifically been accounted for. Thus although Global NEWS gives a good indication of possible eutrophication, a weakness of the study is that for every river local measurements are needed to validate model results for individual rivers.

Second, a weakness of this study is that Global NEWS has been validated in 2010, and that more recent trends and measurements were not considered in the 
analysis. The 2010 version of Global NEWS (Mayorga et al., 2010) includes a set of measurement data for nutrient export at the river mouths (supplementary materials to Mayorga et al., 2010). This data set was used for validation of the model at the global scale. It summarizes monitoring data for rivers across the world, and only includes annual totals for river export of nutrients. These data typically refer to what was then considered cotemporary measurements (around the year 2000). In this thesis I, therefore, apply the model to the years 2000 (past) and 2050 (future). Clearly, what we now would consider contemporary is missing. One could argue that we are missing the most recent developments. However, I believe that for the purpose of this study an analysis for past and present is appropriate. The Global NEWS model is meant to give a first indication of the level of pollution and effective policies.

Third, the model takes a lumped basin approach and, as a result ignores sub-basin processes. This is in particular problematic for large river basins.

Fourth, the model calculates future trends taking a rather technical approach to reduce eutrophication in the coastal waters. The feasibility of reduction options, however, does not only depend on the technical characteristics, but also on costs, practical feasibility, and social acceptance. Moreover, Global NEWS does not consider the most recent policy plans. These could be subject of further analyses.

Fifth, with respect to the useful algae, I did not specify in detail which algae or seaweed species we should grow in factories and sea farms. Obviously, the most suitable species have to be chosen. More study is needed before we can draw firm conclusions on which species are to be preferred.

Sixth, for the factory: as in designing buildings, a factory design on paper needs to be developed without technical uncertainties; it simply needs to work. Only then the design of the algae factory can be implemented. Of course my design is not at that level yet; there are details that need to be specified by practical experts. Moreover, I did not consider the costs.

Seventh, I did not estimate the effect of changing diets. Eating less meat could influence the amount of manure excretion by livestock. This would effectively 
reduce the amount of nutrients in the environment. In my opinion, however, it will be rather unlikely that people will eat less meat in any scenario for the future. If incomes stay high, people will continue to eat meat (Sutton et al., 2011).

\subsection{Comparison with other studies}

My study has several novel aspects.

A difference with earlier Global NEWS studies is that I focus not only on the Millennium Ecosystem Assessment scenarios, but also on sustainable pathways. I use the Global NEWS to calculate maximum allowable loads of nutrients in rivers. My study can serve as an example for other world regions in this respect. Moreover, I do not consider algae merely a threat, but also consider them a solution for environmental problems. Earlier studies using Global NEWS analyse future scenarios (e.g. Seitzinger et al., 2010; Strokal et al., 2010,Yasin et al., 2010), but mostly without such specific solutions. This also holds for some assessments without the use of Global NEWS.

Another novelty is the factory that I designed for production of microalgae. No study in the literature exists that present such a factory. As indicated above, life cycle assessments of biodiesel exist, but these do not account for discharge of nutrients to surface waters. A next step would be to test my design in practice. First at the lab scale, followed by a pilot.

A third novelty is the scenario analysis that I presented in chapter 5.1 do not know of any other study calculating nutrient removal by sea farming as I did. The areas of sea farming needed to reduce the risk of harmful algal blooms is, however, considerable. No other studies exist that link large-scale farming of seaweed to river export of nutrients as I did it.

It is interesting to compare Global NEWS results with other models such as the Global Nutrient Model linked to the IMAGE climate model (IMAGE-GNM) (Beusen et al., 2015). Both are global river export models for nutrients. The most important difference between the model is that Global NEWS takes a lumped basin approach, while IMAGE-GNM is a distributed gridded model. 
We compared model results for two rivers: the Rhine and the Meuse. This comparison indicates that the model results are quite close. Annual nitrogen export by the Rhine is calculated to be $151 \mathrm{Gg}$ (Global NEWS) and $175 \mathrm{Gg}$ (IMAGE-GNM), and by the Meuse $52 \mathrm{Gg}$ (Global NEWS) and (51 IMAGE-GNM). Annual phosphorus export is by the Rhine is calculated to be $5-6 \mathrm{Gg}$ for both models, and by the Meuse around $2 \mathrm{Gg}$. This builds trust in the model output of these two validated models, although the models seem to underestimate river export of $\mathrm{N}$ to some extent (Mayorga et al., 2010). The ICEP values for both rivers are positive, implying that there is a risk for harmful algal blooms to develop.

Another global nutrient model is the mass balance model for nitrogen loading to the landmass with estimates of loads to the river mouths (Green et al., 2009). In this model a lumped approach is presented. For Europe the total river flux (load) is $6 \mathrm{Tg} \mathrm{N} / \mathrm{yr}$, while I calculated $1.8 \mathrm{Tg} \mathrm{N} / \mathrm{yr}$ for 48 rivers (chapter 2). The figures are difficult to compare because Green et al., (2009) estimate fluxes for Europe while I limited my study to the countries of the European Union as of 2000. Nevertheless, we can conclude that the two estimates are not inconsistent.

My conclusion is that global models are useful tools to indicate the risks of coastal eutrophication, and the possible sources of pollution at the continental scale. However, local validation is always needed as a follow up. At the regional and local scale many models exist that estimate regional riverine fluxes of water and nutrients (e.g. Boyer et al., 2006). Such models can also help to better understand local situations. Their performance for local assessments is often better than that of global models.

\subsection{Concluding remarks}

This thesis focused on eutrophication in the coastal waters of Europe. Coastal eutrophication is a serious problem that calls for a solution. I present four model studies related to this issue, with a focus on harmful and useful algae.

In business as usual scenarios nutrient export by European rivers may decrease in the coming decades a as result of existing policies. However, I also show that 
this may change in the future if micro-algae are increasingly produced as a feedstock for, for instance, biodiesel. I study the environmental consequences of cultivating micro-algae on land. Without effective recycling of nutrients, the production of micro-algae on land (in open ponds or tubes) may lead to more eutrophication of the coastal waters. Currently, micro-algae are not yet produced in factories that are completely closed. I present a design of a factory for producing biodiesel with a transport of a minimum of nutrients to the environment. Finally, my study shows that it is possible to reduce eutrophication of coastal waters in Europe. Nutrient inputs to rivers can be reduced by increasing the nutrient use efficiency of agriculture, and by waste water treatment. My study adds to this the removal of nutrients from seawater by growing seaweed. Seaweed farming in the coastal waters could, after harvest, reduce nutrients from the sea.

Algae can be both harmful and useful. I showed that micro-algae can be produced without environmental harm on land, and that macro-algae can be useful in reducing pollution levels in coastal seas. My thesis could serve as a basis for environmental policies to stimulate the production of these useful algae. The methods to mitigate algal blooms and to use algae in a sustainable way in this thesis are also useful for other parts of the world. 



\section{References}

Acién Fernández FG, Fernández Sevilla JM, Molina Grima E. 2013. Photobioreactors for the production of microalgae. Rev Environ Sci Biotechnol. 12, 131-151.

Ahmad AL, Mat Yasin NH, Derek CJC, Lim JK. 2010. Microalgae as a sustainable energy source for biodiesel production: A review. Renew Sustain Energy Rev.

Alchris Woo Go, Sylviana Sutanto, Lu Ki Ong, Phuong Lan Tran-Nguyen, Suryadi Ismadji, Yi-Hsu Ju. 2016. Developments in in-situ (trans) esterification for biodiesel production: A critical review. Renewable and Sustainable Energie Reviews 60, 284-305.

Alcamo J, Van Vuuren D, Cramer W. 2005. Changes in Ecosystem Services and their Drivers across the Scenarios in Ecosystems and |Human Well-being: Scenarios. Washington, D.C.: Island Press., p. 297-373.

Baltissen T. 2014. Sensor-based farming, Wageningen University and Research, PowerPoint presentation, ton.baltissen@wur.nl

Bennett ESC. 2006. Scenarios for Ecosystems Services: Rationale and Overview. Washington, D.C.: Island Press., 121-143.

Besthorn FH. 2013. Vertical Farming Social Work and Sustainable Urban Agriculture in an Age of Global Food Crises. Australian Social Work 66 no. 2, 187-203.

Beusen AHW, Van Beek LPH, Bouwman AF, Mogollón JM, Middelburg JJ. 2015. Coupling global models for hydrology and nutrient loading to simulate nitrogen and phosphorus retention in surface water - description of IMAGE-GNM and analysis of performance. Geosci. Model Dev., 8, 40454067, doi:10.5194/gmd-8-4045-2015

Billen G, Garnier J. 2007. River basin nutrient delivery to the coastal sea: assessing its potential to sustain new production of non siliceous algae. Marine Chemistry 106, 148-160

Billen G, Beusen A, Bouwman LJG. 2010. Anthropogenic nitrogen autotrophy and heterotrophy of the world's watersheds: Past, present, and future trends. Global Biochemical Cycles 24

Blaas H, Kroeze C. 2014. Possible future effects of large-scale algae cultivation for biofuels on coastal eutrophication in Europe. Science of Total Environment 496, 45-51. 
Blaas H, Kroeze C. 2016. Excessive nitrogen and phosphorus in European rivers: 2000-2050. Ecological Indicators 67, 328-337

Blanchard GF, Guarini JM, Richard P, Gros P, Mornet F. 1996. Quantifying the short-term temperature effect on light-saturated photosynthesis of inertidag microphytobenthos. Marine Ecology Progress Series 134, 309-313.

Blanken W, Cuaresma M, Wijffels RH, Janssen M. 2013. Cultivation of microalgae on artificial light comes at cost. Algal Research 2, 333-340.

Bongiovanni R, Lowenberg-De Boer J. 2004. Precision Agriculture and Sustainability, Precision Agriculture, Kluwer Academic Publishers. Manufactured in The Netherlands, 5, 359-387

Bosma R, De Vree JH, Slegers PM, Janssen M, Wijffels RH, Barbosa MJ. 2014. Design and construction of the microalgal pilot facility AlgaeParc. Algae Research 6, 160-169.

Boyer EW, Howarth RW, Galloway JN, Dentener FJ, Green PA, Vörösmarty CJ. 2006. Riverine nitrogen export from the continents to the coasts, Global Biogeochem. Cycles, 20, GB1S91, doi:10.1029/2005GB002537.

Bouwman AF, Kram T, Klein Goldewijk K. 2006. Integrated modelling of global environmental change, An overview of IMAGE 2.4, Netherlands Environmental Agency (MNP), Bilthoven, October 2006, publication number 5001 10002/2006

Bouwman AF, Beusen AH, Billen G. 2009. Human alteration of global nitrogen and phosphorus soil balances for the periode 1970-2050. Global Biogoechemical Cycles 23.

Bouwman AF, Pawłowski M, Liu C, Beusen AHW, Shumway SE, Glibert M, Overbeek CC. 2011. Global Hindcasts and Future Projections of Coastal Nitrogen and Phosphorus Loads Due to Shellfish and Seaweed Aquaculture, Reviews in Fisheries Science, 19:4, 331-357, DOI: 10.1080/10641262.2011.603849

Brentner LB, Eckelman MJ, Zimmerman JB. 2011a. Supporting Information for: Combinational life cycle assessment to inform process design of industrial production of algal biodiesel. Environmental Science \& Technology 45, 7060-7067.

Brentner LB, Eckelman MJ, Zimmerman JB. 2011b. Combinational life cycle assessment to inform process design of industrial production of algal biodiesel. Environ Sci Technol 45:7060-7.

Brown TL, Lemay HE jr, Bursten BE. 1991. Chemistry, The Central Science; Fifth Edition ed. Prentice-Hall. Inc., Simon \& Schuster, Englewood Cliffs, New Yersey 07632. 
Campbell PK, Beer T, Batten D. Greenhouse gas sequestration by algae-energy and greenhouse gas life cycle studies. 2009. Transport Biofuels Stream, CSIRO Energy Transformed Flagship PB1, Aspendale, Vic. 3195, Australia.

Carpenter SR, Pingali PL, Bennett EM. 2005. Ecosystems and Human Well-being: Scenarios, Volume 2. Washington D.C., Island Press.

Char JW, Wang JK, ChowTJ. 2011. Biodiesel Production from Microalgae through Supercritical Carbon Dioxide Extraction. Journal of the Japan Institute of Energy 90, 369-373.

Chen C, Pan J, Kee Lam S. 2014. A review of precision fertilization research, Environ Earth Sci, 71:4073-4080, DOI 10.1007/s12665-013-2792-2

Claquin P, Probert I, Lefebvre S, Verton B. 2008. Effects of temperature on photosynthesic parameters and TEP production in eight species of marine microalgae. Aquatic Microbial Ecology 51:1-11.

Clarens AF, Nassau H, Resurreccion EP, White MA, Colosi LM. 2011. Environmental Impacts of Algae-Derived Biodiesel and Bioelectricity for Transportation. Environmental Science \& Technology 45: 7554-7560.

Clarens AF, Resurreccion EP, White MA, Colosi LM. 2010. Environmental life cycle comparison of algae to other bioenergy feedstocks. Environ Sci Technol 44:1813-19.

Despommier D. 2011. The vertical farm: controlled environment agriculture carried out in tall buildings would create food safety and security for large urban populations. Journal for Consumer Protection and Food Safety 6, 233-236.

Diaz RJ, Rosenberg R. 2008. Spreading Dead Zones and Consequences for Marine Ecosystems. Science 321: 926-929

EEA. 2001.Europhication in Europe's coastal waters. Topic Rep. 7/2001. Eur. Environ. Agency, Copenhage pp. 86.

Eisentraut A. 2010. Sustainable Production of Second-generation Biofuels. International Energy Agency, 9 rue de la Fédération, 75739 Paris Cedex 12, France.

Eurostat. 2011. Energy transport and environmental indicators. Luxembourg: Publications Office of the European Union.

Feteke B, Wisser D, Kroeze C, Mayorga E, Bouwman L, Wolheim WM. 2010. Millennium Ecosystem Assessment scenario drivers (1970-2050): Climate and hydrological alterations. Global Biochem. Cycles 24. 
Fresco LO. 2013. Hamburgers in het paradijs, Uitgverij Bert Bakker, www. uitgeverijbertbakker.nl, ISBN 9789035140998

Garnier J, Beusen A, Thieu V, Billen G, Bouwman L. 2010. N:P:Si nutrient export ratios and ecological consequences in coastal seas evaluated by ICEP appraoch. Global Biochem. Cycles 24.

Germer J, Sauerborn J, Asch F, de Boer J, Schreiber J, Weber G, Mueller J. 2011. Skyfarming an ecological innovation to enhance global food security. Journal for Consumer Protection and Food Safety 6.

Geider RJ, Maclntyre HL, Kana TM. 1996. A dynamic model of photoadaptation in phytoplankton Limnology and Oceanography 41 No.1, 1-15.

Glisic S, Skala D. 2009. The problems in design and detailed analyses of energy consumption for biodiesel synthesis at supercritical conditions. The journal of Supercritical Fluids 49, 293-301.

Green PA, Vörösmarty CJ, Meybeck M, Galloway JN, Peterson BJ, Boyer EW. 2009. Pre-Industrial and Contemporary Fluxes of Nitrogen through Rivers: A Global Assessment Based on Typology. Biogeochemistry, Vol. 68, No. 1 pp. 71-105

Guo H, Daroch M, Liu L, Qiu G, Geng S, Wang G. 2013. Biochemical features and bioethanol production of microalgae from coastal waters of Pearl River Delta Bioresource Technology 127, 422-428.

Gould JL, Keeton WT. 1997. Biological Science, WW Company New York, ISBN 0-393-96920-7

Hart MR, Quin F, Nguyen ML. 2004. Phosphorus runoff from agricultural land and direct fertilizer effects: a review. J. Environ. Qual. 33, 1954-1972.

Hemming S. 2011. Use of Natural and Artificial Light in Horticulture - Interaction of Plant and Technology. Acta Hort. 907.

Howarth R, Chan F, Conley DJ, Garnier J, Doney SC, Marino R. 2011. Coupled biochemical cycles: eutrophication and hypoxia in temperate estuaries and coastal marine ecosystems. Front. Ecol. Environ. 9 (1), 18-26.

Ibarrola Rivas MJ. 2015. The use of agricultural resources for global food supply Understanding its dynamics and regional diversity University of Groningen, Groningen.

Jia Z, Liu Y, Daroch M, Geng S, Cheng JJ. 2014. Screening, Growth Medium Optimisation and Heterotrophic Cultivation of Microalgae for Biodiesel Production, Appl Biochem Biotechnol. 173, 1667-1679. 
Keller DR, Brummer EC. 2002. Putting Food Production in Context: Toward a Postmechanistic Agricultural Ethic BioScience, March 2002 / Vol. 52 No. 3 Koning N, van Ittersum MK. 2009. Will the world have enough to eat?, Current Opinion in Environmental Sustainability 1:77-82, DOI 10.1016/j. cosust.2009.07.005

Kroeze C, Seitzinger SP. 1998. The impact of land use on $\mathrm{N}_{2} \mathrm{O}$ emissions from watersheds draining into the Northeastern Atlantic Ocean and European Seas. Environment Pollution 102, 149-158.

Kroeze C, Seitzinger SP, Steenvoorden J, Claessen F, Willems J. 2002. The impact of land use in Europe on $\mathrm{N}$ inputs to rivers and estuaries and related $\mathrm{N}$ sub (2) O emissions: a scenario analysis. International Association of Hydrological Sciences, IAHS Press Centre for Ecology and Hydrology Wallingford Oxfordshire OX 108 BB UK.

Kroeze C, Bouwman L, Seitzinger S. 2012. Modeling global nutrient export from watersheds, SciVerse ScienceDirect, www.sciencedirect.com, DOI 10.10.16/j. cosust.2012.01.009

Lægreid M, Bockman OC, Kaarstad O. 1999. Agriculture, Fertilizer, and the environment. CABI Publishing New York, ISBN 0851993583

Lardon L, Helias A, Sialve B, Steyer JP, Bernard O. 2009. Life-cycle assessment of biodiesel production from microalgae. Environ Sci Technol 43(17):6475-81.

Liu J, Ma X. 2009. The analysis on energy and environmental impacts of microalgae-based fuel methanol in China. Energie Policy 37: 1479-1488.

MA. Reports. 2005. Available from: http://millenniumassessment.org/en/ index.html

Mackay DJC. 2010. Sustainable Energy - without the hot air: UIT Cambridge. Mata TM, Martins AA, Caetano NS. 2010. Microalgae for biodiesel production and other applications: A review. Renew Sustain Energy Rev. 14, 217-232.

Mayorga E, Seitzinger SP, Harrison JA, Dumont E, Beusen HW, Bouwman AF. 2010. Global Nutrient Export from Watersheds 2 (NEWS 2): Model development and implementation. Environmental Modelling \& Software 25: 837-853.

Patil D, Gude VG, Mannarswamy A, Cooke P, Nirmalakhandan N, Lammers P. 2012. Comparison of direct transesterification of algal biomass under supercritical methanol and microwave irradiation conditions. Fuel, 97, pp. 822-831.

Qu HJ, Kroeze C. 2010. Past and future trends in nutrients export by rivers to the coastal waters of China. Science of the Total Environment 408, 2075-2086. 
Qu HJ, Kroeze C. 2011 Nutrient export by rivers to the coastal waters of China: management strategies and future trends. Reg Environ Change.

Reith JH, Deurwaarder EP, Hemmes K, Curvers APWM, Kamermans P, Brandenburg W, Zeeman G. 2005. Grootschalige teelt van zeewieren in combinatie met offshore windparken in de Noordzee. Energy research Centre of the Netherlands. ECN-C-05-008

Reijnders L. 2009. Microalgal and Terrestrial Transport Biofuels to Displace Fossil Fuels. Energie 2: 48-56.

Romero E, Garnier J, Lassaletta L, Billen G, Le Gendre R, Riou P, Cugier P. 2013. Large-scale patterns of river inputs in southwestern Europe: seasonal and interannuel variations and potential eutrophication effects at the coastal zone. Biogeochemistry 113, 481-505.

Sattar MA, Kroeze C, Strokal M. 2014. The increasing impact of food production on nutrient export by rivers to the Bay of Bengal 1970-2050. Marine Pollution Bulletin 80, 168-178.

Scheffer M. 2010. Foreseeing tipping points. Nature 467.

Seitzinger SP, Mayorga E, Bouwman AF, Kroeze C, Beusen AHW, Billen G, Van Drecht G, Dumont E, Feteke BM, Garnier J, Harrison JA. 2010. Global river nutrient export: A scenario analysis of past and future trends. Global Biochem. Cycles 24.

Seitzinger SP, Harrison JA, Dumont E, Beusen AHW, Bouwman AF. 2005. Sources and delivery of carbon, nitrogen, and phosphorus to the coastal zone: An overview of Global Nutrient Export from Watersheds (NEWS) models and their application. global Biochem. Cycles 19.

Slegers PM, Van Beveren PJM, Wijffels RH, Van Straten G, Van Boxtel AJB. 2013. Scenario analysis of large scale algae production in tubular photobioreactors. Applied Energy 105, 395-406.

Slegers PM, Koetzier BJ, Fasaei F, Wijffels RH, Van Straten G, Van Boxtel AJB. 2014. A model-based combinatorial optimisation approach for energy-efficient processing of microalgae. Algae Research 5, 140-157.

Stephenson AL, Kazamia E, Dennis JS, Howe CJ, Scott A, Smith AG. 2010. LifeCycle Assessment of Potential Algal Biodiesel Production in the United kingdom: A Comparison of Raceways and Air-Lift Tubular Bioreactors. Energy Fuels 24, 0624077.

Strokal M, Kroeze C. 2012. Nitrogen and phosphorus inputs to the Black Sea in 1970-2050. Reg. Environ. Chang. 13, 179-192. 
Sutton MA, Howard CM, Erisman JW, Billen G, Bleeker A, Grennfelt P et al., 2011. The European Nitrogen Assessment. Vol Cambridge University Press.

Thieu V, Mayorga E, Billen G. 2010. Subregional and downscaled global scenarios of nutrient transfer in river basins: Seine-Somme-Scheldt case study. Glob. Biochem. Cycles 24.

Tredici, MR. 2010. Photobiology of microalgae mass cultures: understanding the tools for the next green revolution. Biofuels 1(1), 143-162.

Tysmans DJJ, Löhr AJ, Kroeze C, Ivens WPMF, van Wijnen J. 2012. Spatial and temporal variability of nutrient retention in river basins: a global inventory. Ecol. Indic. 34, 607-615.

van der Hoek KW. 2001. Nitrogen Efficiency in Agriculture in Europe and India. The Scientific World Vol 1(S2).

van der Struijk LF, Kroeze C. 2010. Future trends in nutrient export to the coastal waters of South America: Implications for occurrence of eutrophication. Global Biochem Cycles 24.

Van Drecht G, Bouwman AF, Harrison J, Knoop JM. 2009. Global nitrogen and phosphate in urban wastewater for the period 1970 to 2050. Global Biochem. Cycles 23

Van Wijnen J, Ivens PMFW, Kroeze C. 2015. Coastal eutrophication in urope caused by production of energy crops. Science of the Total Environment 511, 101-111.

Vörösmarty CJ, Feteke BM, Meybeck M. 2000. Geomorphometric attributes of the global system of rivers at 30-minute spatial resolution. Journal of Hydrology 237, 17-39.

Vyas AP, Verma JL, Subrahmanyam N. 2010. Areview on Fame production processes. Fuel 89, 1-9.

Wijffels RH, Bardosa MJ. 2010. An Outlook on Micro-algal Biofuels. Science 329: 796.

Wileman A, Ozkan A, Berberogllu H. 2012. Rheological properties of algae slurries for minimizing harvesting energy requirements in biofuel production. Bioresource Technology 104, 432-439.

Winiwarter W, Leip A, Tuomisto HL, Haastrop PA. 2014. European perspective of innovations towards mitigation of nitrogen-related greenhouse gases. ScienceDirect, Elsevier pp. 37-45.

Wolkers $\mathrm{H}$, Barbosa M, Kleinegris DMM, Bosma R, Wijffels RH. Microalgae: the green gold of the future?: Wageningen UR, 2011. 
Yan W, Maryorga E, Li X, Seitzinger SP, Bouwman AF. Increasing anthropogenic nitrogen inputs and riverine DIN exports from Changjiang River basin under changing human pressures. Global Biochem. Cycles 2010; 24.

Yang J, Ming X, Zhang X, Hu H, Sommerfeld M, Chen Y. Life-Cycle analysis on biodiesel production from microalgae: Water footprint and nutrients balance. bioresour. Technol. 2011; 102: 159-165.

Yasin, J.A., Kroeze, C., Mayorga, E., 2010. Nutrients Export by Rivers to the Coastal Waters of Africa: Past and Future trends. Global Biogeochemical Cycles 24. 


\section{Summary}

Eutrophication of coastal waters is a worldwide phenomenon. This study focuses on eutrophication in the coastal waters of Europe. Eutrophication is mainly a result of the increased transport of nutrients from watersheds by rivers to the coastal waters. Nutrient losses from watersheds are generally from agriculture, sewage, atmospheric deposition and from natural sources. In case of an overload of nutrients in the coastal waters, algal blooms may develop which increase the risk of hypoxia, fish mortality, and loss of biodiversity.

Algae can also be useful. They are increasingly considered an interesting product. For instance, micro-algae can be grow on land to produce proteins, lipids and fatty acids. Some studies indicate that micro-algae can be an important feedstock in the future for, for instance, the production of biodiesel. Moreover, macro-algae can be produced in seawater in sea farms. Macro-algae can be edible, or be used as a feedstock. By yielding macro-algae, nutrients are removed from the water, reducing coastal eutrophication.

The objective of this study is to analyse past and future trends in nutrient export by rivers to European seas with a focus on the role of algae. Three types of algae will be distinguished: (1) harmful algal blooms in coastal seas, (2) cultivation of micro-algae on land for the production of proteins, lipids and fatty acids, and (3) cultivation of multi cellular algae in seaweed farms for human consumption or other products.

To meet the objective the following research questions are addressed:

RQ1 To what extent do $\mathrm{N}$ and $\mathrm{P}$ loads exceed levels that minimize the risk of harmful algal blooms, and what are the relative shares of sources of $\mathrm{N}$ and $\mathrm{P}$ in rivers of the European Union?

RQ2 What are the potential consequences of large-scale land-based production of biodiesel from cultivated micro-algae in Europe for coastal eutrophication? 
RQ3 Would it possible to cultivate and process micro-algae in a factory, and what is the environmental performance?

RQ4 To what extent can seaweed farming in combination with nutrient management in agriculture and waste water treatment reduce the potential for coastal eutrophication?

These questions are answered through model analyses. The Global NEWS (Nutrient Export from WaterSheds) model simulates river export of nutrients as function of human activities on land. It includes more than 6000 rivers worldwide. It can be used to quantify nutrient flows from land to sea for the years 1970, 2000, 2030 and 2050. For future years four scenarios have been implemented. One of these scenarios is named Global Orchestration and mostly used as a reference in this thesis. This scenario assumes a globalised world, with a reactive approach towards environmental problems. The model was released in 2010, has been validated for the years 1970 and 2000. The nutrients considered in the model are nitrogen $(\mathrm{N})$ and phosphorus $(\mathrm{P})$. In this thesis Global NEWS is used to calculate transport of nutrients to the coastal waters of Europe. The model uses ICEP (Indicator for Coastal Eutrophication Potential) values at the river mouths as an indicator for potentially harmful effects of nutrient enrichment. These ICEP values reflect the ratio of nitrogen and phosphorus to silica in coastal seas. A positive ICEP value indicates that nitrogen or phosphorus levels are too high, favouring conditions for potentially harmful algae to bloom.

In chapter 2 Global NEWS is used to calculate the transport of nutrients and ICEP values for 48 European rivers for the years 2000 and 2050. The model calculates a positive ICEP for 38 rivers in the year 2000, and for 34 rivers in the year 2050. This indicates that current policies are not so effective in reducing the river transport of nutrients. For polluted rivers the anthropogenic sources of the nutrients are investigated. For most rivers the dominant polluting sources are agriculture or sewage. The results indicate that a basin-specific policy is needed to reduce the risks of coastal eutrophication.

In chapter 3 the focus is on useful algae: micro-algae cultivation on land for, for instance, biodiesel production. The consequences of large-scale production 
of biodiesel on nutrient export by rivers to the European coastal waters are investigated. A scenario is developed assuming that a production of 0.4 billion $\mathrm{m}^{3}$ diesel from cultivated micro-algae. The cultivation is assumed to be in the open air, for instance in ponds or in closed tube systems. Such production levels would need a land surface area as large as Portugal. The Global NEWS model is used to calculate the amount of waste water from micro-algae production that will be transported to the coastal waters in this scenario. The results indicate that large-scale cultivation of micro-algae on land can become a source of nutrient pollution in rivers. In the scenario with large-scale micro-algae cultivation the future transport of nitrogen and phosphorus is considerably higher than in the reference scenario. To ensure sustainable production of biodiesel from microalgae it is important to develop cultivation systems with low nutrient losses to the environment.

Chapter 4 presents a design of a factory for the cultivation and processing of micro-algae in an environmentally sound way. The factory does not use fossil fuels and applies maximum recycling of water and nutrients. In this factory it is possible to produce lipids, carbohydrates, proteins and minerals. The factory can be built on any piece of land, so there is no need to use arable land. The factory is independent of weather and climate. Energy can be delivered by wind mills. In this chapter an example of producing diesel in the factory is shown. In the 12 stories factory with a cultivation area of 1 hectare, 810 ton micro-algae can be cultivated per year. This is enough for the production of 386 ton diesel per year.

Chapter 5 focuses on mitigation of eutrophication in European coastal waters. A scenario is presented assuming different types of measures. The scenario first assumes that nutrient use efficiencies in agriculture are higher than today, and that waste water treatment in sewage systems is improved. In addition, it assumes that all excess $\mathrm{N}$ and $\mathrm{P}$ in coastal waters is harvested in seaweed farms producing edible macro-algae. In our scenario for 2050 there is seaweed farming in the coastal waters of 34 rivers mouths in Europe .NEWS The areas needed to ensure that ICEP values remain below 0 (low potential for coastal eutrophication) range between 0 and $952 \mathrm{~km}^{2}$ per river mouth.

This thesis shows that algae can be both harmful and useful. River export of nutrients can lead to coastal eutrophication increasing the risks of 
harmful algal blooms. On the other hand, micro-algae can be produced without environmental harm on land, and macro-algae can be useful in reducing pollution levels in coastal seas. This thesis could serve as a basis for environmental policies to stimulate the production of these useful algae. The methods to mitigate algal blooms and to use algae in a sustainable way in this thesis are also useful for other parts of the world. 


\section{Acknowledgements}

Threes Smijs, lecturer at The Open University, mentioned the possibility of doing research after my MSc. She brought me in contact with Carolien Kroeze who was professor at The Open University and is now professor Water Systems and Global Change at Wageningen University.

Carolien introduced me at Wageningen University into the Environmental System Analysis (ESA) Group. The chair of this ESA group is Rik Leemans, and he accepted me as a member of the group, but I did most of the work at home. I could do all the work on the computer. The ESA group consists of enthusiastic staff members and the contacts were always joyful. Thank you all! Apart from the contacts at the university there were the parties at Rik's home. The hospitality of Rik and his wife Carien is great. Also the 'ESA-uitjes' once a year were great.

During my PhD programme Carolien and I had a lot of meetings. The meetings were always pleasant and full of interesting discussions. After each meeting I was motivated to go on with the work. Carolien has taught me how to do the research and how the university life works. Carolien, many thanks!

I also would like to thank Ellen Slegers from Wageningen University. She helped me with the design of the factory described in chapter 4 of my thesis.

Most of all I thank my wife Ed who gave me again the opportunity to study and doing research. 



\section{About the author}

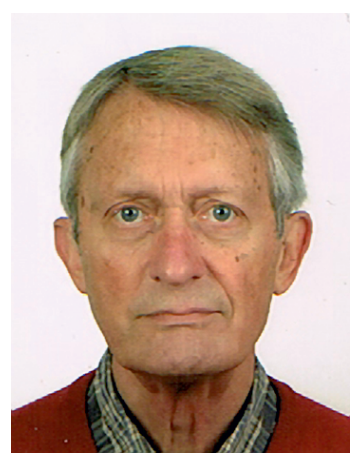

Harry Blaas was born on March 4, 1939 in Amsterdam. He attended the Hogere Technische School in Utrecht and graduated in 1959 in Civil Engineering. After a career of structural engineer and manager of 40 years he was 8 years arbitrator in the building trade. At the age of 72 years his working activities ended.

He had always a big interest in science and mathematics and decided the last years of his career to start at the study Environmental Science at The Open University. In 2008 he received his MSc diploma in Environmental Sciences. The study at the Open University was a great pleasure. The study material is excellent and the contact with teachers and professors was motivating. The study was far from lonely and with all the activities of the university and the student community it was always fascinating. Besides studying he was and is active in the Education Commission and the Counsel of Advice.

The idea of doing research came via teachers of The Open University. After retiring it was a great opportunity, but Heerlen is far to travel to meet the supervisor. Wageningen was easier to reach and the supervisor had an appointment in Heerlen and in Wageningen. So the meetings were always at Wageningen University. In the Environmental Systems Analysis Group of Wageningen University it was possible to start a study of the eutrophication of the coastal waters of the European Union. At the start it was not clear whether or not a PhD thesis would be written, but after publishing some articles I took the opportunity to work towards a public defence. The topic of his PhD thesis is the harmful micro-algae in the coastal waters, to grow micro-algae on land to produce diesel and mitigation of the eutrophication in the coastal waters. 
Photograph cover: designboom.com

Lay-out: Ferdinand van Nispen tot Pannerden, www.my-thesis.nl Printed by GVO drukkers \& vormgevers www.gvo.nl 